
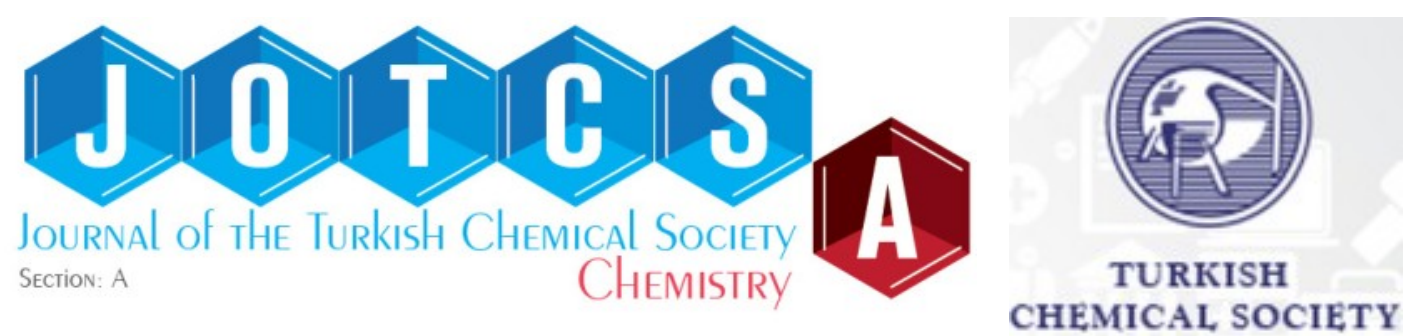

\title{
Synthesis, Characterization, DFT Calculations, and Catalytic Epoxidation of Two Oxovanadium(IV) Schiff Base Complexes
}

\author{
Asha Fadalla Wady ${ }^{1}$ (D), Mohammed Awad Ali Khalid ${ }^{2, *}$ (D), Mohammed Traheeb Alotaibi ${ }^{2}$ \\ and Yusuf Sulfab Ahmed ${ }^{3}$
}

\author{
${ }^{1}$ University of Kordofan, Department of Chemistry, Alobaid, 11111, Sudan \\ 2 University of Taif, Department of Chemistry, Turabah, 21995, Saudi Arabia \\ 3 University of Khartoum, Department of Chemistry, Khartoum, 11115, Sudan
}

\begin{abstract}
The present paper reports the synthesis, characterization, and DFT calculations of two oxovanadium (IV) Schiff base complexes symbolized as $\mathrm{VOL}_{1}$ and $\mathrm{VOL}_{2}$, which prepared by the reaction of

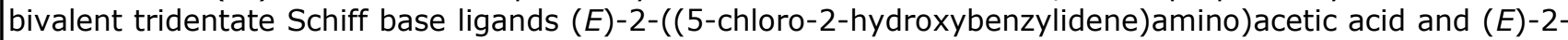
((2-hydoxy-5-nitrobenzylidene)amino)acetic acid and $\mathrm{VO}(\mathrm{acac})_{2}$ as vanadium source. The Schiff base ligands and its oxovanadium (IV) complexes were characterized by the elemental analysis (C, H, N), FTIR, ${ }^{1} \mathrm{H}$ NMR and ${ }^{13} \mathrm{C}$ NMR, DFT calculations were performed to derive some of their molecular properties. Schiff base ligands coordinated to vanadium center via nitrogen from the azomethine group and one oxygen from the hydroxyl attached to the benzene ring and one oxygen from hydroxyl of carboxyl group. The catalytic activity of the two complexes were tested against cyclooctene and found that both complexes were highly effective and selective in optimized conditions when used as cyclooctene epoxidation catalysts with the conversion percentage of $91.85 \%$ (with $\mathrm{VOL}_{1}$ ) and $87.40 \%$ (with $\mathrm{VOL}_{2}$ ) at $78{ }^{\circ} \mathrm{C}$ within a period of ten hours. To understand the structural properties of the two complexes, the two complexes were well optimized at B3LYP/6-31G(d,p) level of theory, structural parameters such as electron affinity, global electrophilicity, global hardness, electronegativity, ionization potential, and electron chemical potential based on HOMO and LUMO energy values were calculated.
\end{abstract}

Keywords: Schiff base, DFT calculations, epoxidation catalysis, geometry optimizations, oxovanadium complexes, global chemical reactivity.

Submitted: October 15, 2021. Accepted: December 29, 2021.

Cite this: Wady AF, Khalid MAA, Alotaibi MT, Ahmed YS. Synthesis, Characterization, DFT Calculations, and Catalytic Epoxidation of Two Oxovanadium(IV) Schiff Base Complexes. JOTCSA. 2022;9(1):163-208.

DOI: https://doi.org/10.18596/jotcsa.1008578.

*Corresponding author. E-mail: m.khalid@tu.edu.sa , mkhalid@uofk.edu, Telephone: +966534173719.

\section{INTRODUCTION}

Transition metal complexes synthesized from Schiff bases have shown high potential to be versatile catalysts in organic synthesis and have remarkable developments in recent decades, and engage in some types of chemical transformations such as hydrogenation, hydration (1), decarbonylation (2), olefin metathesis (3), Diels-Alder reaction (4), nitro aldol reaction (5), isomerization (6), cyclopropanation (7), enol-ester synthesis (8), oxidation of hydrocarbon $(9,10)$, epoxidation $(11,12)$, and other related catalytic process (1). Metal complexes synthesized from Schiff bases have also showed high activity in asymmetric catalysis (13), and those complexes derived from aromatic carbonyl compounds have found to be very active in metalloprotein modeling as well as asymmetric catalysis (14-16). Epoxidation reaction catalysis as a special field has received great attention in last few years and many reports have raised on several methods of synthesis of catalytic complexes from 
many Schiff bases along with their catalytic activity evaluation (17-20).

One of the most important petrochemical industrial reactions is conversion of alkenes to alkene epoxides (21), a process that considers as a primary source for many fine chemicals, hence in organic synthesis researchers from over the globe have engaged in such catalytic epoxidation of alkenes and investigation is directed to olefin epoxidation catalysis $(22,23)$, many transition metal complexes of titanium (24), manganese (25), molybdenum (26), and rhenium (27) have been synthesized and their activities were tested in the alkene epoxidation. Remarkably, styrene oxide as industrial precursor has been synthesized in good yield using transition metal catalysts, since then this epoxide has been used in many industries, among them is soap, pharmaceuticals, cosmetic essences, perfumes, and food flavoring agents $(28,29)$. After establishing of many industrial epoxide's synthesis methods, researchers have directed their efforts to understand the catalytic pathways, many reports agreed with the pathways through generation of some transition metal ions as reaction intermediates with higher oxidation states (21), one interesting example is the asymmetric epoxides that synthesized from cis-disubstituted and cistrisubstituted olefins, in this regard manganese(III) complexes of specific chiral salen are found to be enantioselective with very high yields (30), in some other cases, pathways have been found to pass through synthesis of heterogeneous complexes which were found to be of great advantage over homogeneous catalysts because of their higher stability under wide range of temperatures, and easy products separation $(31,32)$, following this Janssen et al. have synthesized manganese(III) salen dimeric complex (33), which is retained in cross-linked polymer membrane have shown high activity in epoxidation synthesis. Special interests have been forwarded to pharmaceutical and agrochemical fields to use asymmetric epoxidation of alkenes for synthesis of desired drugs through chiral intermediates mechanisms, in this regard Jacobsen-Katsuki Salen (Mn)-catalyzed reaction is widely used for the asymmetric epoxidation of nonfunctionalized olefins $(34,35)$.

Vanadium complexes have been commonly utilized and widely used in epoxidation catalysis, oxovanadium complexes prepared from Schiff-based ligands are the most useful, for example, oxovanadium (IV) complexes when combined with oxygen or other peroxide were found to be very effective in sulfide and olefin epoxidation $(36,37)$. Mukaiyama aldol additions have been unraveled by the catalytic activity of vanadyl complexes based on 2,2'-biphenol core ligands, hence diastereoselectivity (up to 90/10 (anti/syn)) was achieved, the other worthy mentioned finding is that revealed by Uang (38), he used $\mathrm{V}(\mathrm{O})(\mathrm{acac})_{2}$ in the aerobic oxidative coupling of 2-naphthols.

In this paper, we focused on developing a new type of active vanadyl complexes specifically for the epoxidation process by study the synthesize and characterization of two new oxidovanadium (IV) complexes obtained from the reaction of $\mathrm{VO}$ (acac) 2 and $\mathrm{H}_{2} \mathrm{~L}_{1}$ (5-chlorosalicylaldehyde-glycine) and $\mathrm{H}_{2} \mathrm{~L}_{2}$ (5-nitrosalicylaldehyde-glycine) ligands (Scheme 1) and to carry out catalytic activity and a detailed DFT investigation of these complexes. The structures of the two complexes are shown in Figure 1.

\section{EXPERIMENTAL SECTION}

\section{Materials}

For synthesis and analysis processes all reagents and solvents were purchased from Merck and were used as received without further purification. Deuterium oxide, 99.9\%, was obtained from Aldrich chemical company USA. Cis-cyclooctene, 95\%, Substituted salicylaldehyde (5-chloro, 5-nitro), amino acids (glycine), sodium hydroxide, tris(acetylacetonato)vanadium (IV) and $\mathrm{VO}(\mathrm{acac})_{2}$ were purchased from (Sigma Aldrich). Ethanol, acetonitrile, n-hexane, methanol, p-xylene, acetophenone, and isopropanol were used as solvents for purification, recrystallization, epoxidation, and solution making.

\section{Instrumentation}

Infrared spectra of the ligands and their corresponding catalysts were recorded on FTIR spectrometer 10.5.1, frontier (FTIR)-Perkin ElmerZnSe/Diamond-ATR. NMR spectra of the ligands and catalysts were recorded on Bruker AVIII 40, ${ }^{1} \mathrm{H}$ NMR $500 \mathrm{MHz},{ }^{13} \mathrm{C}$ NMR $126 \mathrm{MHz}$, US. For complexes and ligands, elemental analyses were recorded on HEKA tech EURO EA (CHSN). an Agilent GC Model 7890B was used for determining the epoxidation of cyclooctene to cyclooctane epoxide, GC column used as Agilent HP-5 with dimensions $0.25 \mu \mathrm{m}$, the oven temperature was set at $70^{\circ} \mathrm{C}$.

\section{Synthesis of the ligands $\left(H_{2} L_{1}\right.$ and $\left.H_{2} L_{2}\right)$}

The preparation of the ligands $\mathrm{H}_{2} \mathrm{~L}_{1}$ and $\mathrm{H}_{2} \mathrm{~L}_{2}$ were carried out by mixing of $1: 1$ molar ratio solution of nitro-salicylaldehyde or chloro-salicylaldehyde in methanol with a solution of glycine dissolved in methanolic solution under reflux condition for several hours.

The reaction is carried in a $250 \mathrm{~mL}$ round-bottomed flask containing $150 \mathrm{~mL}$ of absolute ethanol, to the flask's content $10 \mathrm{mmol}(1.565 \mathrm{~g})$ of 5chlorosalicylaldehyde or $10 \mathrm{mmol}(1.671 \mathrm{~g})$ 5nitrosalicylaldehyde, $10 \mathrm{mmol}(0.75 \mathrm{~g})$ of glycine, and $10 \mathrm{mmol}(0.40 \mathrm{~g})$ of $\mathrm{NaOH}$, the mixture was refluxed with stirring for $5 \mathrm{hrs}$. After cooling to room 
temperature, the mixture was poured into a $100 \mathrm{~mL}$ ice-water in a beaker and left overnight in a refrigerator, yellow crystals were precipitated, filtered off, washed with slightly cold water, and dried in an oven (39), and finally recrystallized from ethanol until a pure product was obtained, the synthesized ligand from substituted chlorosalicylaldehyde $\left(\mathrm{H}_{2} \mathrm{~L}_{1}\right)$ is $2-\{[(E)-(5$-chloro-2hydroxyphenyl) methylidene) amino $\}$ acetic acid and from substituted nitro-salicylaldehyde $\left(\mathrm{H}_{2} \mathrm{~L}_{2}\right)$ is 2-\{[(E)-(2-hydroxy-5-nitrophenyl) methylidene] amino\} acetic acid.

\section{$\mathrm{H}_{2} \mathrm{~L}_{1}$ [(E)-2-((5-chloro-2-hydroxybenzylidene) amino)acetic acid]}

Color: Shiny yellow. Yield: 92\%. FT-IR $(\mathrm{KBr}, \mathrm{v}, \mathrm{cm}$ $\left.{ }^{1}\right): 3100(\mathrm{OH})(\mathrm{Ar}-\mathrm{OH}), 3050(\mathrm{OH})(\mathrm{Carboxyl}-\mathrm{OH})$, $1910(\mathrm{C}=\mathrm{O})$ (Carboxyl), $1680(\mathrm{C}=\mathrm{N}) .{ }^{1} \mathrm{H}$ NMR $(500$ $\left.\mathrm{MHz}, \mathrm{D}_{2} \mathrm{O}, \delta, \mathrm{ppm}\right): 9.90(\mathrm{~s}, 1 \mathrm{H}, \mathrm{COOH}), 8.15(\mathrm{~s}$, $1 \mathrm{H}, \mathrm{CH}=\mathrm{N}), 7.37(\mathrm{~s}, 1 \mathrm{H}, \mathrm{C}-\mathrm{H}$ ring $), 6.59(\mathrm{~d}, 2 \mathrm{H}, \mathrm{CH}-$ $\mathrm{CH}$ ring), $3.37\left(\mathrm{~s}, 2 \mathrm{H}, \mathrm{CH}_{2} \mathrm{COOH}\right) .{ }^{13} \mathrm{CNMR}(126$ $\left.\mathrm{MHz}, \mathrm{CDCl}_{3}, \delta, \mathrm{ppm}\right): 118.32$ (1C, $\left.\mathrm{Ar}-\mathrm{CH}-\mathrm{CCl}\right)$, 167.07 (1C, Ar-CCl), 125.30 (1C, Ar-CH-C), 115.93 (1C, Ar-C-CH2), 129.79 (1C, Ar-C-O), 124.74 (1C, Ar- $\mathrm{CH}-\mathrm{CH}), 172.66(1 \mathrm{C}, \mathrm{C}=\mathrm{N}), 42.15\left(1 \mathrm{C}, \mathrm{CH}_{2}-\mathrm{N}\right)$, 193.30 (1C, $\mathrm{COOH})$. Anal. Calcd. for $\mathrm{C}_{9} \mathrm{H}_{8} \mathrm{ClNO}_{3}$ : C, $50.55 ; \mathrm{H}, 3.77 ; \mathrm{N}, 6.56$. Found: $\mathrm{C}, 50.30 ; \mathrm{H}, 3.40$; $\mathrm{N}, 6.53$.

\section{$\mathrm{H}_{2} \mathrm{~L}_{2}$ [(E)-2-((2-hydroxy-5-nitrobenzylidene) amino)acetic acid]}

Color: Faint Yellow. Yield: $86 \%$. FT-IR $\left(\mathrm{KBr}, \mathrm{V}, \mathrm{cm}^{-}\right.$ $\left.{ }^{1}\right): 2890(\mathrm{OH})(\mathrm{Ar}-\mathrm{OH}), 2605(\mathrm{OH})(\mathrm{Carboxyl}-\mathrm{OH})$, $1725(\mathrm{C}=\mathrm{O})$ (Carboxyl), $1650(\mathrm{C}=\mathrm{N}) .{ }^{1} \mathrm{H}$ NMR (500 $\left.\mathrm{MHz}, \mathrm{D}_{2} \mathrm{O}, \delta, \mathrm{ppm}\right): 9.92(\mathrm{~s}, 1 \mathrm{H}, \mathrm{COOH}), 8.3(\mathrm{~s}, 1 \mathrm{H}$, $\mathrm{CH}=\mathrm{N}), 8.05(\mathrm{~s}, 1 \mathrm{H}, \mathrm{C}-\mathrm{H}$ ring $), 6.52(\mathrm{~d}, 2 \mathrm{H}, \mathrm{CH}-\mathrm{CH}$ ring), 3.45 (s, $\left.2 \mathrm{H}, \mathrm{CH}_{2} \mathrm{COOH}\right) .{ }^{13} \mathrm{CNMR}(126 \mathrm{MHz}$, $\left.\left.\mathrm{CDCl}_{3}, \delta, \mathrm{ppm}\right): 128.53(1 \mathrm{C}, \mathrm{Ar}-\mathrm{CH}-\mathrm{C} \mathrm{NO})_{2}\right), 172.49$ (1C, Ar-CCl), 124.00 (1C, Ar-CH-C), 123.25 (1C, Ar$\mathrm{C}-\mathrm{CH} 2), 131.18(1 \mathrm{C}, \mathrm{Ar}-\mathrm{C}-\mathrm{O}), 135.10$ (1C, $\mathrm{Ar}-\mathrm{CH}-$ $\mathrm{CH}), 179.68(1 \mathrm{C}, \mathrm{C}=\mathrm{N}), 41.43\left(1 \mathrm{C}, \mathrm{CH}_{2}-\mathrm{N}\right), 193.57$ (1C, $\mathrm{COOH})$. Anal. Calcd. for $\mathrm{C}_{9} \mathrm{H}_{8} \mathrm{~N}_{2} \mathrm{O}_{5}: \mathrm{C}, 48.17 ; \mathrm{H}$, $3.60 ; \mathrm{N}, 12.50$. Found: $\mathrm{C}, 48.08 ; \mathrm{H}, 3.14 ; \mathrm{N}, 12.30$.

\section{Synthesis of $\mathrm{VOL}_{1}$ and $\mathrm{VOL}_{2}$ complexes}

Subsequently, after successful preparation of the two ligands, the prepared ligands $\mathrm{H}_{2} \mathrm{~L}_{1}$ or $\mathrm{H}_{2} \mathrm{~L}_{2}$ and $\mathrm{VO}(\mathrm{acac})_{2}$ in a molar ratio of $1: 1$ in methanol were refluxed for 10 hours, then the vanadyl Schiff base complexes were separated.

In a $100 \mathrm{~mL}$ round-bottomed flask, $5 \mathrm{mmol}$ of each ligand $\left(1.138 \mathrm{~g}\right.$ of $\mathrm{H}_{2} \mathrm{~L}_{1}$ or $1.190 \mathrm{~g}$ of $\mathrm{H}_{2} \mathrm{~L}_{2}$ ) were dissolved in $45 \mathrm{~mL}$ of methanol and to this solution $5 \mathrm{mmol}$ of $\mathrm{VO}(\mathrm{acac})_{2}(1.280 \mathrm{~g})$ dissolved in $10 \mathrm{~mL}$ of $\mathrm{MeOH}$ was added, the content was refluxed with stirring for 4 hours. After reducing the solvent to one-fifth volume, the content was left to cool to room temperature and kept in a refrigerator for seven days, greenish crystals were separated, filtered off, washed with n-hexane, and dried in an oven (39).

$\mathrm{VOL}_{1}$

Color: Faint green. Yield: $67 \%$. FT-IR $\left(\mathrm{KBr}, \mathrm{v}, \mathrm{cm}^{-1}\right)$ : $940(\mathrm{~V}=\mathrm{O}), 1740(\mathrm{C}=\mathrm{O}), 1620(\mathrm{C}=\mathrm{N}) .{ }^{13} \mathrm{CNMR}(126$ $\left.\mathrm{MHz}, \mathrm{CDCl}_{3}, \delta, \mathrm{ppm}\right): 121.6(1 \mathrm{C}, \mathrm{Ar}-\mathrm{CH}-\mathrm{CCl}), 166.1$ (1C, Ar-CCl), 134.9 (1C, Ar-CH-C), 122.4 (1C, Ar-C$\mathrm{CH} 2), 164.5$ (1C, $\mathrm{Ar}-\mathrm{C}-\mathrm{O}), 132.4$ (1C, $\mathrm{Ar}-\mathrm{CH}-\mathrm{CH})$, $174.8(1 \mathrm{C}, \mathrm{C}=\mathrm{N}), 62.1\left(1 \mathrm{C}, \mathrm{CH}_{2}-\mathrm{N}\right), 204.0(1 \mathrm{C}$, COO). Anal. Calcd. for $\mathrm{C}_{9} \mathrm{H}_{6} \mathrm{ClNO}_{4} \mathrm{~V}: \mathrm{C}, 41.01 ; \mathrm{H}$, $2.73 ; \mathrm{N}, 4.78$. Found: $\mathrm{C}, 41.09 ; \mathrm{H}, 2.83 ; \mathrm{N}, 4.38$.

$\mathrm{VOL}_{2}$

Color: Faint greenish blue. Yield: $64 \%$. FT-IR $(\mathrm{KBr}$, $\left.v, \mathrm{~cm}^{-1}\right)$ : $995(\mathrm{~V}=\mathrm{O}), 1645(\mathrm{C}=\mathrm{O}), 1593(\mathrm{C}=\mathrm{N})$. ${ }^{13} \mathrm{CNMR}\left(126 \mathrm{MHz}, \mathrm{CDCl}_{3}, \delta, \mathrm{ppm}\right): 121.7$ (1C, Ar$\left.\mathrm{CH}-\mathrm{CNO}_{2}\right), 137.0(1 \mathrm{C}, \mathrm{Ar}-\mathrm{C} \mathrm{NO})_{2}, 129.8(1 \mathrm{C}, \mathrm{Ar}-\mathrm{CH}-$ C), 119.7 (1C, $\mathrm{Ar}-\mathrm{C}-\mathrm{CH} 2), 131.4$ (1C, $\mathrm{Ar}-\mathrm{C}-\mathrm{O})$, $135.0(1 \mathrm{C}, \mathrm{Ar}-\mathrm{CH}-\mathrm{CH}), 191.29(1 \mathrm{C}, \mathrm{C}=\mathrm{N}), 62.92$ $\left(1 \mathrm{C}, \mathrm{CH}_{2}-\mathrm{N}\right), 204.1$ (1C, COO). Anal. Calcd. for $\mathrm{C}_{9} \mathrm{H}_{6} \mathrm{~N}_{2} \mathrm{O}_{6} \mathrm{~V}: \mathrm{C}, 39.58 ; \mathrm{H}, 2.63 ; \mathrm{N}, 9.23$. Found: $\mathrm{C}$, $39.55 ; \mathrm{H}, 2.82 ; \mathrm{N}, 9.03$.

\section{General procedure of the epoxidation reaction}

Batch reactions were conducted in $4 \mathrm{~mL}$ of GCgrade acetonitrile as solvent. The reactions were started by the addition of a solution of the catalyst $\left(\mathrm{VOL}_{1}\right.$ or $\left.\mathrm{VOL}_{2}\right)$ dissolved in acetonitrile to a solution of cis-cyclooctene $(0.2015 \mathrm{mmol})$ and $\mathrm{H}_{2} \mathrm{O}_{2}(50 \%$ $(w: v)$ in water) $(0.403 \mathrm{mmol})$ according to the stoichiometry of (1 cis-cyclooctene: $2 \quad \mathrm{H}_{2} \mathrm{O}_{2}$ : 1 catalyst) in acetonitrile to give a total reaction volume of $4 \mathrm{~mL}$. The progress of the reaction was monitored by periodic sampling for GC determination, therefore aliquots of the reaction mixture were withdrawn and added to activated $\mathrm{MnO}_{2}$ as a $\mathrm{H}_{2} \mathrm{O}_{2}$ decomposition agent to quench the reactions (39). To remove solid materials, quenched reaction mixture was filtered off over activated neutral alumina oxide, then two GC samples were prepared for each experiment using $200 \mu \mathrm{L}$ of filtrate, $500 \mu \mathrm{L}$ of external standard solution ( $p$ xylene and acetophenone $4 \mathrm{mg} / \mathrm{mL}$ in $\mathrm{iPrOH}$ ) and $800 \mu \mathrm{L}$ of $n$-hexane. Time-dependent yield experiments were conducted in a total volume of 12 $\mathrm{mL}$ using the same stoichiometry and concentrations. Control experiments were performed as a reference without the use of a catalyst.

\section{Computational method}

Electronic structure calculations were performed using the Gaussian 16W software (40) mainly to reveal the vibrational properties and structural characteristics of the ligands and their corresponding complexes. Geometry optimizations for the target complexes $\mathrm{VOL}_{1}$ and $\mathrm{VOL}_{2}$ were fulfilled using Density Functional Theory (DFT) based on Beck's three parameter exchange functional and Lee-Yang-Parr nonlocal correlation 
functional (B3LYP) $(41,42)$ and the $6-31+G(d, p)$ orbital basis sets for all atoms to describe their molecular properties including their stability and reactivity. Characterization of the located stationary points as minimal or transitional states is carried out by vibrational frequency calculations at the same level of theory. Unrestricted DFT at the B3LYP/6$31+G(d, p)$ level of theory is used to fully optimize the two complexes with no constraints and extract the geometries in gas phase and some selected solvents, in this regard all calculations were performed in the presence of the selected solvent by placing the molecules in a cavity within the solvent field. The integral equation formalism variant along with the Polarizable Continuum Model (IEFPCM) is used for the calculations (43).

With the help of the ChemCraft program (44) the vibrational modes were examined. To correlate between experimental and calculated frequencies a factor of 0.96 is used to account for the inharmonicity of the calculated frequencies. For both complexes the natural population analysis (NPA) is used for assigning the partial charge distributions. GaussView version 6.0.16 (45) is used to visualize the final optimized structures. Then the relationship between the molecular, the electronic structure, and the stability of the molecules were investigated. Therefore, some molecular descriptors such as the calculation of the highest occupied molecular orbitals (HOMOs) and the lowest unoccupied molecular orbitals (LUMOs), frontier orbital energy gap, molecular dipole moment $(\mu)$, electron affinity (EA), ionization potential (IP), electronegativity (X) that determines the tendency of the electrophile to acquire an additional electronic charge, global hardness $(\eta)$, softness $(\sigma)$, and electrophilicity index $(\omega)$, were calculated using the DFT method along with Koopman's theorem and have been used to understand the properties and activity of the newly prepared complexes, reference 46 accounts for more theoretical equations. Furthermore, $\mathrm{VOL}_{2}$ as a representative, its optimization is confirmed by a higher basal set using Orca Program Version 4.2.1 (47), and Gamess US Program Version 30 JUN 2019-R1-Patch-1-mkl (48), for both programs, Avogadro software version 1.2 .0 (49) is used to draw molecular structures and generate input files, as well as GaussSum version 3.0 (50) which is used for NBO and frontier molecular orbital analysis, finally the catalytic cycle mechanistic aspects are followed with the DFT at the B3LYP/6-31+G(d,p) and UPBEPBE (unrestricted Perdew, Burke, and Enzerhof exchange and correlation functional)/LanL2DZ (Los Alamos National Laboratory Double Zeta) level (51-54).

\section{RESULTS AND DISCUSSION}

In this work, the two isomers of the ligands and their complexes were characterized by spectroscopic techniques (FT-IR, ${ }^{1} \mathrm{H}$ and ${ }^{13} \mathrm{C} N \mathrm{NMR}$ ) and theoretical DFT is carried to confirm their molecular structures. The preparation procedure of the ligands $\mathrm{H}_{2} \mathrm{~L}_{1}$ and $\mathrm{H}_{2} \mathrm{~L}_{2}$ and their corresponding $\mathrm{VOL}_{1}$ and $\mathrm{VOL}_{2}$ complexes was presented in Scheme 1 (detailed method of preparation can be found above). After ligands preparation, the ligands $\mathrm{H}_{2} \mathrm{~L}_{1}$ or $\mathrm{H}_{2} \mathrm{~L}_{2}$ and $\mathrm{VO}(\mathrm{acac})_{2}$ in a molar ratio of $1: 1$ in methanol were refluxed for 10 hours, then the vanadyl Schiff base complexes were separated.

The complexation reaction of metal:ligand was proceeded as 1:1 molar ratio, this pattern was indicated from the analytical data and suggested a coordination through azomethine nitrogen and two oxygen atoms from the deprotonated phenolic groups and the carboxyl group, also the analytical data revealed that four of the $\mathrm{V}$ (IV) equatorial coordination sites are bound to the ligand molecule leaving fifth site empty which will be filled later to maintain the epoxidation reaction. Figure 1 shows the optimized structure diagram of complexes $\mathrm{VOL}_{1}$ and VOL2.

\section{Elemental analysis}

The elemental analysis of $\mathrm{C}, \mathrm{H}$, and $\mathrm{N}$ of the compounds considered are given under each compound experimental data, the results of $\mathrm{C}, \mathrm{H}$ and $\mathrm{N}$ percentages agreed with the structural composition suggested for the ligand and the vanadyl complexes and confirmed a 1:1 (metal: ligand) stoichiometry.

\section{Infrared spectral studies}

The FTIR spectra of the ligands and their complexes were compared to determine any changes during complexation and to confirm their structures. The assignment of infrared bands of the Schiff bases and their vanadyl complexes agreed with the expected values. The ligands $\left(\mathrm{H}_{2} \mathrm{~L}_{1}\right.$ and $\left.\mathrm{H}_{2} \mathrm{~L}_{2}\right)$ showed a medium broad band in the range of $3000-3080 \mathrm{~cm}^{-1}$ which attributed to the phenolic and carboxylic $\mathrm{OH}$ groups, an intense band at $1680 \mathrm{~cm}^{-1}$ for $\mathrm{H}_{2} \mathrm{~L}_{1}$ and $1650 \mathrm{~cm}^{-1}$ for $\mathrm{H}_{2} \mathrm{~L}_{2}$ that are due to $\mathrm{v}(\mathrm{C}=\mathrm{N})$ stretching vibration mode, medium band at $1739 \mathrm{~cm}^{-1}$ for $\mathrm{H}_{2} \mathrm{~L}_{1}$ and $1736 \mathrm{~cm}^{-1}$ for $\mathrm{H}_{2} \mathrm{~L}_{2}$ are assigned to $\mathrm{v}(\mathrm{C}=\mathrm{O})$ stretching frequency, and phenolic $\mathrm{C}-\mathrm{O}$ stretching absorption is seen at $1273 \mathrm{~cm}^{-1}$ for $\mathrm{H}_{2} \mathrm{~L}_{1}$ and 1288 $\mathrm{cm}^{-1}$ for $\mathrm{H}_{2} \mathrm{~L}_{2}$. 


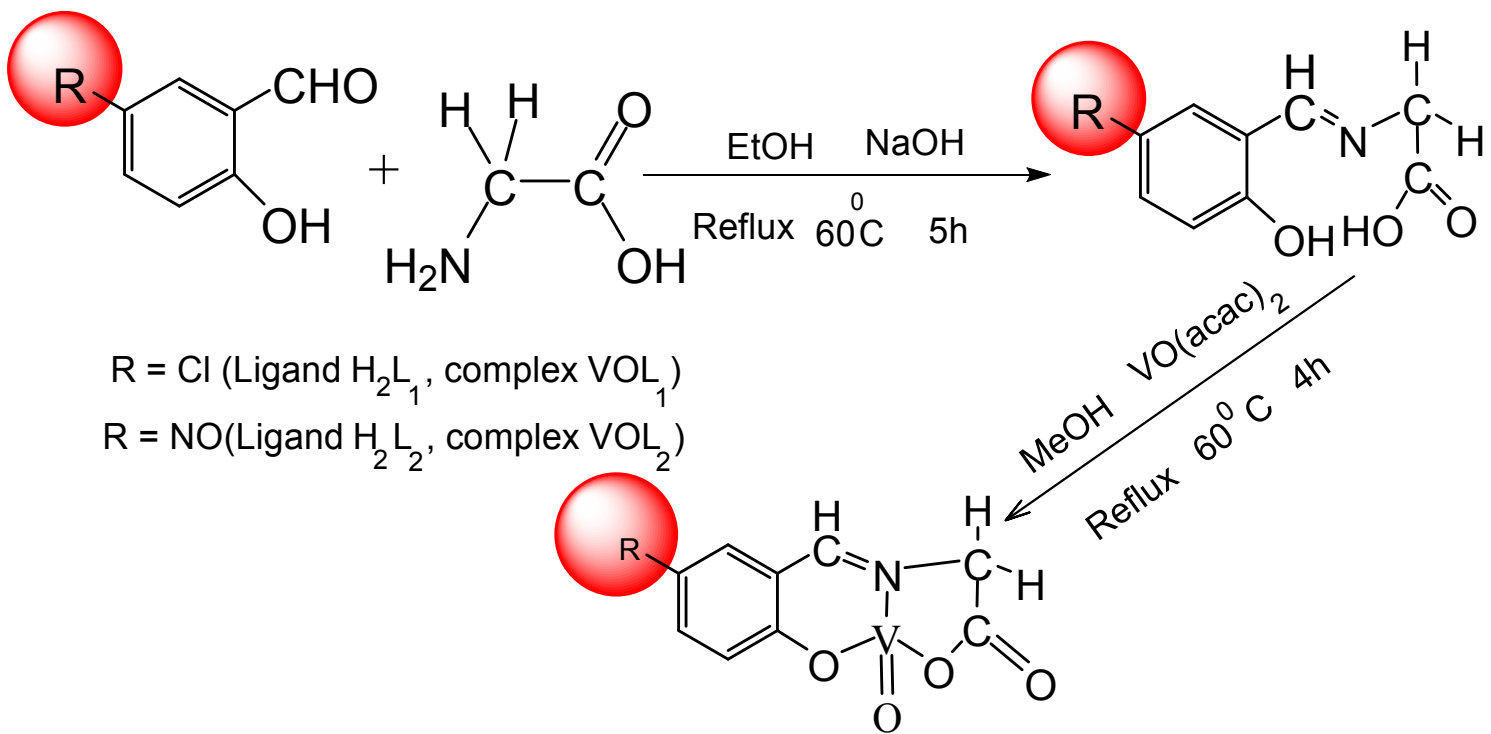

Scheme 1: Preparation pattern of the new tridentate $(O, N)$ Schiff base ligands $H_{2} L_{1}$ and $H_{2} L_{2}$ and its $V O L_{1}$ and $\mathrm{VOL}_{2}$ complexes.

The FTIR spectra of the complexes compared with those of the ligands indicated that the $\mathrm{v}(\mathrm{C}=\mathrm{N})$ band appeared at $1620 \mathrm{~cm}^{-1}$ for $\mathrm{VOL}_{1}$ and $1592 \mathrm{~cm}^{-1}$ for $\mathrm{VOL}_{2}$ complexes which are shifted on complexation indicating complexation through the nitrogen atom of azomethine $(55,56)$, the band showed at 1300 $\mathrm{cm}^{-1}$ for $\mathrm{VOL}_{1}$ and $1290 \mathrm{~cm}^{-1}$ for $\mathrm{VOL}_{2}$ attributed to
$\mathrm{v}(\mathrm{PhC}-\mathrm{O})$ stretching, the $\mathrm{OH}$ stretching bands found in the ligands' spectra appeared on the region of 3000-3080 $\mathrm{cm}^{-1}$ are absent in the complexes' spectra, indicative of complexation of vanadium by $\mathrm{OH}$ group of phenolato and carboxyl after deprotonation.

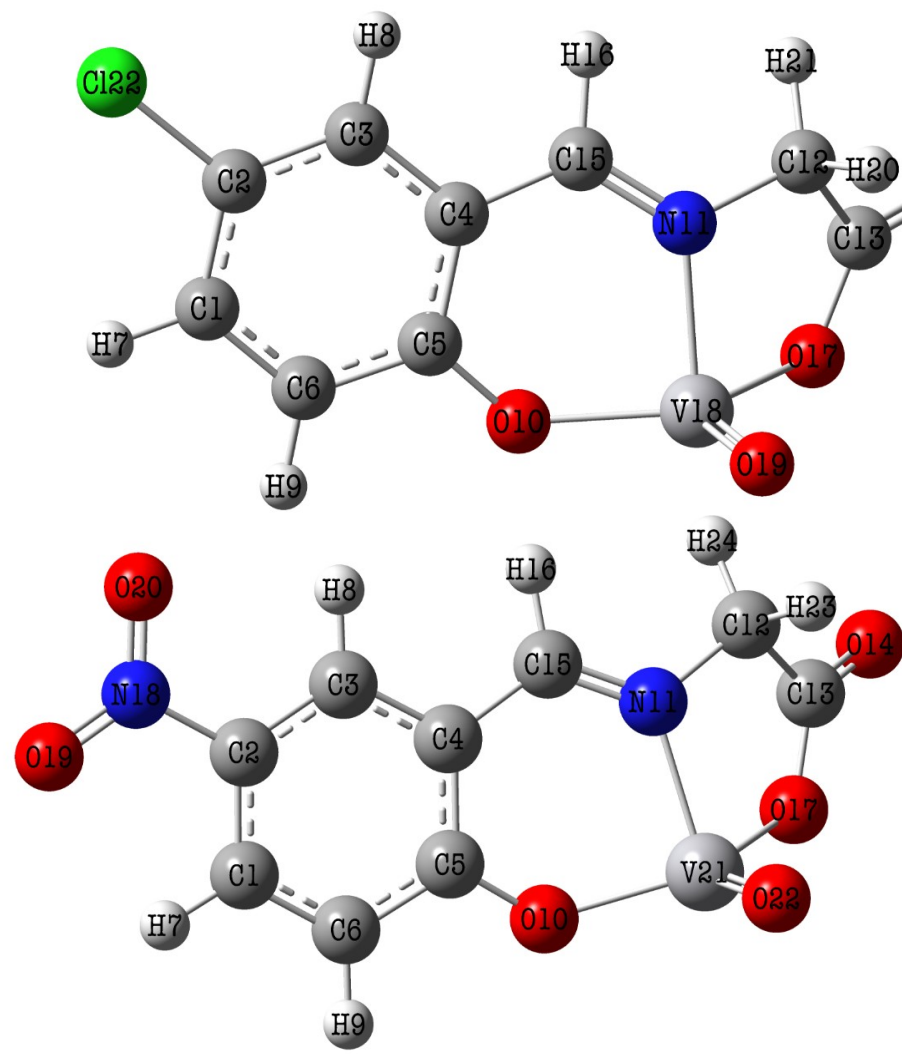

Figure 1: The optimized structure and atom numbering scheme for complex VOL $\mathrm{L}_{1}$ (top) and $\mathrm{VOL}_{2}$ (bottom), structure optimization is carried out using $B 3 L Y P / 6-31+G(d, p)$ level of theory. 
The $\mathrm{v}(\mathrm{C}=\mathrm{O})$ stretching absorptions emerged at the region (1740 and $1730 \mathrm{~cm}^{-1}$ for complexes $\mathrm{VOL}_{1}$ and $\mathrm{VOL}_{2}$ respectively). Conclusive evidence of bonding is also shown by the observation of new bands in the spectra of the complexes appearing at (870 and $840 \mathrm{~cm}^{-1}$ for complex $\left.\mathrm{VOL}_{1}\right)$ and $\left(840\right.$ and $800 \mathrm{~cm}^{-1}$ for complex $\left.\mathrm{VOL}_{2}\right)$ where these are assigned to $\mathrm{v}(\mathrm{V}$ $\mathrm{O}$-carboxyl) and $\mathrm{v}(\mathrm{V}-\mathrm{O}$-phenol) stretching respectively, these two bands are not observed in the ligand's spectrum. Oxovanadium complexes generally showed $\mathrm{V}_{(\mathrm{V}=0)}$ of polynuclear linear chain structures $(V=0 \ldots . . V=O \ldots \ldots)$ at around $860 \mathrm{~cm}^{-1}$ with orange color, and monomeric structure at around $950 \mathrm{~cm}^{-1}$ with a green color in the solid state and solution $(57,58)$. Sharp FTIR bands at $941 \mathrm{~cm}^{-1}$ and $937 \mathrm{~cm}^{-1}$ for complexes $\mathrm{VOL}_{1}$ and $\mathrm{VOL}_{2}$ respectively are noticed and attributed to the monomeric form of VOL complexes in the solid state (59). Vergopoulos et.al (60) used crystallographic means to establish similar monomeric nature of related complexes. Beside that the $\Pi$-bond located in the $\mathrm{C}=\mathrm{C}$ benzene ring of the ligand does not show a significant shift of the stretching mode that noticed around $1600 \mathrm{~cm}^{-1}$ upon complexation. Hence the FTIR data indicated a pattern of complexation through the azomethine nitrogen, phenolic and carboxylic oxygens, similar structure of vanadium complex is suggested by Jamaluddin et. al. (61), for more details please refer to Figures S-1 to S-6 in the appendices.

\section{NMR spectra}

The ${ }^{1} \mathrm{H}$ NMR and ${ }^{13} \mathrm{C}$ NMR spectra of Schiff bases ligands $\mathrm{H}_{2} \mathrm{~L}_{1}$ and $\mathrm{H}_{2} \mathrm{~L}_{2}$ and their complexes $\mathrm{VOL}_{1}$ and $\mathrm{VOL}_{2}$ have been studied using $\mathrm{D}_{2} \mathrm{O}$ as a solvent. All expected region of protons calculated from the integration curves and those obtained from the values of the expected ( $\mathrm{CHN})$ analysis agreed with each other. In the ${ }^{1} \mathrm{H}$ NMR spectral data of the two ligands as shown in Table 1 , both ligands show a broad signal at $9.90 \mathrm{ppm}$ (13.00-DFT) $\left(\mathrm{H}_{2} \mathrm{~L}_{1}\right)$ and $9.92 \mathrm{ppm}$ (13.00-DFT) $\left(\mathrm{H}_{2} \mathrm{~L}_{2}\right)$ due to the carboxylic $\mathrm{OH}$ resonance.

The absence of this signal in the complexes (as the whole NMR spectrum of the complexes are not found due to the paramagnetic nature of the vanadium (IV)), suggested that this is in conformity with the coordination of the phenolate oxygen to the vanadium center. Phenolic proton does not usually appear in proton NMR because they are rapidly exchanged with $\mathrm{D}_{2} \mathrm{O}$ and or (in this case) hid due to the chloro group's orientation in benzene ring.

The proton observed as a signal at around $8.15 \mathrm{ppm}$ (8.70-DFT) $\left(\mathrm{H}_{2} \mathrm{~L}_{1}\right)$ and $8.30 \mathrm{ppm}$ (8.74-DFT) $\left(\mathrm{H}_{2} \mathrm{~L}_{2}\right)$ corresponding to azomethine proton resonance $(\mathrm{CH}=\mathrm{N})$, which have been showed a slight calculated downfield shift ( $\Delta \delta$-DFT $0.02-0.12 \mathrm{ppm}$ ) of the proton signal in the ligands with respect to the corresponding complexes suggested the coordination of the azomethine nitrogen atom to the vanadium center.

Aromatic and $\mathrm{CH}_{2}$ protons of the ligands, as well as in the complexes, appeared well within their expected ranges. The ${ }^{1} \mathrm{H}$ NMR of oxovanadium (IV) complexes $\mathrm{VOL}_{1}$ and $\mathrm{VOL}_{2}$ were recorded in DMSO$\mathrm{d}_{6}$ at 500 and $126 \mathrm{MHz}$. In all cases, no signal was observed. This is due to the paramagnetic nature of the vanadium (IV) center.

It has been found from ${ }^{13} \mathrm{C}$ analysis, Table 1 , that large $\Delta \delta$ ( $=\delta$-complex- $\delta$-ligand) values (not shown in the Table) for the carbon atoms attached to the phenolic oxygen $\left(C_{5}\right)$, azomethine nitrogen $\left(C_{16}\right.$ in case of $\mathrm{H}_{2} \mathrm{~L}_{1}$ and $\mathrm{C}_{15}$ in case of $\mathrm{H}_{2} \mathrm{~L}_{2}$ and both complexes), and carboxylic carbon atom ( $\mathrm{C}_{14}$ in case of $\mathrm{H}_{2} \mathrm{~L}_{1}$ and $\mathrm{C}_{13}$ in case of $\mathrm{H}_{2} \mathrm{~L}_{2}$ and both complexes) suggest coordination of these atoms to the vanadium center (62).

DFT calculations is also carried out with the ${ }^{17} \mathrm{O}$ NMR, which revealed that a large downfield shift occurred for phenolic oxygen, giving rise for $\Delta \delta$ values to be 153.6, and for carboxylic $\mathrm{OH}$ oxygen to be 144.5 , also ${ }^{15} \mathrm{~N}$ NMR of azomethine nitrogen reveals upfield shift, and giving rise for $\Delta \delta$ to be 31.0. All these findings suggest the coordination of these atoms. Good correlation between the calculated and experimental ${ }^{1} \mathrm{H}$ and ${ }^{13} \mathrm{C}$ chemical shifts in $\mathrm{D}_{2} \mathrm{O}$, and $\mathrm{DMSO}-d_{6}$ results is confirmed in Figure $\mathrm{S}-7$ in the appendices with good correlation factor $\mathrm{R}^{2}$ ranged from $0.80-0.98$ values, for more details please refer to Figures $S-8$ to $S-15$ in the appendices.

\section{UV-Vis spectral analysis}

TD-DFT calculations were carried out to obtain information on the nature of the excited state, UVVis absorption spectra of $\mathrm{VOL}_{1}$ and $\mathrm{VOL}_{2}$ in gas phase and some selected polar and nonpolar solvents were simulated by using Time-Dependent density functional theory (TD-DFT) and the polarizable continuum model (PCM) method with the unrestricted $6-31+G(d, p)$ basis set. The electric charges were obtained using natural bond orbital (NBO) calculations.

Due to the presence of many $n$ electrons allocated in the aromatic ring and many nonbonding electrons allocated in oxygen and nitrogen atoms in the two complexes $\mathrm{VOL}_{1}$ and $\mathrm{VOL}_{2}$, the $\Pi \rightarrow \Pi^{*}$ and $\mathrm{n} \rightarrow \Pi^{*}$ electronic transitions are the main contributors to UV-Vis absorption. These electronic transitions emerge from electron motions between the frontier molecular orbitals (FMOs), which are the higher occupied molecular orbitals (HOMOs) and the lower unoccupied molecular orbitals (LUMOs). PCM/TD$B 3 L Y P / 6-31+G(d, p)$ method is used to calculate the theoretical UV-Visible electronic transitions in some solvents, results are shown in Figures 2 and 3. The 
absorption wavelengths maxima are obtained by applying the above method of theory from single point calculations on the ground state, optimized geometries in gas phase and selected solvents (vertical transitions). One interesting observation that can be derived from Figures 2 and 3 (internal graphs) is that the slight but continuous change in excitation wavelength with the change in solvent polarity, in the case of $\mathrm{VOL}_{1}$ the excitation wavelength (excitation energy) is decreased with increasing solvent polarity, while in the case of VOL the excitation wavelengths is decreased with decreasing solvent polarity.

This contradictory effect is observed due to the difference in electronic density around the molecule which in turn comes from the difference in the functional group presence in the benzene ring, the chloro group in $\mathrm{VOL}_{1}$ is classified as a donor group, hence increasing electron density in the whole molecule specially around vanadium center, and more energy needed to excite the vanadium individual electron upon increasing solvent polarity, inversely nitro group in $\mathrm{VOL}_{2}$ is classified as withdrawing group, hence the electron density from the whole molecule is withdrawn, and the electron density around vanadium center is became less intense and electron is excited easily, this lead to notice that the excited state in both complexes is affected by solvent polarity, and indicates that beside $\Pi \rightarrow \Pi^{*}$ and $n \rightarrow \Pi^{*}$ electronic transitions the excited state has a dominant ligand to metal charge transfer character (LMCT).

\section{Geometry optimization}

The structures of $\mathrm{VOL}_{1}$ and $\mathrm{VOL}_{2}$ were optimized using DFT at the unrestricted B3LYP/6-31+G(d,p) level of theory.

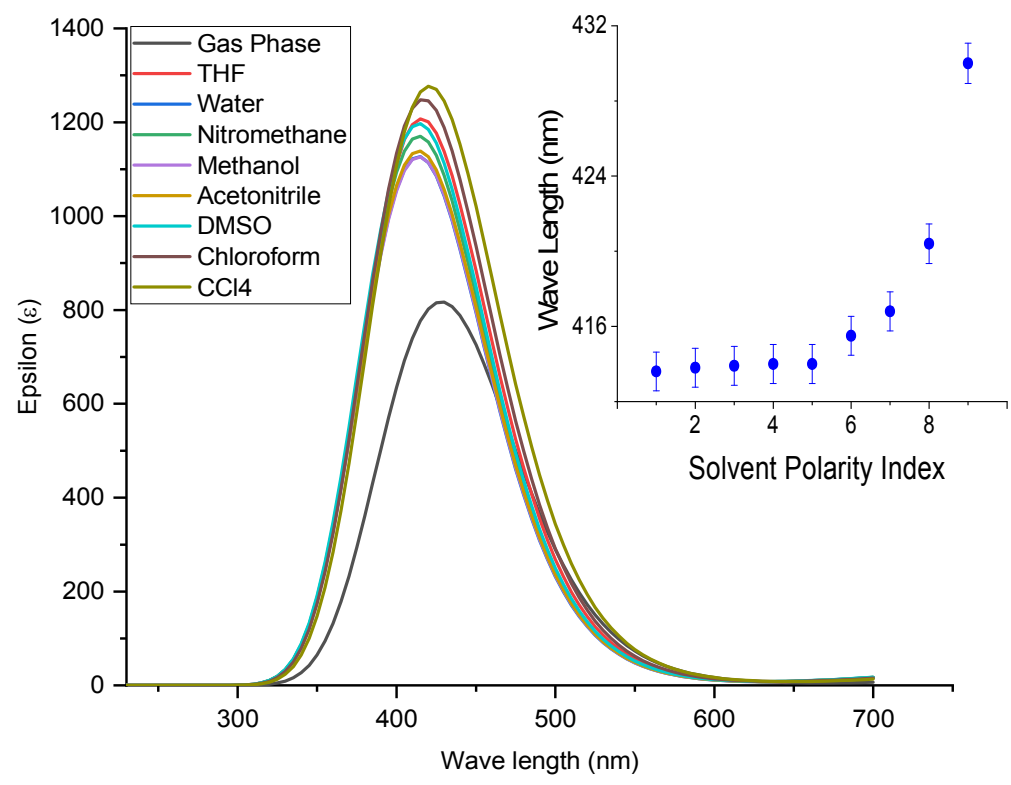

Figure 2: $\mathrm{VOL}_{1}$ complex absorbance wavelengths for solvents: Gas phase $=430.0 \mathrm{~nm}, \mathrm{THF}=415.5 \mathrm{~nm}$, Water $=413.6 \mathrm{~nm}$, Nitromethane $=414.0 \mathrm{~nm}$, Methanol $=413.9 \mathrm{~nm}$, Acetonitrile $=413.9 \mathrm{~nm}, \mathrm{DMSO}=$ $414.0 \mathrm{~nm}$, Chloroform $=416.8 \mathrm{~nm}, \mathrm{CCl}_{4}=420.4 \mathrm{~nm}$, calculated UV-Vis is simulated by using the TimeDependent density functional theory (TD-DFT) and the polarizable continuum model (PCM) method with the unrestricted $B 3 L Y P / 6-31+G(d, p)$ level of theory. 
Table 1: Comparison of the calculated chemical shifts (GIAO B3LYP/6-31+G(d,p)) with experimental ones in $D_{2} \mathrm{O}$.

\begin{tabular}{|c|c|c|c|c|c|c|c|c|c|c|}
\hline \multirow{2}{*}{$\begin{array}{l}\text { Comp. } \\
H_{2} L_{1}\end{array}$} & \multicolumn{10}{|c|}{ Atom numbering and NMR values } \\
\hline & & H-7 & H-8 & H-9 & H-17 & H-19 & H-21 & H-22 & & \\
\hline & Exp. & 7.40 & 7.25 & 6.70 & 8.15 & 3.35 & 9.90 & 3.35 & & \\
\hline & DFT-1 & 7.77 & 7.71 & 7.40 & 8.70 & 5.00 & 13.00 & 4.43 & & \\
\hline & & C-1 & C-2 & C-3 & C-4 & C-5 & C-6 & C-13 & C-14 & C-16 \\
\hline & Exp. & 129.79 & 124.74 & 125.30 & 118.32 & 167.07 & 115.93 & 42.15 & 193.30 & 172.66 \\
\hline & DFT-1 & 119.80 & 118.70 & 119.50 & 107.60 & 147.20 & 105.40 & 53.45 & 158.30 & 155.40 \\
\hline \multirow[t]{6}{*}{$\mathrm{H}_{2} \mathrm{~L}_{2}$} & & $\mathrm{H}-7$ & H-8 & H-9 & H-16 & H-18 & H-20 & H-21 & & \\
\hline & Exp. & 8.30 & 7.90 & 6.55 & 8.30 & 3.40 & 9.92 & 3.40 & & \\
\hline & DFT-1 & 8.70 & 8.73 & 7.34 & 8.74 & 5.13 & 13.92 & 4.18 & & \\
\hline & & C-1 & C-2 & C-3 & $C-4$ & C-5 & C-6 & C-12 & $C-13$ & $C-15$ \\
\hline & Exp. & 131.18 & 135.10 & 124.00 & 128.53 & 172.49 & 123.25 & 41.43 & 193.57 & 172.49 \\
\hline & DFT-1 & 115.80 & 128.70 & 117.60 & 105.90 & 153.2 & 104.60 & 52.31 & 155.3 & 152.00 \\
\hline \multirow[t]{9}{*}{ VOL $_{1}$} & & $\mathrm{H}-7$ & H-8 & H-9 & H-16 & H-2O & H-21 & & & \\
\hline & DFT-1 & 7.91 & 7.86 & 7.21 & 8.72 & 5.16 & 4.69 & & & \\
\hline & DFT-2 & 7.91 & 7.85 & 7.21 & 8.70 & 5.16 & 4.68 & & & \\
\hline & DFT-3 & 7.91 & 7.85 & 7.21 & 8.71 & 5.16 & 4.69 & & & \\
\hline & & $C-1$ & $C-2$ & $C-3$ & $C-4$ & C-5 & C-6 & C-12 & $C-13$ & $C-15$ \\
\hline & Exp. & 164.50 & 132.40 & 134.90 & 121.60 & 166.10 & 122.40 & 62.10 & 204.00 & 174.80 \\
\hline & DFT-1 & 124.86 & 119.85 & 122.43 & 111.01 & 152.19 & 106.63 & 58.25 & 161.38 & 156.57 \\
\hline & DFT-2 & 124.87 & 119.90 & 122.36 & 110.98 & 152.18 & 106.67 & 58.26 & 161.16 & 156.46 \\
\hline & DFT-3 & 124.87 & 119.88 & 122.39 & 111.00 & 152.18 & 106.65 & 58.25 & 161.27 & 156.51 \\
\hline \multirow[t]{9}{*}{$\mathrm{VOL}_{2}$} & & $\mathrm{H}-7$ & H-8 & H-9 & H-16 & H-23 & H-24 & & & \\
\hline & DFT-1 & 8.92 & 9.09 & 7.26 & 8.87 & 5.22 & 4.77 & & & \\
\hline & DFT-2 & 8.92 & 9.08 & 7.26 & 8.86 & 5.21 & 4.76 & & & \\
\hline & DFT-3 & 8.92 & 9.08 & 7.26 & 8.87 & 5.22 & 4.76 & & & \\
\hline & & C-1 & C-2 & C-3 & $C-4$ & C-5 & C-6 & C-12 & $C-13$ & C-15 \\
\hline & Exp. & 131.40 & 135.00 & 129.80 & 121.70 & 137.00 & 119.70 & 62.92 & 204.10 & 191.29 \\
\hline & DFT-1 & 119.68 & 130.42 & 121.36 & 110.78 & 158.04 & 107.44 & 58.56 & 160.70 & 153.03 \\
\hline & DFT-2 & 119.71 & 130.40 & 121.27 & 110.73 & 157.99 & 107.45 & 58.57 & 160.48 & 153.93 \\
\hline & DFT-3 & 119.70 & 130.41 & 121.31 & 110.76 & 158.01 & 107.45 & 58.57 & 160.59 & 153.98 \\
\hline
\end{tabular}

Solvents: (DFT-1 = $\mathrm{D}_{2} \mathrm{O}, \mathrm{DFT}-2=$ Ethanol, DFT-3 = Nitromethane). For atom labeling, see structure diagram Figure 1. 


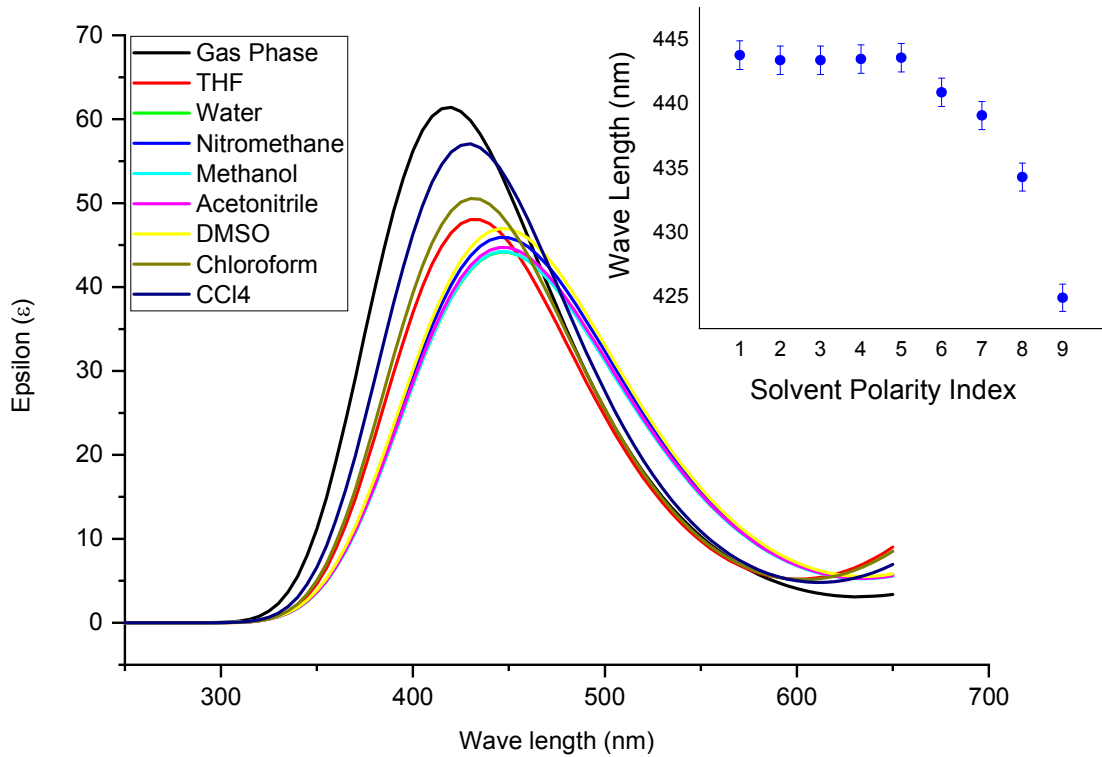

Figure 3: VOL2 complex absorbance wavelengths for solvents: Gas phase $=424.9 \mathrm{~nm}, \mathrm{THF}=440.9 \mathrm{~nm}$, Water $=443.8 \mathrm{~nm}$, Nitromethane $=443.5 \mathrm{~nm}$, Methanol $=443.4 \mathrm{~nm}$, Acetonitrile $=443.4 \mathrm{~nm}, \mathrm{DMSO}=$ $443.6 \mathrm{~nm}$, Chloroform $=439.1 \mathrm{~nm}, \mathrm{CCl}_{4}=449.7 \mathrm{~nm}$, calculated UV-Vis is simulated by using the TimeDependent density functional theory (TD-DFT) and the polarizable continuum model (PCM) method with the unrestricted B3LYP/6-31+G(d,p) level of theory.

Table 2: Selected bond distances $(\AA)$ and angles $\left(^{\circ}\right)$ for $\mathrm{VOL}_{2}$ optimized complex using three different

\begin{tabular}{|c|c|c|c|c|c|}
\hline Characters & $\begin{array}{l}\text { G16W DFT } \\
\text { B3LYP/6- } \\
31+G(d, p)\end{array}$ & $\begin{array}{l}\text { Orca M06L def2- } \\
\text { TZVP def2- } \\
\text { TZVP/C }\end{array}$ & $\begin{array}{l}\text { Gamess- } \\
\text { US UHF- } \\
\text { M06 -SPK- } \\
\text { DZP }\end{array}$ & Experimental & Reference \\
\hline \multicolumn{6}{|c|}{ Optimized bonds $(\AA)$} \\
\hline $\mathrm{V}_{21}-\mathrm{O}_{22}$ & 1.5610 & 1.5827 & 1.567 & $\begin{array}{l}1.581 \\
1.599\end{array}$ & $\begin{array}{l}(63) \\
(64)\end{array}$ \\
\hline $\mathrm{V}_{21}-\mathrm{O}_{10}$ & 1.8837 & 1.9147 & 1.886 & 1.869 & $(63)$ \\
\hline $\mathrm{V}_{21}-\mathrm{O}_{17}$ & 1.8900 & 1.9070 & 1.893 & 1.891 & $(63)$ \\
\hline $\mathrm{V}_{21}-\mathrm{N}_{11}$ & 2.0175 & 2.0071 & 2.006 & 2.076 & $(63)$ \\
\hline $\mathrm{O}_{10}-\mathrm{C}_{5}$ & 1.3100 & 1.3046 & 1.306 & 1.355 & $(64)$ \\
\hline $\mathrm{O}_{17}-\mathrm{C}_{13}$ & 1.3237 & 1.3260 & 1.327 & & \\
\hline \multicolumn{6}{|c|}{ Optimized angles $\left({ }^{\circ}\right)$} \\
\hline $\mathrm{O}_{22}-\mathrm{V}_{21}-\mathrm{O}_{17}$ & 115.6 & 118.9 & 115.6 & & \\
\hline $\mathrm{O}_{22}-\mathrm{V}_{21}-\mathrm{O}_{10}$ & 115.7 & 120.5 & 115.6 & & \\
\hline $\mathrm{O}_{22}-\mathrm{V}_{21}-\mathrm{N}_{11}$ & 106.8 & 107.1 & 106.0 & & \\
\hline $\mathrm{V}_{21}-\mathrm{O}_{10}-\mathrm{C}_{5}$ & 130.8 & 129.7 & 128.5 & & \\
\hline $\mathrm{V}_{21}-\mathrm{O}_{17}-\mathrm{C}_{13}$ & 120.0 & 119.6 & 119.7 & & \\
\hline $\mathrm{V}_{21}-\mathrm{N}_{11}-\mathrm{C}_{12}$ & 109.9 & 110.0 & 110.1 & & \\
\hline $\mathrm{V}_{21}-\mathrm{N}_{11}-\mathrm{C}_{15}$ & 126.4 & 125.8 & 125.9 & 121.7 & $(64)$ \\
\hline $\begin{array}{l}\text { Elect. Energy } \\
\text { (Hartree) }\end{array}$ & -1851.44 & -1860.59 & -1850.93 & & \\
\hline
\end{tabular}

The HF energies were found to be -2106.52 and 1851.44 Hartree, respectively. To confirm the optimized structures, $\mathrm{VOL}_{2}$ is further optimized with two more different methods, first the structure were inserted in Avogadro software and input files were generated, one input file is called by Orca Program
Version 4.2.1 and M06L def2-TZVP def2-TZVP/C bases set is applied which took $127 \mathrm{hrs}$. to converge, the other input file is called by Gamess US Program Version 2019-R1-Patch-1-mkl, and UHF M06 SPK-DZP bases set is applied which took 168 hrs. to converge. The bond lengths and angles are 
listed in Table 2. The bond distances in optimized structures are shown in Figure 1. Generally, there are no significant differences in the angles and bond distances between the three optimized structures, and this in agreement with some bond distances found in literature for some known bond distances, for example, $(\mathrm{V}=\mathrm{O})$.

\section{Frontier Molecular Orbitals (FMO)}

To get some insights in to the chemical stability of a molecule and in the interactions between atoms, frontier molecular orbitals (FMOs) are performed. FMOs effectively can determines some interesting characteristics of the molecules, including optical properties and biological activities, and mostly can be used in the HOMO (highest occupied molecular orbital) and the LUMO (lowest unoccupied molecular orbital) determination. Determining the HOMO and LUMO can, in turn, represents what parts on the molecule that can play as the donor or acceptor.

Figures S-16 and S-17 (in the appendices) show the electron density in HOMO and LUMO molecular orbitals for $\mathrm{VOL}_{1}$ and $\mathrm{VOL}_{2}$ complexes, respectively. The HOMO and LUMO orbitals were found to be delocalized over the complex molecule. The high electron density is concentrated on nitrogen atoms in HOMO and reduced in LUMO suggesting a transition pattern of $n \rightarrow \Pi^{*}$. In LUMO of the two complexes, part of the electron density was found to be localized on the benzene rings. The TD-DFT calculations indicate that the absorption spectra of complex $\mathrm{VOL}_{1}$ have three dominant bands at 404.5 $\mathrm{nm}, 423.5 \mathrm{~nm}$, and $430.0 \mathrm{~nm}$, and for complex VOL 2 there are four dominant absorption bands at 400.7 $\mathrm{nm}, 424.9 \mathrm{~nm}, 457.6 \mathrm{~nm}$, and $498.3 \mathrm{~nm}$ in the region studied theoretically, more details can be found in Tables 4 and 5.

The essential band for VOL $\mathrm{V}_{1}$ complex is $430 \mathrm{~nm}\left(R_{\text {rel }}\right.$ $=14.15)$ corresponding to a-spin $\operatorname{HOMO}(a)$ to LUMO(a) transition ( $34 \%$ and $\Delta \mathrm{E}=0.98 \mathrm{eV}$ ) and $\mathrm{H}$ 1 (a) to $L+4(a)$ transition ( $13 \%$ and $\Delta E=0.37 \mathrm{eV}$ ), together with a $\beta$-spin $\operatorname{HOMO}(\beta)$ to $\operatorname{LUMO}(\beta)$ transition $(41 \%$ and $\Delta \mathrm{E}=1.18 \mathrm{eV})$, while the essential band for complex VOL 2 is $424.9 \mathrm{~nm}\left(\mathrm{R}_{\text {rel }}=\right.$ 10.71) corresponds to a-spin $\mathrm{HOMO}(\mathrm{a})$ to $\mathrm{L}+4(\mathrm{a})$ transition ( $48 \%$ and $\Delta \mathrm{E}=1.40 \mathrm{eV}$ ) and $\mathrm{HOMO}(\mathrm{a})$ to $\mathrm{L}+5$ (a) transition $(17 \%$ and $\Delta \mathrm{E}=0.50 \mathrm{eV}$ ).

Table 3: The calculated vertical excitation energies $(\mathrm{eV})$, wavelengths $(\mathrm{nm})$, oscillatory strength, and main orbital contributions to the excited states (only contributions $>10 \%$ are given) for the $\mathrm{VOL}_{1} \mathrm{complex}$ calculated with TD-DFT/6-31+G(d,p) method in the gas phase.

\begin{tabular}{|c|c|c|c|}
\hline $\begin{array}{l}\text { Energy } \\
\text { (eV) }\end{array}$ & $\begin{array}{l}\text { Wavelength } \\
\text { (nm) }\end{array}$ & $\begin{array}{l}\text { Oscillatory } \\
\text { strength }\end{array}$ & Major orbital contribution \\
\hline 2.40 & 517.3 & 0.0001 & $\begin{array}{l}\mathrm{HOMO}(a) \rightarrow \operatorname{LUMO}(a)(53 \%), \mathrm{HOMO}(\beta) \rightarrow \operatorname{LUMO}(\beta) \\
(38 \%)\end{array}$ \\
\hline 2.49 & 498.0 & 0.0002 & $\begin{array}{l}H-1(a) \rightarrow L+2(a)(56 \%) \\
H-1(a) \rightarrow L+3(a)(16 \%)\end{array}$ \\
\hline 2.89 & 430.0 & 0.0161 & $\begin{array}{l}\operatorname{HOMO}(a) \rightarrow \operatorname{LUMO}(a)(34 \%), \operatorname{HOMO}(\beta) \rightarrow \operatorname{LUMO}(\beta) \\
(41 \%), \\
\mathrm{H}-1(a) \rightarrow L+4(a)(13 \%)\end{array}$ \\
\hline 2.93 & 423.5 & 0.0032 & $\mathrm{H}-1(\mathrm{a}) \rightarrow \mathrm{L}+4(\mathrm{a})(53 \%)$ \\
\hline 3.07 & 404.5 & 0.001 & $\begin{array}{l}H-2(a) \rightarrow \operatorname{LUMO}(a)(18 \%), \\
H-3(a) \rightarrow \operatorname{LUMO}(a)(11 \%), \\
H-1(\beta) \rightarrow \operatorname{LUMO}(\beta)(17 \%), \\
H-2(\beta) \rightarrow \operatorname{LUMO}(\beta)(13 \%)\end{array}$ \\
\hline
\end{tabular}

When investigating the electronic density distribution in the orbitals involved in these transitions Figures $\mathrm{S}-16$ and $\mathrm{S}-17$ (in the appendices) for $\mathrm{VOL}_{1}$ and $\mathrm{VOL}_{2}$ complexes respectively, both indicated that these excitations have dominant ligand to metal charge transfer characters (LMCT), this is supported by the observation held in the inner graphs Figures 2 and 3 which involves the change in the excitation wavelengths with change in solvent polarity, and accordingly both excited states are sensitive to any change in the surrounding environment that involve charging species or polar solvents. Simulated spectrum for complex $\mathrm{VOL}_{1}$ Figure S-16 (in the appendices) holds other electronic transitions, the band at $423.5 \mathrm{~nm}$ involves the contribution from $\mathrm{H}$ -
1 (a) to $L+4(a)(53 \%$ and $\Delta E=1.55 \mathrm{eV})$ and is seen as ligand-based transitions with a dominant $\Pi \rightarrow \Pi^{*}$ character. The band at $404.5 \mathrm{~nm}$ includes more transitions, which involves contributions from $\mathrm{H}$ 2(a) $(18 \%$ and $\Delta \mathrm{E}=0.55 \mathrm{eV})$, and $\mathrm{H}-3(\mathrm{a})(11 \%$ and $\Delta \mathrm{E}=0.34 \mathrm{eV})$ to $\operatorname{LUMO}(\mathrm{a})$, and $\mathrm{H}-1(\beta)(17 \%$ and $\Delta \mathrm{E}=0.52 \mathrm{eV})$, and $\mathrm{H}-2(\beta)(13 \%$ and $\Delta \mathrm{E}=0.40$ $\mathrm{eV})$ to $\operatorname{LUMO}(\beta)$, and are ligand-based transitions with dominant $\Pi \rightarrow \Pi^{*}$, and to less extent transition from $\mathrm{n} \rightarrow \Pi^{*}$ and $\mathrm{n}$ (nitrogen) $\rightarrow \mathrm{d}$ (one of vanadium $\mathrm{d}$ orbital) characters, the effect of chlorine atom on the electron density of excited state is significantly observed in the transition at $430 \mathrm{~nm}$ which involve $\operatorname{HOMO}(a)$ to $\operatorname{LUMO}(a), \operatorname{HOMO}(\beta)$ to $\operatorname{LUMO}(\beta)$ and $\mathrm{H}$ 1 (a) to $L+4(a)$. 
Table 4: The calculated vertical excitation energies $(\mathrm{eV})$, wavelengths $(\mathrm{nm})$, oscillatory strength, and main orbital contributions to the excited states (only contributions $>10 \%$ are given) for the $\mathrm{VOL}_{2} \mathrm{Complex}$

calculated with TD-DFT/6-31+G(d,p) method in the gas phase.

\begin{tabular}{llll}
\hline Energy (eV) & Wavelength $(\mathbf{n m})$ & Oscillatory strength & Major orbital contribution \\
\hline 2.49 & 498.3 & 0.0002 & $H O M O(a) \rightarrow L+3(a)(55 \%)$ \\
2.71 & 457.6 & 0.0002 & $H-1(a) \rightarrow L U M O(a)(38 \%)$, \\
& & & $H O M O(\beta) \rightarrow L U M O(\beta)(33 \%)$ \\
2.89 & 430.1 & 0.000045 & $H-7(a) \rightarrow L+1(a)(42 \%)$, \\
2.92 & 424.9 & 0.0006 & $H-6(\beta) \rightarrow L+1(\beta)(40 \%)$ \\
& & & $H O M O(a) \rightarrow L+4(a)(48 \%)$, \\
3.10 & 400.7 & 0.0008 & $H O M O(a) \rightarrow L+5(a)(17 \%)$ \\
& & & $H-1(a) \rightarrow L U M O(a)(17 \%)$, \\
& & $H-1(a) \rightarrow L+1(a)(25 \%)$, \\
& & $H O M O(\beta) \rightarrow L+1(\beta)(24 \%)$
\end{tabular}

Ligand to metal charge transfer character (LMCT) can be observed in the simulated spectrum for complex VOL2, Figure S-17 (in the appendices) at $498.3 \mathrm{~nm}$ band, which involves the transition $\mathrm{HOMO}(\mathrm{a})$ to $\mathrm{L}+3(\mathrm{a})(55 \%$ and $\Delta \mathrm{E}=1.37 \mathrm{eV})$, beside that the band at $400.7 \mathrm{~nm}$ involves the transitions $\mathrm{H}-1(\mathrm{a})$ to $\operatorname{LUMO}(\mathrm{a})(17 \%$ and $\Delta \mathrm{E}=0.53$ eV), $\mathrm{H}-1$ (a) to $\mathrm{L}+1$ (a) $(25 \%$ and $\Delta \mathrm{E}=0.78 \mathrm{eV})$, and $\mathrm{HOMO}(\beta)$ to $\mathrm{L}+1(\beta)(24 \%$ and $\Delta \mathrm{E}=0.74 \mathrm{eV})$ and is ligand based transitions with dominant $\Pi \rightarrow \Pi^{*}$, the band at $457.6 \mathrm{~nm}$ involves contributions from $\mathrm{H}$ 1 (a) to $\operatorname{LUMO}(\mathrm{a})(38 \%$ and $\Delta \mathrm{E}=1.03 \mathrm{eV})$ and $\operatorname{HOMO}(\beta)$ to $\operatorname{LUMO}(\beta)(33 \%$ and $\Delta \mathrm{E}=0.89 \mathrm{eV})$, and is seen as ligand based transitions with dominant $n$ $\rightarrow \Pi^{*}$, and to less extent transition from $n \rightarrow \Pi^{*}$, also the effect of nitro group on the electron density of excited state is significantly observed in the transition at $424.9 \mathrm{~nm}$ which involves transition from $\mathrm{HOMO}(a)$ to $L+5(a)$.

\section{Molecular electrostatic potential surface}

To investigate the molecular structure of both oxovanadium complexes more deeply, molecular electrostatic potential surface (MEP) calculations were performed using the results from TD-DFT calculations. MEP calculation is performed to illustrate the distribution of charges (positive, negative, and neutral) regions in the complex and that help in understanding the interactions between the molecules, also to determine the nature of the chemical bond (65). For both complex molecules
$\mathrm{VOL}_{1}$ and $\mathrm{VOL}_{2}$ the MEP surface of as calculated on the ground state optimized geometry in the gas phase at B3LYP/6-31+G(d,p) level of theory are presented in Figure 4. The MEP maps revealed according to color code values between -0.122 (deepest red) to $+0.122 \mathrm{a} . \mathrm{u}$. (deepest blue) for $\mathrm{VOL}_{1}$ complex, and from -0.135 (deepest red) to +0.135 a.u. (deepest blue) for $\mathrm{VOL}_{2}$ complex. Different colors are used to represent different values of the electrostatic potential at the complex molecule surface, and the potential decreases in the order blue<green<yellow<orange $<$ red. Analysis of the MEP map suggests that in $\mathrm{VOL}_{1}$ complex, the negative region (yellow coded region) is localized around carboxylate oxygen, and the positive region (bluish coded region) is localized around the vanadium atom, for $\mathrm{VOL}_{2}$ complex the negative region is localized around carboxylate oxygens and nitro group oxygen, and the positive region is localized around the vanadium center, and finally the greater regions of faint-blue color in both complexes represent intermediary potential. Since the green color is towards the increasing range of potential (towards the blue color), the complexes possess smaller electronegativity, with electrondeficient regions preferring an approach by nucleophiles (65). The MEP maps are in accordance with the calculated atomic charges of both complex molecules and indicated that an asymmetrical charge distribution in the complexes may have implications on their physicochemical properties. 

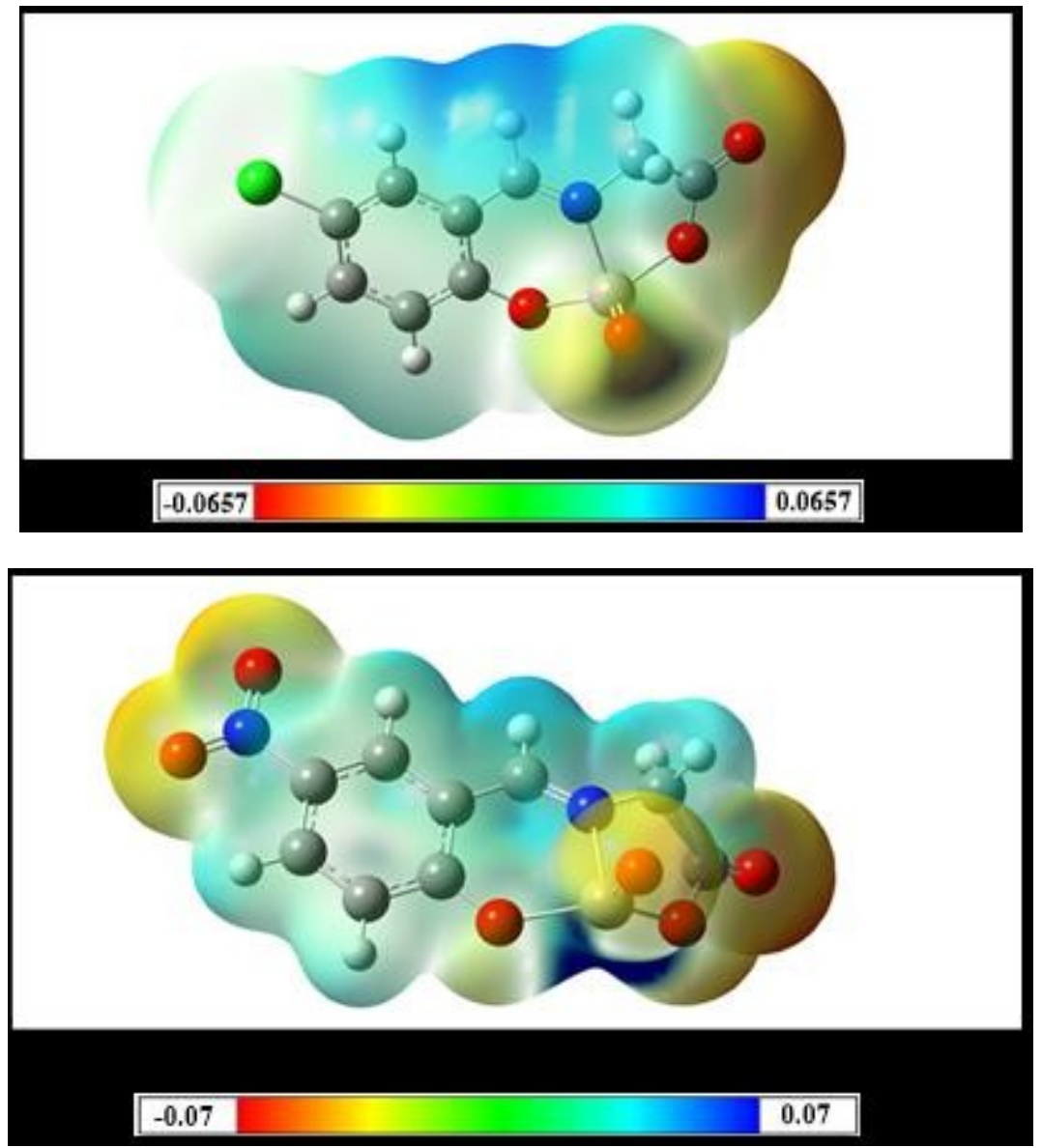

Figure 4: Molecular electrostatic potential (MEP) map for the ground state optimized geometry of $\mathrm{VOL}_{1}$ (upper panel) and $\mathrm{VOL}_{2}$ (lower panel) complexes calculated at gas phase using B3LYP/6-31+G(d,p) level of theory.

\section{Global chemical reactivity}

Density functional theory (DFT) (66) in this type of calculation is to provide theoretical insights into the chemical reactivity and selectivity of the two complexes, this includes the electronegativity $(X)$, hardness $(\eta)$, softness (S), electrophilicity index $(\omega)$. The first who made links between chemical reactivity and density functional theory is Parr et al. (67), in this regards the chemical potential (DFT) links the first derivative of the energy with respect to the $n$ number of electrons, and therefore with the negative of the electronegativity $x$. Via the application of Koopmans' theorem (68), the ionization potential (I) is defined as the amount of energy required to remove an electron from a molecule. Electron affinity $(A)$ is defined as the energy released when a proton is added to a system. It is related to the energy of the $\mathrm{E}_{\text {номо }}$ and Elumo through the equation of:

$$
\begin{aligned}
& I=-E_{\text {Hомо }} \\
& A=-E_{\text {LUMO }}
\end{aligned}
$$

By knowing the values of $A$ and I, values of global hardness $(n)$ and electronegativity $x$ can be determined. The electronegativity is defined as the measure of the power of an atom or a group of atoms to attract electrons towards itself, Hardness (n) (69) can be defined within the DFT as the second derivative of the $\mathrm{E}$ with respect to $\mathrm{N}$ as the $\mathrm{v}(\mathrm{r})$ property which measures both the stability and reactivity. It can be estimated by using the equation:

$$
\begin{aligned}
& \chi=\frac{1}{2}(I+A) \\
& \eta=\frac{1}{2}(I-A)
\end{aligned}
$$

Chemical softness $(S)$ is the measure of the capacity of an atom or a group of atoms to receive electrons, it is estimated by using the equation: 


$$
S=\frac{1}{\eta}
$$

It is further anticipated that electrophilicity index as a measure of energy lowering due to maximal electron flow between donor and acceptor (70). They defined the electrophilicity index $(\omega)$ as follows.

$$
\omega=\frac{\mu^{2}}{2 \eta}
$$

According to the definition, this index measures the propensity of chemical species to accept electrons. A good reactive nucleophile is characterized by a lower value of $\mu, \omega$; and conversely, a good electrophile is characterized by a high value of $\mu, \omega$. All the global quantities of SLG were calculated.

Table 5: Quantum chemical parameters for $\mathrm{VOL}_{1}$ and $\mathrm{VOL}_{2}$ complexes obtained with the DFT at B3LYP/6-

\begin{tabular}{|c|c|c|}
\hline Quantum chemical parameters & VOL $_{1}$ & $\mathrm{VOL}_{2}$ \\
\hline $\mathrm{E}_{\text {LUMO }}(\mathrm{eV})$ & -3.396 & -3.710 \\
\hline $\mathrm{E}_{\text {номо }}(\mathrm{eV})$ & -6.934 & -7.453 \\
\hline$\Delta \mathrm{E}(\mathrm{eV})$ & 3.538 & 3.743 \\
\hline Ionization Potential, IP (eV) & 6.934 & 7.453 \\
\hline Electron Affinity, EA (eV) & 3.396 & 3.710 \\
\hline Electronegativity, $\mathrm{x}(\mathrm{eV})$ & 5.165 & 5.582 \\
\hline Global Hardness, $\eta(\mathrm{eV})$ & 1.769 & 1.872 \\
\hline Molecular Dipole Moment, $\mu$ (debye) & 5.157 & 1.215 \\
\hline Global Softness, $\sigma(e V)^{-1}$ & 0.565 & 0.534 \\
\hline Electrophilicity Index, $\omega(\mathrm{eV})$ & 13.297 & 0.738 \\
\hline Electronic Energy (Hartree) & -2106.52 & -1851.44 \\
\hline
\end{tabular}
$31+G(d, p)$ method in gas phase.

It has been common that the molecule with high energy gap is the one with higher hardness, from the data showed in Table 5 that $\mathrm{VOL}_{2}$ complex is the one with the high energy gap, higher global hardness, and less global softness than the values of $\mathrm{VOL}_{1}$ complex.

\section{Application in epoxidation catalysis}

Epoxidation reactions were investigated under optimized conditions using $\mathrm{VOL}_{1}$ or $\mathrm{VOL}_{2}$ complexes as catalysts, cis-cyclooctene as substrate, and $\mathrm{H}_{2} \mathrm{O}_{2}$ as oxidant. The time course of the epoxidation reaction have been followed for at least ten hours at a specific temperature, Figure 5 shows the increasing of converted amount of cyclooctene in mmol at three different temperatures, at low temperature $\left(20^{\circ} \mathrm{C}\right) \mathrm{VOL}_{2}$ gives a higher conversion percent, while at high temperature $\left(78^{\circ} \mathrm{C}\right) \mathrm{VOL}_{1}$ is better and gives a higher conversion, this is confirmed by study of the total conversion at different temperatures as it can be shown in Table 6 , the highest conversion is observed at 60 and 78 ${ }^{\circ} \mathrm{C}$. Blank reactions show that no significant amounts of epoxide are formed in the absence of catalysts.

In the case of using $\mathrm{VOL}_{1}$, the conversion percent at $78{ }^{\circ} \mathrm{C}$ reached a maximum of $68 \%$ after the first two hours, when the reaction time was increased to ten hours the conversion was a little changed and finally reached $91.85 \%$, in the case of using VOL2 it took four hours to reach a maximum of $71.27 \%$ and then increasing by $16.13 \%$ to reach $87.40 \%$ after another six hours.
Making a comparison between withdrawing and donating substituted groups allocated in the benzene ring toward enhancing catalytic efficacy of the two complexes, $\mathrm{VOL}_{1}$ is designated with a donating chloro substituted group at $\mathrm{C}_{2}$ and $\mathrm{VOL}_{2}$ with a nitro withdrawing group at $\mathrm{C}_{2}$, for atom numbering see structure diagram Figure 1 , the conversion of cyclooctene in the presence of catalyst $\mathrm{VOL}_{1}\left(91.85 \%\right.$ at $\left.78^{\circ} \mathrm{C}\right)$ is higher than that of $\mathrm{VOL}_{2}$ $\left(88.42 \%\right.$ at $\left.78^{\circ} \mathrm{C}\right)$, it seems from this finding that the catalytic efficacy is increased with increasing the whole molecule electron density, this is agreed with the finding of Vergopoulos et al. (60).

Throughout the course of the reaction, at higher temperatures the color of the reaction contents is gradually changed in the presence of both catalysts from the original green to brownish red, the color change occurs much faster in presence of $\mathrm{VOL}_{1}$ than that of $\mathrm{VOL}_{2}$ catalyst, indicating the conversion of $\mathrm{V}(\mathrm{IV})$ oxidation state to $\mathrm{V}(\mathrm{V})$. Catalytic activities of some V(IV) Schiff base complexes were investigated by Rayati et al (71), they used tertiary butyl hydrogen peroxide (TBHP) as an oxidant for cyclooctene epoxidation reaction, the conversion found is high as (94-95\%).

Another epoxidation reaction is studied by Martins and his co-workers (72), they used tertiary butyl hydrogen peroxide (TBHP) and $\mathrm{H}_{2} \mathrm{O}_{2}$ as an oxidant, and diamine bis(phenolate) vanadium complex as catalyst for the epoxidation of cyclooctene, they found that the catalyst activity for the epoxidation reaction in the presence of $\mathrm{H}_{2} \mathrm{O}_{2}$ is much lower than that in the presence TBHP in acetonitrile as solvent. 
From the two studies and others, a higher epoxidation conversion is observed if the reaction is carried out in aprotic solvents, such as carbon tetrachloride, and chloroform, than in protic solvents such as water and alcohol, and the reason for such decrease is attributed to the higher ability of protic solvents to coordinate with metallic center in the catalyst complex in the vacant position that should be accommodated by the substrate molecule to maintain the catalyst reaction.
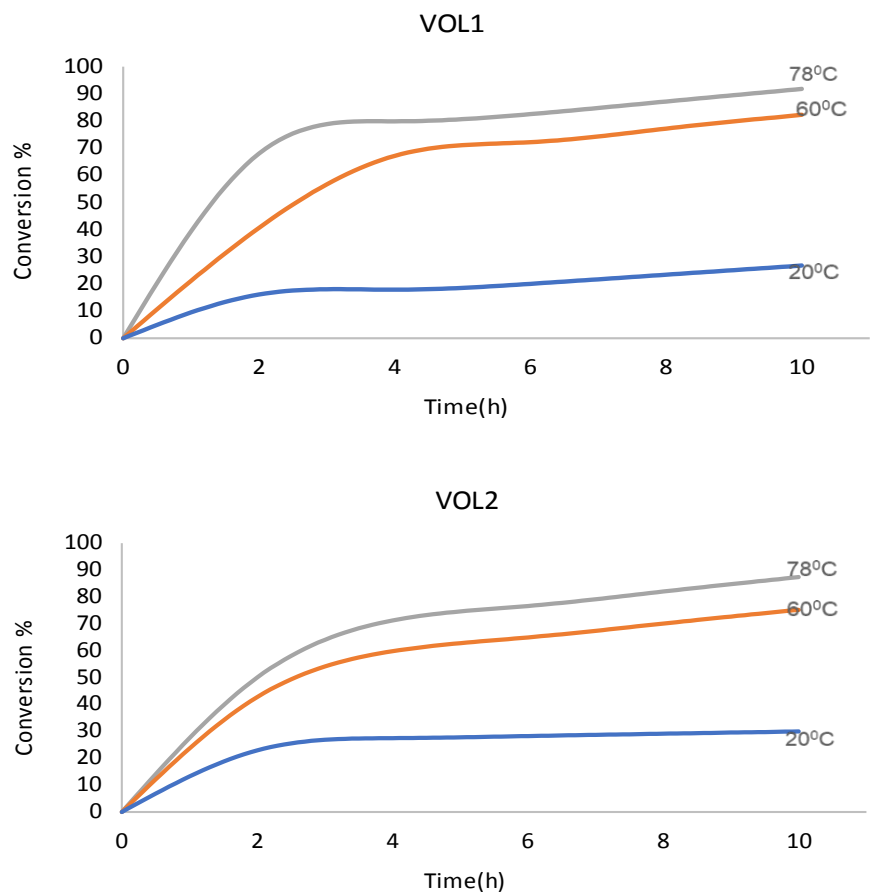

Figure 5: Conversion percent of cyclooctene in amount percent at three different temperatures, for $\mathrm{VOL}_{1}$ (top) and $\mathrm{VOL}_{2}$ (bottom), for more details please refer to Figures (S-18 to S-26) in the appendices.

Table 6: Conversion percent at different reaction temperatures for cyclooctene epoxidation by $\mathrm{VOL}_{1}, \mathrm{VOL}_{2}$ complexes.

\begin{tabular}{|c|c|c|c|c|c|c|c|}
\hline \multirow[t]{3}{*}{ Run } & \multirow{3}{*}{$\begin{array}{l}\text { Time } \\
\text { (h) }\end{array}$} & \multicolumn{6}{|c|}{ Conversion (\%) } \\
\hline & & \multicolumn{2}{|c|}{$20^{\circ} \mathrm{C}$} & \multicolumn{2}{|c|}{$60^{\circ} \mathrm{C}$} & \multicolumn{2}{|c|}{$78^{\circ} \mathrm{C}$} \\
\hline & & $\mathrm{VOL}_{1}$ & $\mathrm{VOL}_{2}$ & VOL $_{1}$ & $\mathrm{VOL}_{2}$ & $\mathrm{VOL}_{1}$ & $\mathrm{VOL}_{2}$ \\
\hline 1 & 2 & 16.11 & 22.92 & 40.63 & 42.77 & 68.00 & 50.05 \\
\hline 2 & 4 & 17.90 & 27.46 & 67.19 & 59.81 & 79.91 & 71.27 \\
\hline 3 & 6 & 20.05 & 28.23 & 72.22 & 64.96 & 82.56 & 76.65 \\
\hline 4 & 8 & 23.41 & 29.12 & 77.23 & 70.11 & 87.21 & 82.03 \\
\hline 5 & 10 & 26.78 & 29.96 & 82.29 & 75.25 & 91.85 & 87.40 \\
\hline
\end{tabular}

Recently the mechanistic aspects of the catalytic epoxidation of alkenes by vanadium(IV) complexes were reviewed by Conte et al. (73). The formation of peroxovanadium( $\mathrm{V})$ species in the epoxidation route for alkenes has been established. This can be examined by titration of a solution of the vanadium(IV) Schiff base complex with TBHP, and confirmed by the reduction of the intensity of the bands at 375 and $285 \mathrm{~nm}$, along with the gradual appearance of two new bands at 330 and $265 \mathrm{~nm}$, this agreed with the same findings in references, the disappearance of spectral peaks and the presence of two peaks at 355 and $310 \mathrm{~nm}$ suggest the oxidation of vanadium(IV) and the interaction of the formed vanadium $(\mathrm{V})$ complex with TBHP to give oxoperoxovanadium $(\mathrm{V})$ species, which is believed to be the active center in the epoxidation of cyclooctene by the vanadium(IV) Schiff base, this is further confirmed by the addition of the highly coordinating molecule imidazole during the epoxidation under optimized conditions, where upon the addition of the imidazole to the reaction mixture the epoxide yield was lowered, another interesting evidence of changing oxidation state from vanadium(IV) to vanadium( $\mathrm{V}$ ) upon addition of oxidant is came from the work of Correia et. al. (74) as they used ${ }^{51} \mathrm{~V}$ NMR spectroscopy to monitor the oxidation state change, upon the addition of an 
aqueous $30 \%$ solution of $\mathrm{H}_{2} \mathrm{O}_{2}$ to the methanolic solutions of their complexes the resonance at ca. -485 ppm progressively disappears and a new resonance appears between ca. -525 and -580 ppm, and tentatively they assigned this species to be a peroxidovanadate complex.

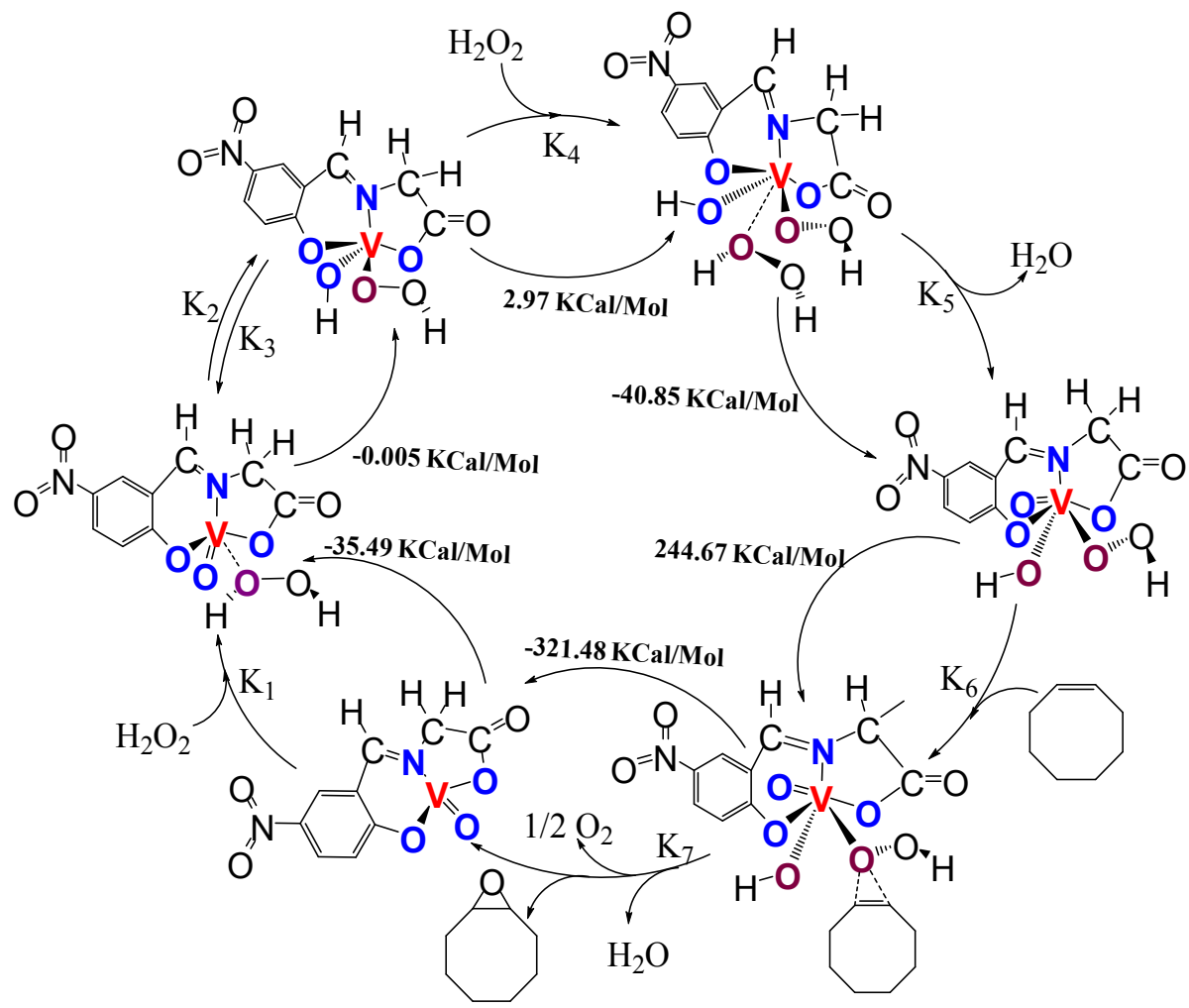

Figure 6: Illustration of a six-step mechanism for account of our and previous findings on the epoxidation of cyclooctene.

Figure 6 illustrates the proposed six step mechanism to account for the findings of ours and others on the epoxidation of cyclooctene under optimized conditions using $\mathrm{H}_{2} \mathrm{O}_{2}$ as oxidant, the first step is include binding of the $\mathrm{VOL}_{2}\left(\mathrm{VOL}_{2}\right.$ took as a representative) catalyst to the oxidant, this step is evolving of heat as from gaussian calculations the free energy difference is equal to $-35.49 \mathrm{Kcal} / \mathrm{mol}$, the second step is believed to be reversible as the free energy difference is very small, -0.005 $\mathrm{kcal} / \mathrm{mol}$, this step is involved a hydrogen transfer from peroxo group to convert the $\mathrm{V}=\mathrm{O}$ to $\mathrm{V}-\mathrm{OH}$, product of step two is subject to binding with the next oxidant molecule in step three, leading to unstable product with the free energy difference of $+2.97 \mathrm{kcal} / \mathrm{mol}$, stabilization of this molecule is occurred after evolving of one water molecule with the following internal rearrangement in step four.

Now the product of step four is bind to the cyclooctene molecule to give far unstable molecule with a free energy difference of $+244.67 \mathrm{kcal} / \mathrm{mol}$, cyclooctane peroxide is evolved in the last step along with the other water and oxygen molecules, and the catalyst molecule is being free to start another catalytic cycle, the free energy difference of last step is $-321.48 \mathrm{kcal} / \mathrm{mol}$, all steps are one direction except step two which believed is reversible. Having this mechanism established, another confirmation of this mechanism to be logic is needed.

Therefore further confirmation of this mechanism is performed with computer simulation using the commercially available program Berkeley Madonna 10.1.2 (75), via the variable step-size Rosenbrock integration method for stiff systems of a differential equation, differential equation of the six steps reaction rates is generated and three modules are suggested, one for each temperature $(20,60$ and $78^{\circ} \mathrm{C}$ ), the simulations yield values quite close to the experimental results, the root mean square values, as a sign of goodness of the simulation, is found to be $0.00117,0.00402$, and 0.00475 for simulation carried out at each temperature respectively, which indicate very nice correlation between simulated and experimental results. Values of partial reaction rate constants are calculated and tabulated in Table 7, from Table 7 one can assumes that the mechanism is involved two rate determining steps, step one when the first $\mathrm{H}_{2} \mathrm{O}_{2}$ molecule is bound to the catalyst molecule and the other one is step five when the cyclooctene molecule is bound to the cycle, the observed rate 
constants (the sum of all rate constant values) are calculated and related to Arrhenius equation, and subsequently theoretical activation energy of the reaction is calculated and found to be around 24.2 $\mathrm{kJ} / \mathrm{mol}$ with a frequency factor (Arrhenius constant) of around $0.2 \mathrm{E}+6 \mathrm{mmol} / \mathrm{sec}$.

Table 7: Values of partial reaction rate constants of the suggested model used for simulations (Dot Lines) are shown in Figure 7.

\begin{tabular}{llll}
\hline Parameter & k values $\left(\mathbf{2 0}^{\circ} \mathbf{C}\right)$ & $\left.\mathbf{k ~ v a l u e s ~}^{\circ} \mathbf{6 0}^{\circ} \mathbf{C}\right)$ & $\left.\mathbf{k ~ v a l u e s ~}^{\circ} \mathbf{7 8}{ }^{\circ} \mathbf{C}\right)$ \\
\hline $\mathrm{k}_{1}(\mathrm{mmol} / \mathrm{s})$ & $4.96 \mathrm{E}-03$ & $1.3 \mathrm{E}-03$ & $1.82 \mathrm{E}-03$ \\
$\mathrm{k}_{2}(1 / \mathrm{s})$ & 3.89 & 98.8 & 105.1 \\
$\mathrm{k}_{3}(1 / \mathrm{s})$ & $4.0 \mathrm{E}-03$ & $1.1 \mathrm{E}-06$ & 140.1 \\
$\mathrm{k}_{4}(\mathrm{mmol} / \mathrm{s})$ & $4.0 \mathrm{E}-04$ & 43.27 & 34.4 \\
$\mathrm{k}_{5}(1 / \mathrm{s})$ & 45.05 & 0.57 & 2.97 \\
$\mathrm{k}_{6}(\mathrm{mmol} / \mathrm{s})$ & 0.86 & $8.6 \mathrm{E}-04$ & $5.8 \mathrm{E}-04$ \\
$\mathrm{k}_{7}(1 / \mathrm{s})$ & 12.32 & 2.65 & 7.30 \\
$\mathrm{k}_{\text {obs }}$ & 8.87 & 37.18 & 41.40 \\
$\mathrm{~T} \mathrm{k}$ & 293.15 & 333.15 & 351.15 \\
$1 / \mathrm{T}$ & $3.41 \mathrm{E}-03$ & $3.00 \mathrm{E}-03$ & $2.85 \mathrm{E}-03$ \\
Ln kobs & 2.18 & 3.62 & 3.72 \\
Observed Activation Energy $(\mathrm{J} / \mathrm{mol})$ & 24173.0 & & \\
Frequency factor & $0.2 \mathrm{E}+6$ & & \\
\hline
\end{tabular}

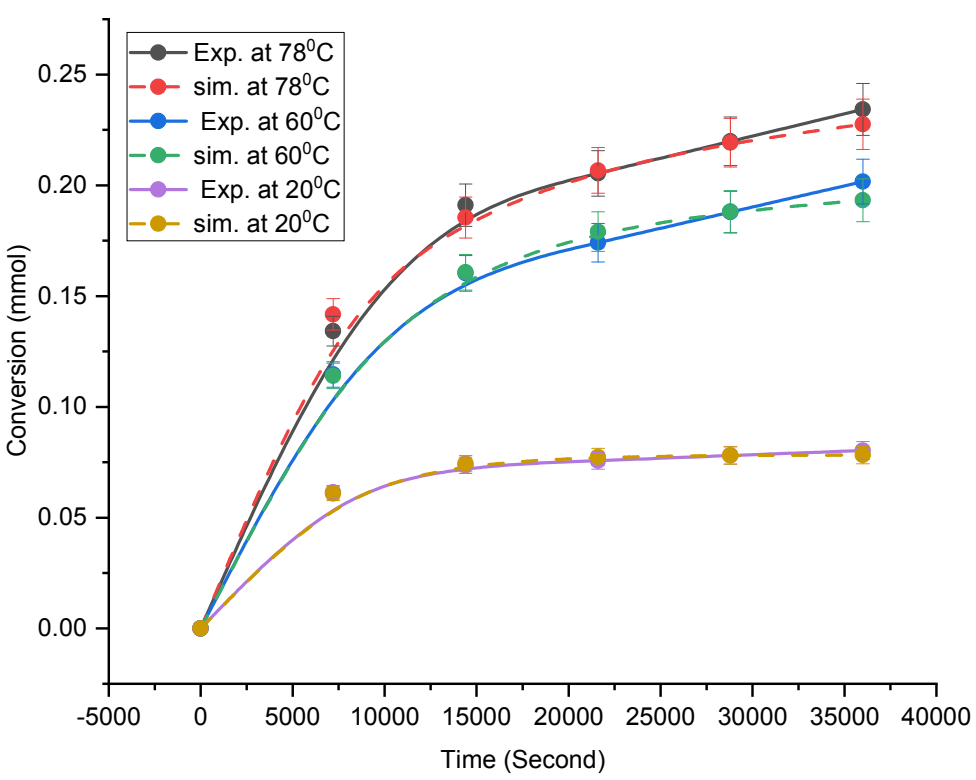

Figure 7: Computer simulation of cyclooctene epoxidation conversion with $\mathrm{VOL}_{1}$ as catalyst, Berkeley Madonna 8.0 program (commercial) from the University of California, Berkeley is used for the simulation, the variable used is step-size Rosenbrock integration method for stiff systems of differential equations.

(Solid lines represent the trend of the measured points, dot lines represent the fit to the solid lines).

Figure 7 shows the correlation between experimental and simulated results, both lines are almost typical, indicating the validity of the model used. This mechanism is quite similar to that suggested by Mathavan (76), the critical step in Mathavan mechanism is the change in the oxidation state of the vanadium catalyst from oxidation state IV to $\mathrm{V}$, then followed by the subsequent binding of the substrate compound (phenol in this case), and the final product.

\section{CONCLUSION}

In summary, we have synthesized and characterized two Schiff-base vanadium (IV) complexes and have used them as catalysts in olefin epoxidation. Both are found to be catalytically active in industrially important epoxidation reactions in acetonitrile solvent media under homogeneous conditions. Hydrogen peroxide was used as the oxidant and cyclooctene as a representative of olefins. The 
catalytic efficacy is increased with increasing reaction temperatures. With the aid of computer softwares, some interesting findings have been derived, after optimizing the molecular structures of both catalysts, molecular structures are confirmed in terms of correlation between FTIR, ${ }^{1} \mathrm{H} N M R$, and ${ }^{13} \mathrm{C} \mathrm{NMR}$, the energy gap between ground and excited states is calculated, some other properties in term of HOMO and LUMO is defined, finally hypothetical mechanism of reaction involved six reaction steps are suggested, and found to be logic and pretty similar to other published ones.

\section{CONFLICT OF INTEREST}

The authors have no conflicts of interest to declare that are relevant to the content of this article.

\section{ACKNOWLEDGMENTS}

The Author would like to thank The German Academic Exchange Services for funding this research, and the author like to thank the Gamess Us Company and Orca company for providing free academic softwares.

\section{REFERENCES}

1. Drozdzak R, Allaert B, Ledoux N, Dragutan I, Dragutan $V$, Verpoort F. Ruthenium complexes bearing bidentate Schiff base ligands as efficient catalysts for organic and polymer syntheses. Coordination Chemistry Reviews. 2005 Dec;249(24):3055-74. <DOI>

2. Pariya C, Jayaprakash KN, Sarkar A. Alkene metathesis: new developments in catalyst design and application. Coordination Chemistry Reviews. 1998 Jan;168:1-48. $<$ DOI $>$.

3. Gan C, Lai G, Zhang Z, Wang Z, Zhou M-M. Efficient and enantioselective nitroaldol reaction catalyzed by copper Schiff-base complexes. Tetrahedron: Asymmetry. 2006 Mar;17(5):725-8. <DOI >

4. Liu D-F, Lü X-Q, Lu R. Homogeneous and heterogeneous styrene epoxidation catalyzed by copper(II) and nickel(II) Schiff base complexes. Transition Met Chem. 2014 Sep;39(6):705-12. <DOI>.

5. Ray A, Rosair GM, Pilet G, Dede B, Gómez-García CJ, Signorella $S$, et al. Preferential azido bridging regulating the structural aspects in cobalt(III) and copper(II)-Schiff base complexes: Syntheses, magnetostructural correlations and catalytic studies. Inorganica Chimica Acta. 2011 Sep;375(1):20-30. <DOI>.

6. de Vries JG, Roelfes G, Green R. Ruthenium catalysed redox transformation of cinnamaldehyde to 3phenylpropionic acid and methyl ester. Tetrahedron

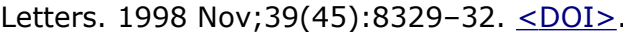

7. Odenkirk W, Rheingold AL, Bosnich B. Homogeneous catalysis: a ruthenium-based Lewis-acid catalyst for the Diels-Alder reaction. J Am Chem Soc. 1992 Jul;114(16):6392-8. <DOI>.
8. Kardanpour R, Tangestaninejad S, Mirkhani V, Moghadam M, Mohammadpoor-Baltork I, Zadehahmadi F. Efficient alkene epoxidation catalyzed by molybdenyl acetylacetonate supported on aminated UiO-66 metal-organic framework. Journal of Solid State Chemistry. 2015 Mar;226:262-72. <DOI>.

9. Sabater MJ, Corma A, Domenech A, Fornés V, García H. Chiral salen manganese complex encapsulated within zeolite $Y$ : a heterogeneous enantioselective catalyst for the epoxidation of alkenes. Chem Commun. 1997;(14):12856. $\leq \mathrm{DOI}>$.

10. Srikanth A, Nagendrappa G, Chandrasekaran S. Catalytic epoxidation of cyclic vinylsilanes by ruthenium(II) complexes under aerobic conditions. Tetrahedron. 2003 Sep;59(39):7761-5. $\leq$ DOI $>$.

11. de Clercq B, Verpoort F. Assessing the Scope of the Introduction of Schiff Bases as Co-Ligands for Monometallic and Homobimetallic Ruthenium Ring-Opening Metathesis Polymerisation and Ring-Closing Metathesis Initiators. Adv Synth Catal. 2002 Aug;344(6-7):639-48. $\leq \mathrm{URL}>$.

12. Xi Z, Wang $H$, Sun $Y$, Zhou N, Cao G, Li M. Direct epoxidation of olefins catalyzed by heteropolyoxometalates with molecular oxygen and recyclable reductant. Journal of Molecular Catalysis A: Chemical. 2001 Mar;168(1-2):299301. <DOI>

13. Canali $L$, Sherrington DC. Utilisation of homogeneous and supported chiral metal(salen) complexes in asymmetric catalysis. Chem Soc Rev. 1999;28(2):85-93. $\leq \mathrm{DOI}>$.

14. Berkessel A, Frauenkron M, Schwenkreis $T$, Steinmetz A. Pentacoordinated manganese complexes as biomimetic catalysts for asymmetric epoxidations with hydrogen peroxide. Journal of Molecular Catalysis A: Chemical. 1997 Mar;117(1-3):339-46. <DOI $>$.

15. Ho C-W, Cheng W-C, Cheng M-C, Peng S-M, Cheng K$\mathrm{F}$, Che C-M. Preparation and reactivities of chiral manganese(III) and copper(II) complexes of binaphthyl Schiff bases. J Chem Soc, Dalton Trans. 1996;(4):405. $<$ DOI $>$.

16. Solomon EI, Sundaram UM, Machonkin TE. Multicopper Oxidases and Oxygenases. Chem Rev. 1996 Jan $1 ; 96(7): 2563-606$. $\leq \mathrm{DOI}>$.

17. Judmaier ME, Holzer C, Volpe M, Mösch-Zanetti NC. Molybdenum(VI) Dioxo Complexes Employing Schiff Base Ligands with an Intramolecular Donor for Highly Selective Olefin Epoxidation. Inorg Chem. 2012 Sep 17;51(18):9956-66. <DOI $>$.

18. Lu X-H, Lei J, Wei X-L, Ma X-T, Zhang T-J, Hu W, et al. Selectively catalytic epoxidation of a-pinene with dry air over the composite catalysts of Co-MOR(L) with Schiffbase ligands. Journal of Molecular Catalysis A: Chemical. 2015 May;400:71-80. <DOI $>$.

19. Pasayat S, Böhme M, Dhaka S, Dash SP, Majumder S, Maurya MR, et al. Synthesis, Theoretical Study and Catalytic Application of Oxidometal (Mo or V) Complexes: Unexpected Coordination Due to Ligand Rearrangement 
through Metal-Mediated C-C Bond Formation. Eur J Inorg Chem. 2016 Apr;2016(10):1604-18. <DOI>.

20. Wei FY. A mononuclear nickel(II) complex and a dinuclear manganese(III) complex derived from $\mathrm{N}, \mathrm{N}^{\prime}-$ bis(5-methoxysalicylidene)-1,2-ethanediamine: Synthesis, crystal structures and catalytic epoxidation property. Russ J Coord Chem. 2016 Jan;42(1):44-9. <DOI>.

21. Adhikary C, Bera R, Dutta B, Jana S, Bocelli G, Cantoni $A$, et al. Catalytic efficacy of Schiff-base copper(II) complexes: Synthesis, X-ray structure and olefin oxidation. Polyhedron. 2008 Apr;27(6):1556-62. <DOI>.

22. Koola JD, Kochi JK. Nickel catalysis of olefin epoxidation. Inorg Chem. 1987 Mar;26(6):908-16. $\leq$ DOI $>$.

23. Groves JT, Watanabe Yoshihito. The mechanism of olefin epoxidation by oxo-iron porphyrins. Direct observation of an intermediate. J Am Chem Soc. 1986 Feb;108(3):507-8. <DOI $>$.

24. Maschmeyer T, Rey F, Sankar G, Thomas JM. Heterogeneous catalysts obtained by grafting metallocene complexes onto mesoporous silica. Nature. 1995 Nov;378(6553):159-62. <DOI $>$.

25. Mohajer D, Tangestaninejad S. Efficient catalytic epoxidation of alkenes by a manganese porphyrin and periodate in the presence of imidazole. J Chem Soc, Chem Commun. 1993;(3):240. <DOI>.

26. Martos-Calvente $R$, de la Peña O'Shea VA, CamposMartin JM, Fierro JLG, Gutiérrez-Puebla E. Synthesis of bis $\left[\mathrm{N}, \mathrm{O}-\left\{2^{\prime}\right.\right.$-pyridyl-methanolate $\}$ dioxomolybdenum(VI) epoxidation catalyst and novel crystal structure derived from X-ray diffraction and DFT calculations. Journal of Molecular Catalysis A: Chemical. 2004 Jun;214(2):269-72. $\leq$ DOI $>$.

27. Herrmann WA, Fischer RW, Marz DW. Methyltrioxorhenium as Catalyst for Olefin Oxidation. Angew Chem Int Ed Engl. 1991 Dec;30(12):1638-41. $\leq$ DOI $>$.

28. Copéret $C$, Adolfsson $H$, Sharpless KB. A simple and efficient method for epoxidation of terminal alkenes. Chem Commun. 1997;(16):1565-6. <DOI>

29. De Vos DE, Sels BF, Reynaers M, Subba Rao YV, Jacobs PA. Epoxidation of terminal or electron-deficient olefins with $\mathrm{H} 2 \mathrm{O} 2$, catalysed by $\mathrm{Mn}$ trimethyltriazacyclonane complexes in the presence of an oxalate buffer. Tetrahedron Letters. 1998 May;39(20):3221-4. <DOI .

30. Palucki M, Pospisil PJ, Zhang W, Jacobsen EN. Highly Enantioselective, Low-Temperature Epoxidation of Styrene. J Am Chem Soc. 1994 Oct;116(20):9333-4. <DOI>.

31. Jiang J, Ma K, Zheng Y, Cai S, Li R, Ma J. Cobalt salophen complex immobilized into montmorillonite as catalyst for the epoxidation of cyclohexene by air. Applied Clay Science. 2009 Jul;45(3):117-22. <DOI $>$.

32. Yang $Y$, Zhang $Y$, Hao $S$, Guan J, Ding $H$, Shang $F$, et al. Heterogenization of functionalized $\mathrm{Cu}(\mathrm{II})$ and $\mathrm{VO}(\mathrm{IV})$
Schiff base complexes by direct immobilization onto amino-modified SBA-15: Styrene oxidation catalysts with enhanced reactivity. Applied Catalysis A: General. 2010 Jun;381(1-2):274-81. <DOI>.

33. Janssen KBM, Laquiere I, Dehaen $W$, Parton RF, Vankelecom IFJ, Jacobs PA. A dimeric form of Jacobsen's catalyst for improved retention in a polydimethylsiloxane membrane. Tetrahedron: Asymmetry. 1997 Oct; $8(20): 3481-7 . \leq$ DOI $>$.

34. Feng $H-X$, Wang R-M, He $Y-F$, Lei Z-Q, Wang $Y-P$, Xia C-G, et al. Preparation and catalysis of porous silica supported metal Schiff-base complex. Journal of Molecular Catalysis A: Chemical. 2000 Sep;159(1):25-9. <DOI>.

35. Katsuki T. Catalytic asymmetric oxidations using optically active (salen)manganese(III) complexes as catalysts. Coordination Chemistry Reviews. 1995 Mar;140:189-214. $\leq$ DOI $>$.

36. Bolm C, Bienewald F. Asymmetric Sulfide Oxidation with Vanadium Catalysts and $\mathrm{H} 2 \mathrm{O} 2$. Angew Chem Int Ed Engl. 1996 Jan 5;34(2324):2640-2. <DOI $>$.

37. Dichmann K, Hamer G, Nyburg SC, Reynolds WF. The 2:1 vanadyl acetylacetonate:1,4-dioxan complex. A nuclear magnetic resonance and X-ray crystal structure

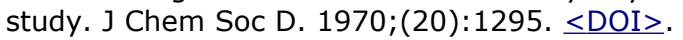

38. Hwang D-R, Chen C-P, Uang B-J. Aerobic catalytic oxidative coupling of 2-naphthols and phenols by VO(acac)2. Chem Commun. 1999;(13):1207-8. <DOI>.

39. Grivani G, Bruno G, Rudbari HA, Khalaji AD, Pourteimouri P. Synthesis, characterization and crystal structure determination of a new oxovanadium(IV) Schiff base complex: The catalytic activity in the epoxidation of cyclooctene. Inorganic Chemistry Communications. 2012 Apr;18:15-20. <DOI $>$.

40. Frisch M, Trucks G, Schlegel $H$, Scuseria G, Robb M, Cheeseman J. Gaussian 16 Rev. C. 01. Gaussian, Inc., Wallingford, CT; 2016.

41. Becke AD. A new mixing of Hartree-Fock and local density-functional theories. The Journal of Chemical Physics. 1993 Jan 15;98(2):1372-7. <DOI.

42. Lee C, Yang W, Parr RG. Development of the ColleSalvetti correlation-energy formula into a functional of the electron density. Phys Rev B. 1988 Jan 15;37(2):785-9. $\leq \mathrm{DOI}>$.

43. Tomasi J, Mennucci B, Cammi R. Quantum Mechanical Continuum Solvation Models. Chem Rev. 2005 Aug 1;105(8):2999-3094. <DOI .

44. Anonymous. Chemcraft - graphical software for visualization of quantum chemistry computations. [Internet]. ChemCraft. $\leq$ URL $>$.

45. Dennington $R$, Keith $T$. Gaussview, version 6.1 [Internet]. Gaussview software. 2019 [cited 2022 Jan 1]. $\leq \mathrm{URL}>$.

46. Hait D, Head-Gordon M. How Accurate Is Density Functional Theory at Predicting Dipole Moments? An 
Assessment Using a New Database of 200 Benchmark Values. J Chem Theory Comput. 2018 Apr 10;14(4):196981. $\langle\mathrm{DOI}>$.

47. Neese F. Software update: the ORCA program system, version 4.0. WIREs Comput Mol Sci [Internet]. 2018 Jan [cited 2022 Jan 1];8(1). <DOI $>$.

48. Schmidt MW, Baldridge $K K$, Boatz JA, Elbert ST, Gordon MS, Jensen $\mathrm{JH}$, et al. General atomic and molecular electronic structure system. J Comput Chem. 1993 Nov; 14(11):1347-63. <DOI>.

49. Hanwell MD, Curtis DE, Lonie DC, Vandermeersch $T$, Zurek E, Hutchison GR. Avogadro: an advanced semantic chemical editor, visualization, and analysis platform. J Cheminform. 2012 Dec;4(1):17. <DOI $>$.

50. O'Boyle NM, Tenderholt AL, Langner KM. cclib: A library for package-independent computational chemistry algorithms. J Comput Chem. 2008 Apr 15;29(5):839-45. $\leq$ DOI $>$.

51. Hay PJ, Wadt WR. Ab initio effective core potentials for molecular calculations. Potentials for the transition metal atoms Sc to $\mathrm{Hg}$. The Journal of Chemical Physics. 1985 Jan;82(1):270-83. <DOI $>$.

52. Wadt WR, Hay PJ. Ab initio effective core potentials for molecular calculations. Potentials for main group elements $\mathrm{Na}$ to $\mathrm{Bi}$. The Journal of Chemical Physics. 1985 Jan;82(1):284-98. <DOI $>$.

53. Hay PJ, Wadt WR. Ab initio effective core potentials for molecular calculations. Potentials for $\mathrm{K}$ to $\mathrm{Au}$ including the outermost core orbitals. The Journal of Chemical Physics. 1985 Jan;82(1):299-310. <DOI .

54. Perdew JP, Burke K, Ernzerhof M. Generalized Gradient Approximation Made Simple. Phys Rev Lett. 1996 Oct $28 ; 77(18): 3865-8 . \leq$ DOI $>$.

55. Goodgame M, Hayward PJ. Infrared spectra (1650-400 $\mathrm{cm} .-1$ ) of $\gamma$-picoline metal co-ordination complexes. J Chem Soc A. 1966;0(0):632-4. <DOI>.

56. Syamal A, Kale KS. Magnetic and spectral properties of oxovanadium(IV) complexes of ONO donor tridentate, dibasic Schiff bases derived from salicylaldehyde or substituted salicylaldehyde and o-hydroxybenzylamine. Inorg Chem. 1979 Apr;18(4):992-5. <DOI>.

57. Selbin J. The Chemistry of Oxovanadium(IV). Chem Rev. 1965 Apr 1;65(2):153-75. <DOI>.

58. Selbin J. Oxovanadium(IV) complexes. Coordination

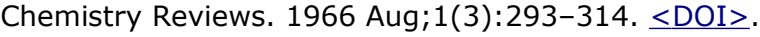

59. Dinda R, Sengupta $P$, Ghosh S, Mak TCW. Valence Delocalization in a Mixed-Oxidation Divanadium (IV, V) Complex Electrogenerated from Its Structurally Characterized Divanadium (V) Analogue with a Tridentate (ONO) Ligand. Inorg Chem. 2002 Mar 1;41(6):1684-8. $\leq$ DOI $>$.

60. Vergopoulos V, Priebsch W, Fritzsche M, Rehder D. Binding of L-histidine to vanadium. Structure of exo-
[VO2\{N-(2-oxidonaphthal)-His $\}$ ]. Inorg Chem. 1993 Apr;32(9):1844-9. <DOI>.

61. Abrarin S, Ahmed MJ. A highly sensitive and selective spectrophotometric method for the determination of vanadium at nanotrace levels in some environmental, biological, soil, food, and pharmaceutical samples using salicylaldehyde-benzoylhydrazone. Eur J Chem. 2020 Dec 31;11(4):385-95. <DOI>.

62. Keramidas $A D$, Papaioannou $A B$, Vlahos $A$, Kabanos TA, Bonas G, Makriyannis A, et al. Model Investigations for Vanadium-Protein Interactions. Synthetic, Structural, and Physical Studies of Vanadium(III) and Oxovanadium(IV/V) Complexes with Amidate Ligands. Inorg Chem. 1996 Jan $1 ; 35(2): 357-67 . \leq$ DOI $>$.

63. Schmidt $A-C$, Hermsen $M$, Rominger $F$, Dehn R, Teles $\mathrm{JH}$, Schäfer A, et al. Synthesis of Mono- and Dinuclear Vanadium Complexes and Their Reactivity toward Dehydroperoxidation of Alkyl Hydroperoxides. Inorg Chem. 2017 Feb 6;56(3):1319-32. <DOI.

64. Maurya RC, Chourasia J, Rajak D, Malik BA, Mir JM, Jain $\mathrm{N}$, et al. Oxovanadium(IV) complexes of bioinorganic and medicinal relevance: Synthesis, characterization and 3D molecular modeling of some oxovanadium(IV) complexes involving $\mathrm{O}, \mathrm{N}$-donor environment of salicylaldehyde-based sulfa drug Schiff bases. Arabian Journal of Chemistry. 2016 Nov;9:S1084-100. <DOI>.

65. Politzer $\mathrm{P}$, Laurence $\mathrm{PR}$, Jayasuriya $\mathrm{K}$. Molecular electrostatic potentials: an effective tool for the elucidation of biochemical phenomena. Environmental Health Perspectives. 1985 Sep;61:191-202. <DOI .

66. Frenking G, Shaik S, editors. The chemical bond. 1: Fundamental aspects of chemical bonding. Weinheim: Wiley-VCH; 2014. 411 p. ISBN: 978-3-527-33314-1.

67. Parr RG, Szentpály L V., Liu S. Electrophilicity Index. J Am Chem Soc. 1999 Mar 1;121(9):1922-4. <DOI $>$.

68. Koopmans T. Über die Zuordnung von Wellenfunktionen und Eigenwerten zu den Einzelnen Elektronen Eines Atoms. Physica. 1934 Jan;1(1-6):10413. $\leq \mathrm{DOI}>$.

69. Ayers PW. The physical basis of the hard/soft acid/base principle. Faraday Discuss. 2007;135:161-90. $<$ DOI $>$.

70. Chattaraj PK, Sarkar U, Roy DR. Electrophilicity Index. Chem Rev. 2006 Jun 1;106(6):2065-91. <DOI>.

71. Rayati S, Koliaei M, Ashouri F, Mohebbi S, Wojtczak A, Kozakiewicz A. Oxovanadium(IV) Schiff base complexes derived from 2,2'-dimethylpropandiamine: A homogeneous catalyst for cyclooctene and styrene oxidation. Applied Catalysis A: General. 2008 Aug;346(12):65-71. <DOI $>$.

72. Madeira F, Barroso S, Namorado S, Reis PM, Royo B, Martins AM. Epoxidation of cis-cyclooctene using diamine bis(phenolate) vanadium, molybdenum and tungsten complexes as catalysts. Inorganica Chimica Acta. 2012 Mar;383:152-6. <DOI $>$. 
73. Conte V, Coletti A, Floris B, Licini G, Zonta C. Mechanistic aspects of vanadium catalysed oxidations with peroxides. Coordination Chemistry Reviews. 2011 Oct;255(19-20):2165-77. <DOI $>$.

74. Maurya MR, Sarkar B, Avecilla F, Correia I. Vanadium( iv and $v$ ) complexes of pyrazolone based ligands: Synthesis, structural characterization and catalytic applications. Dalton Trans. 2016;45(43):17343-64. <DOI $>$.
75. Marcoline F, Grabe M, Nayak S, Zahnley T, Oster G, Robert M. Berkeley Madonna version 10.1.2 [Internet]. Berkeley Madonna version 10.1.2. 2017. Available from: $\leq \mathrm{URL}>$.

76. Mathavan A, Ramdass A, Rajagopal S. Kinetic study of the oxovanadium(IV)-salen-catalyzed $\mathrm{H} 2 \mathrm{O} 2$ oxidation of phenols. Transition Met Chem. 2015 May;40(4):355-62. $<$ DOI $>$. 


\section{Supplementary Information}

Synthesis, Characterization, DFT Calculations, and Catalytic Epoxidation of Two Oxovanadium(IV) Schiff Base Complexes

Asha Fadalla Wady ${ }^{1}$, Mohammed Awad Ali Khalid ${ }^{2}, *$, Mohammed Traheeb Alotaibi2 and Yusuf Sulfab Ahmed ${ }^{3}$

${ }^{1}$ University of Kordofan, Department of Chemistry, Alobaid, 11111, Sudan

2 University of Taif, Department of Chemistry, Turabah, 21995, Saudi Arabia

3 University of Khartoum, Department of Chemistry, Khartoum, 11115, Sudan

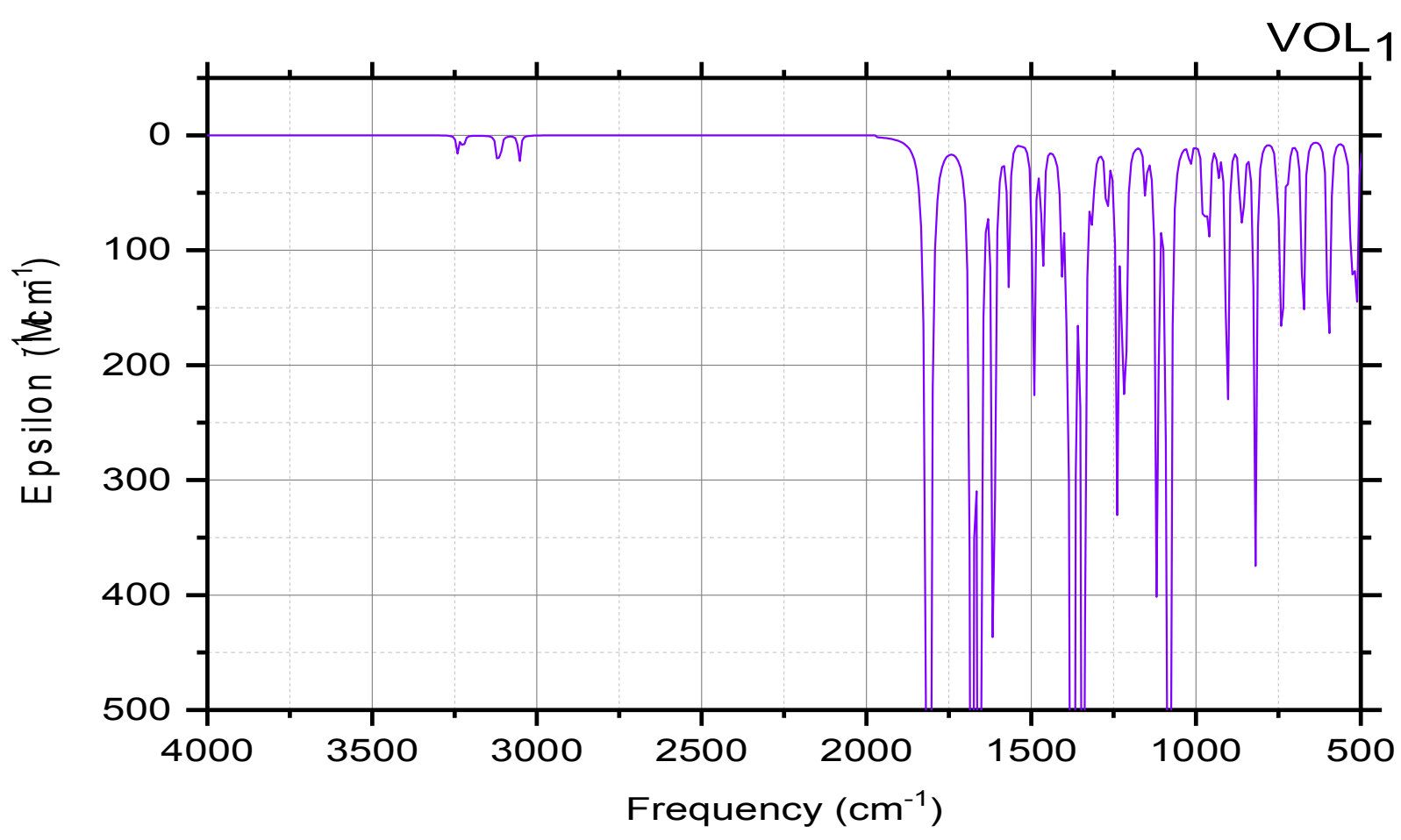

Figure S-1. Calculated FTIR for $\mathrm{VOL}_{1}$ Complex Using B3LYP/ 6-31+G(d,p) level of theory. 


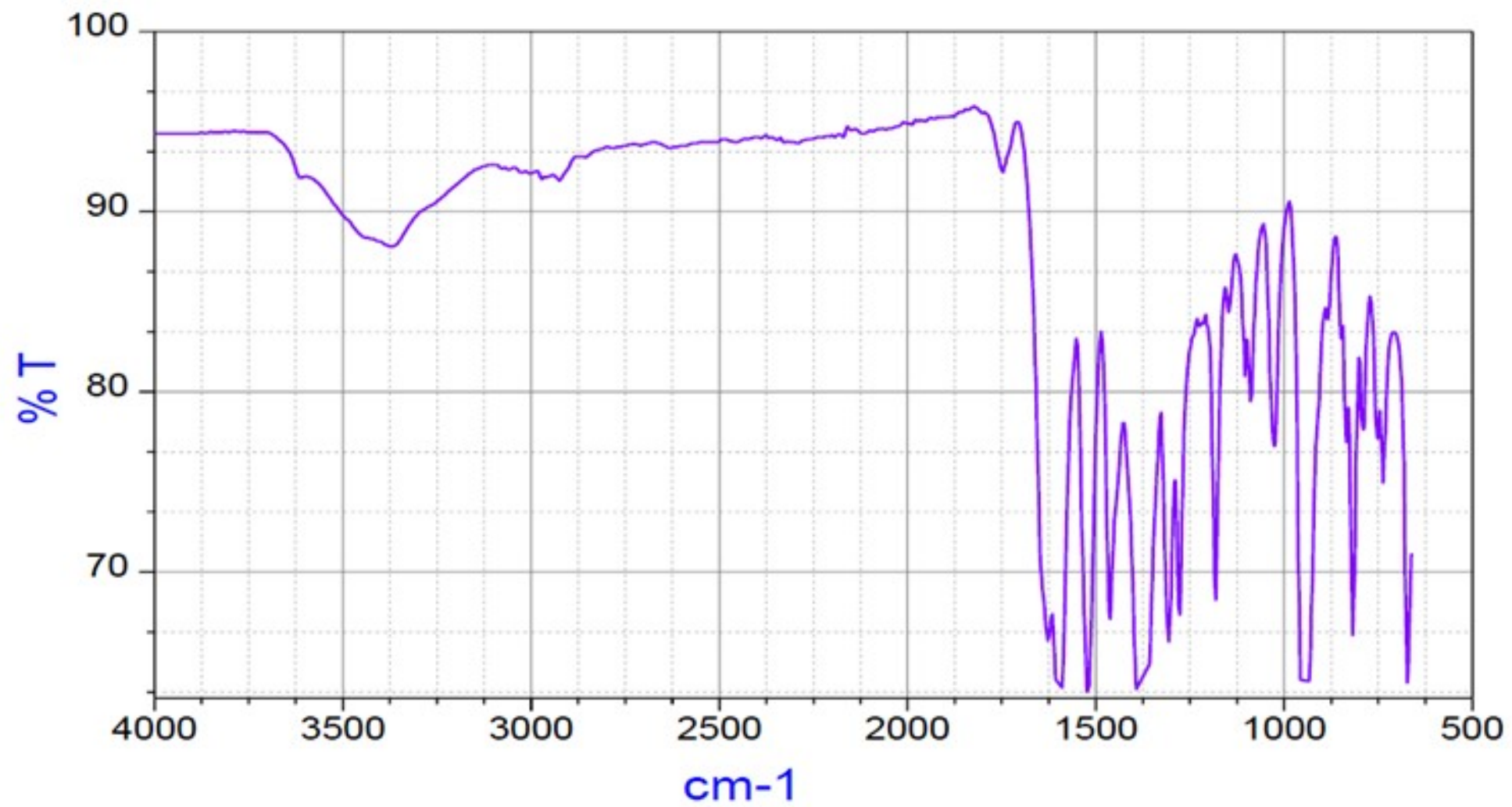

Figure S-2. Experimental FTIR for $\mathrm{VOL}_{1}$ Complex. 


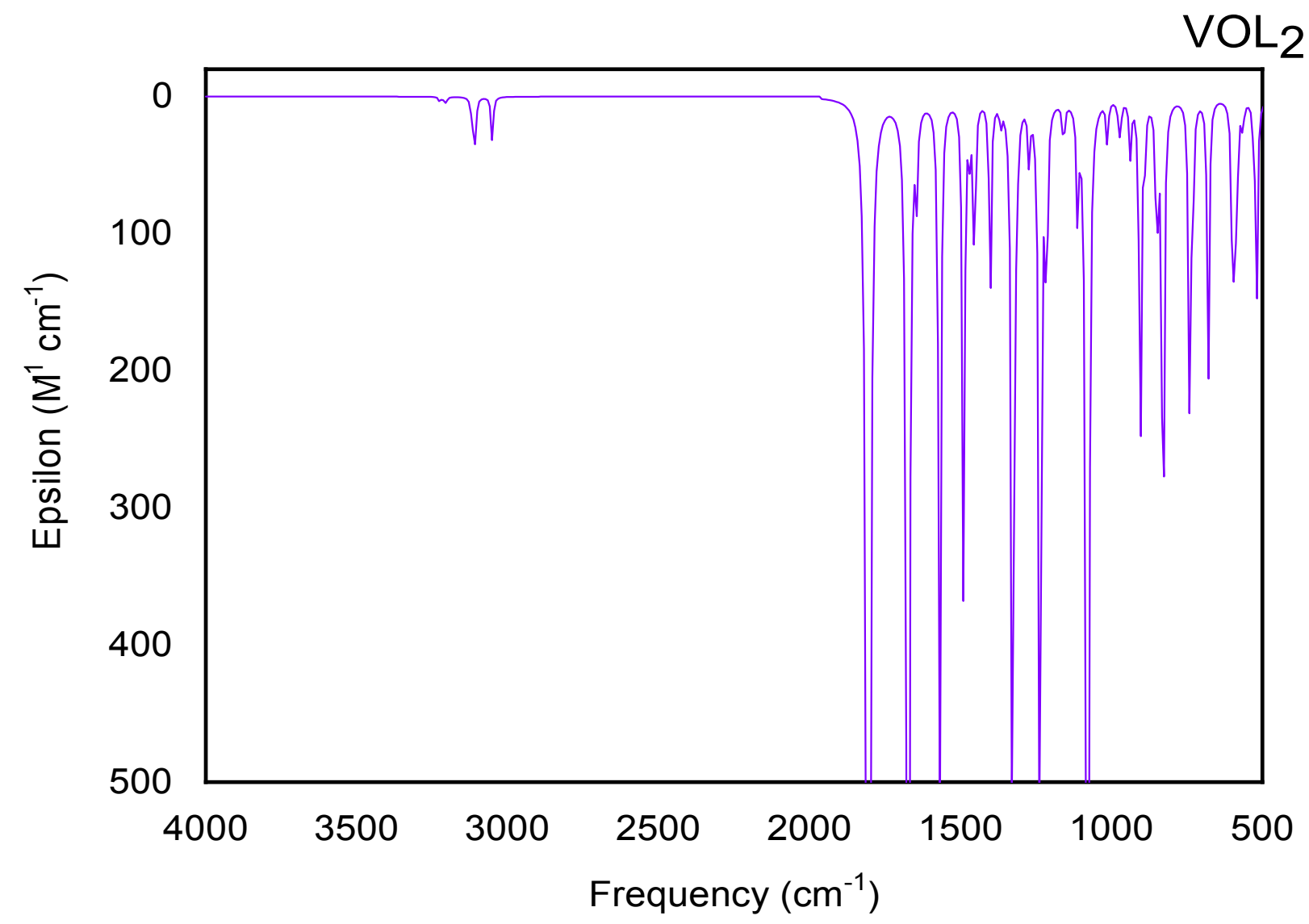

Figure S-3. Calculated FTIR for VOL2 Complex Using B3LYP/ 6-31+G(d,p) level of theory. 


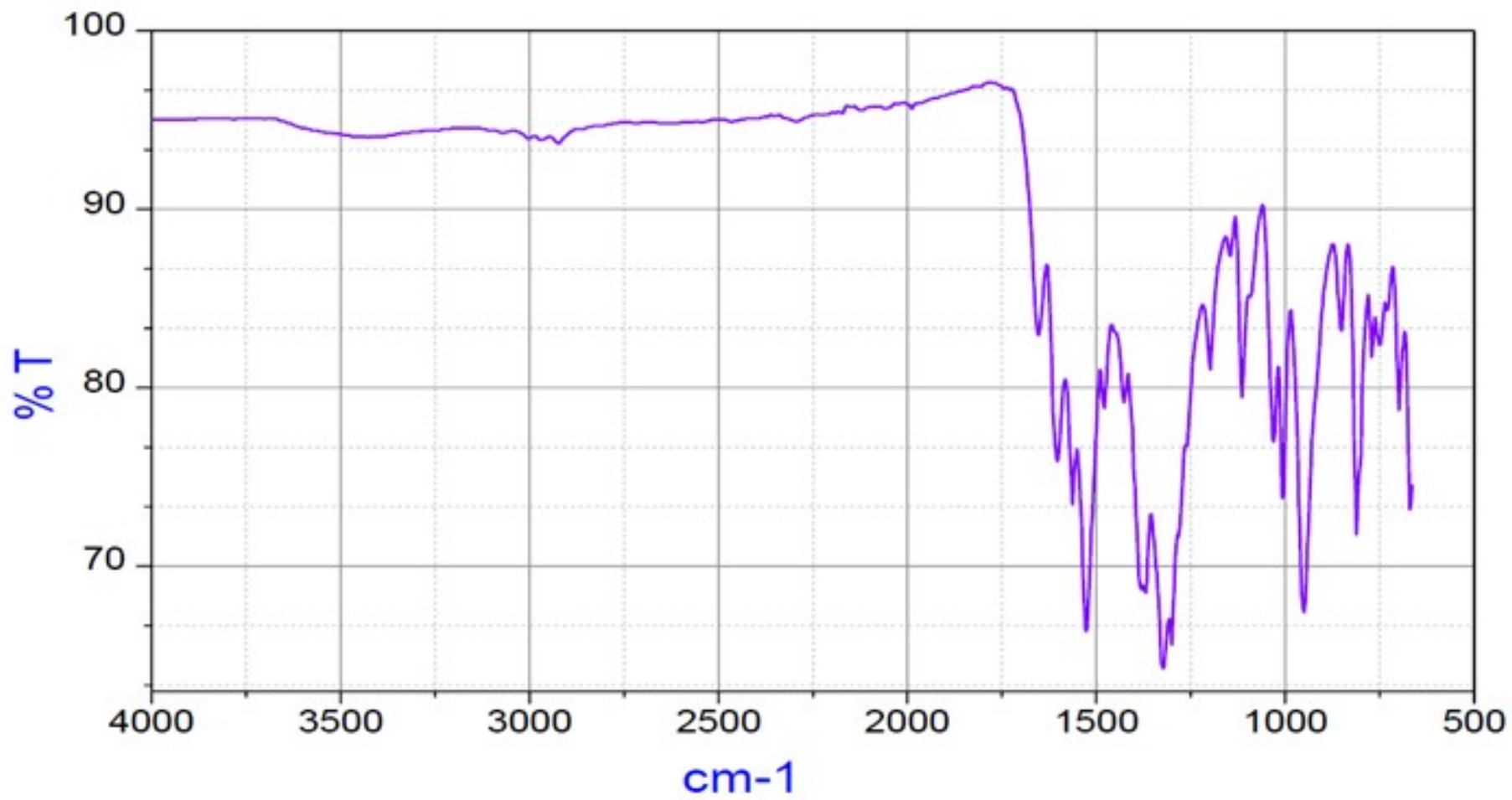

Figure S-4. Experimental FTIR for VOL 2 Complex. 


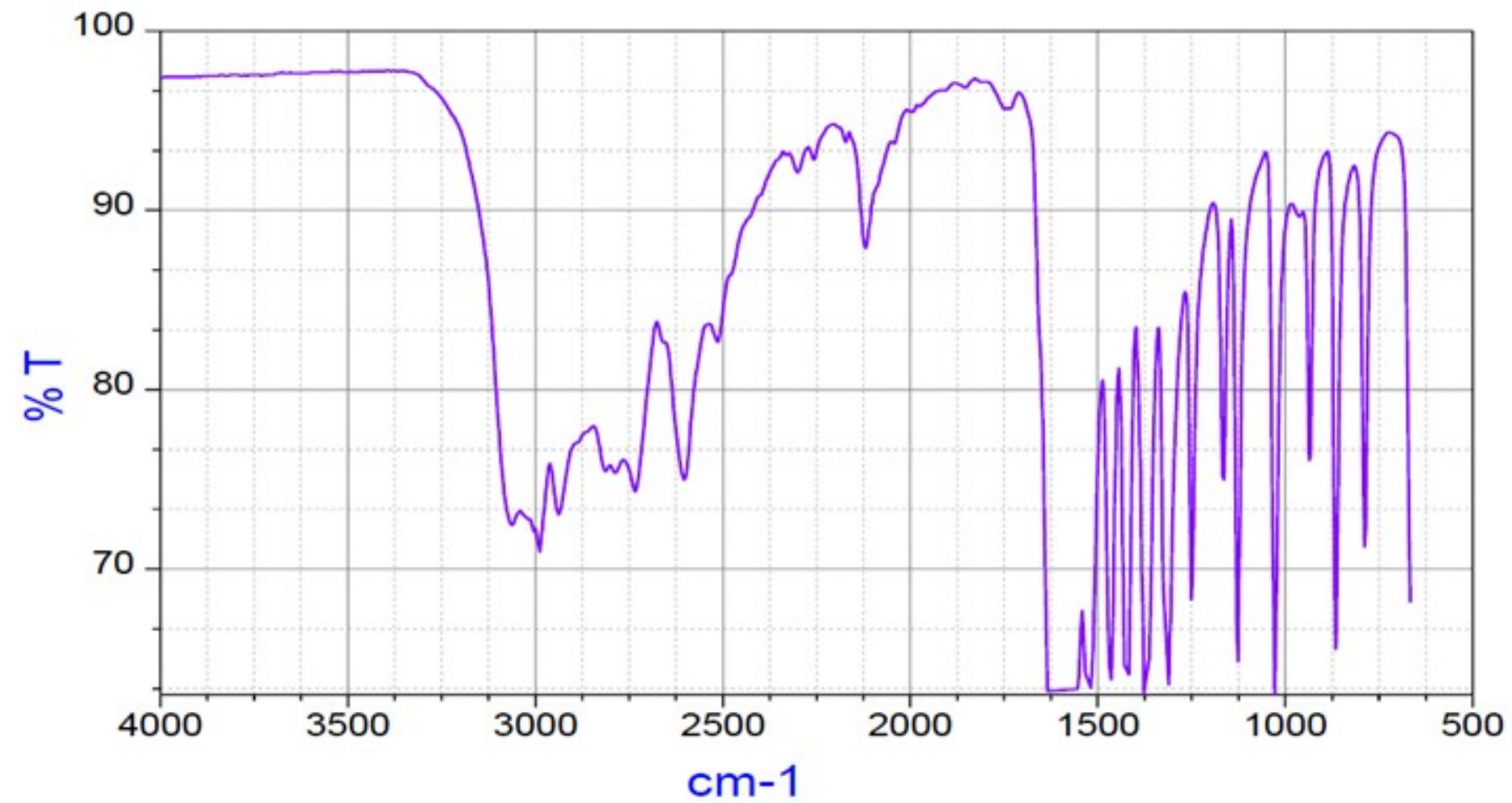

Figure S-5. Experimental FTIR for $\mathrm{H}_{2} \mathrm{~L}_{1}$ ligand. 


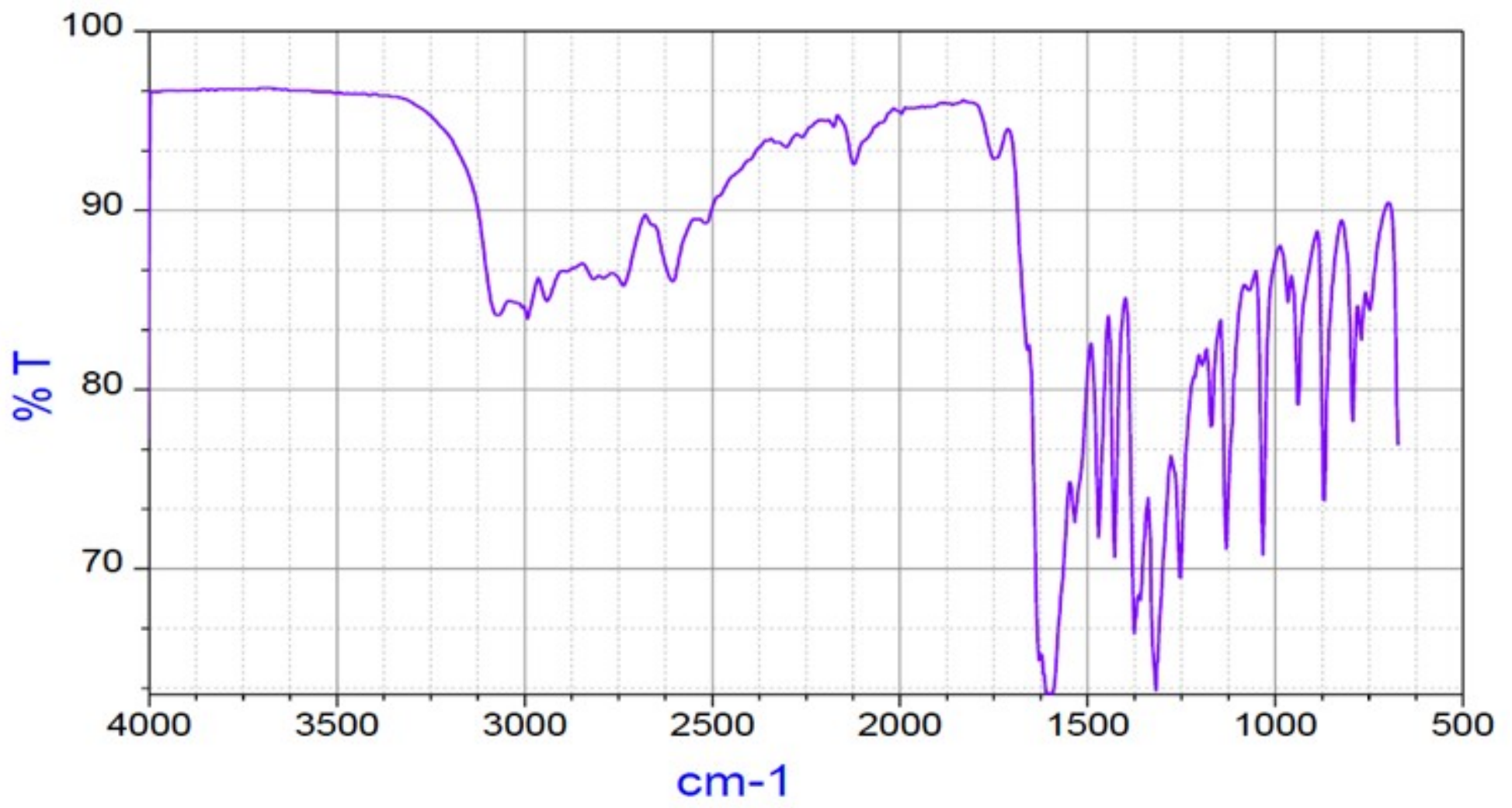

Figure S-6. Experimental FTIR for $\mathrm{H}_{2} \mathrm{~L}_{2}$ ligand. 


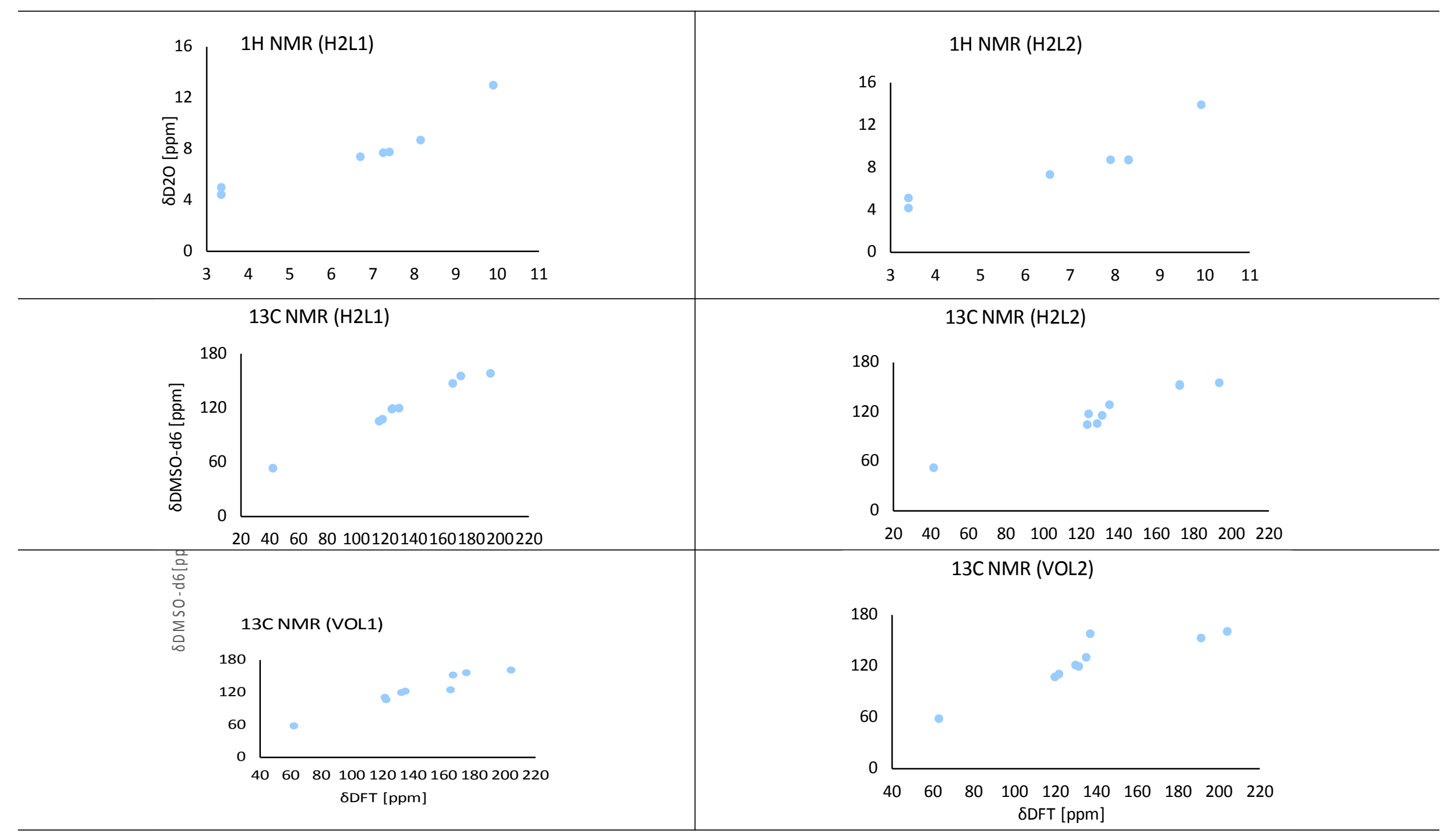

Figure S-7. Correlation between experimental and calculated ${ }^{1} \mathrm{H}$ and ${ }^{13} \mathrm{C}$ chemical shifts in $\mathrm{D}_{2} \mathrm{O}$, and DMSO- $d_{6}$ solvents. 


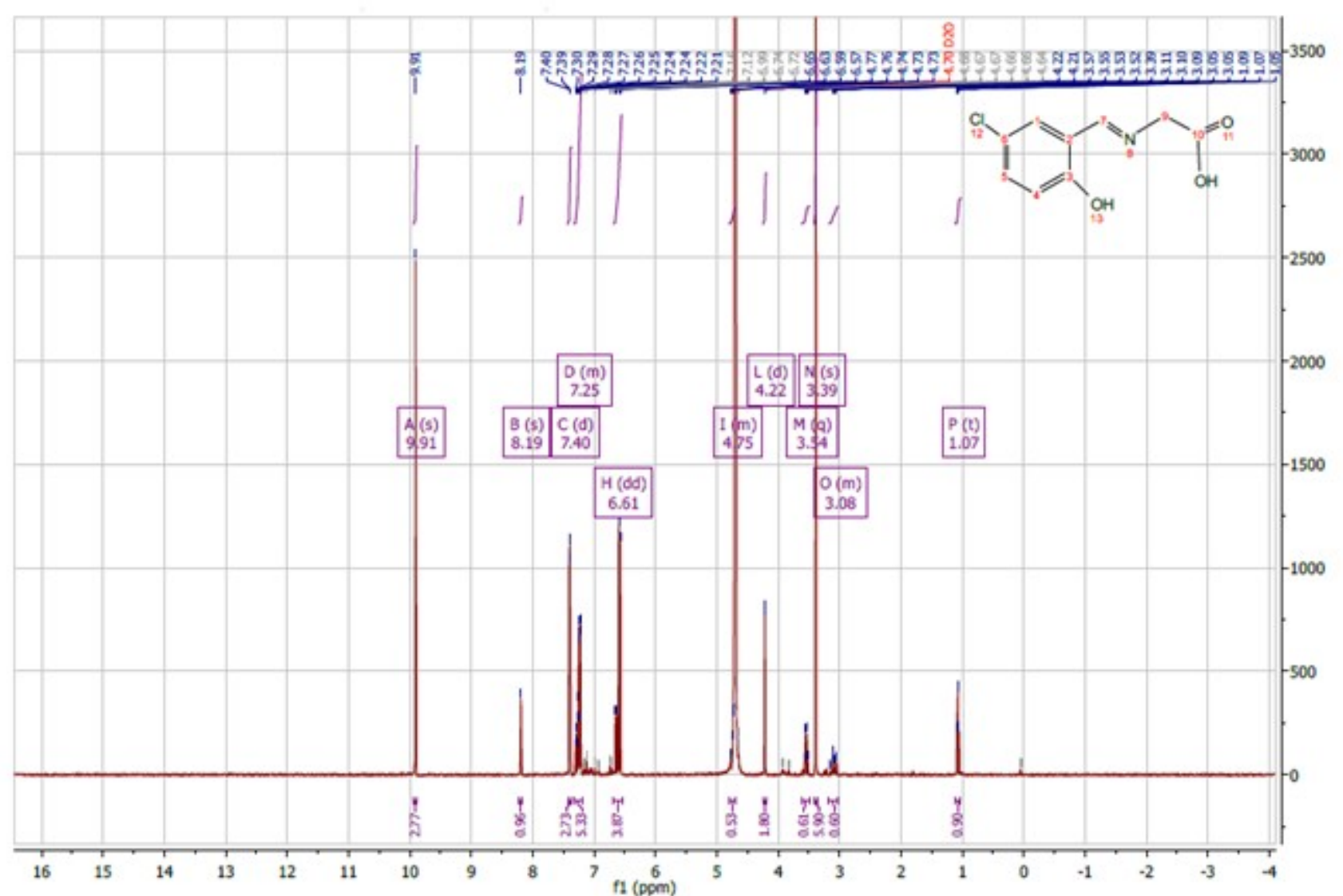

Figure S-8. Experimental ${ }^{1} \mathrm{H}$ NMR for the $\mathrm{H}_{2} \mathrm{~L}_{1},{ }^{1} \mathrm{H}$ NMR spectra is recorded on Bruker AVIII $40,500 \mathrm{MHz}$, US. 


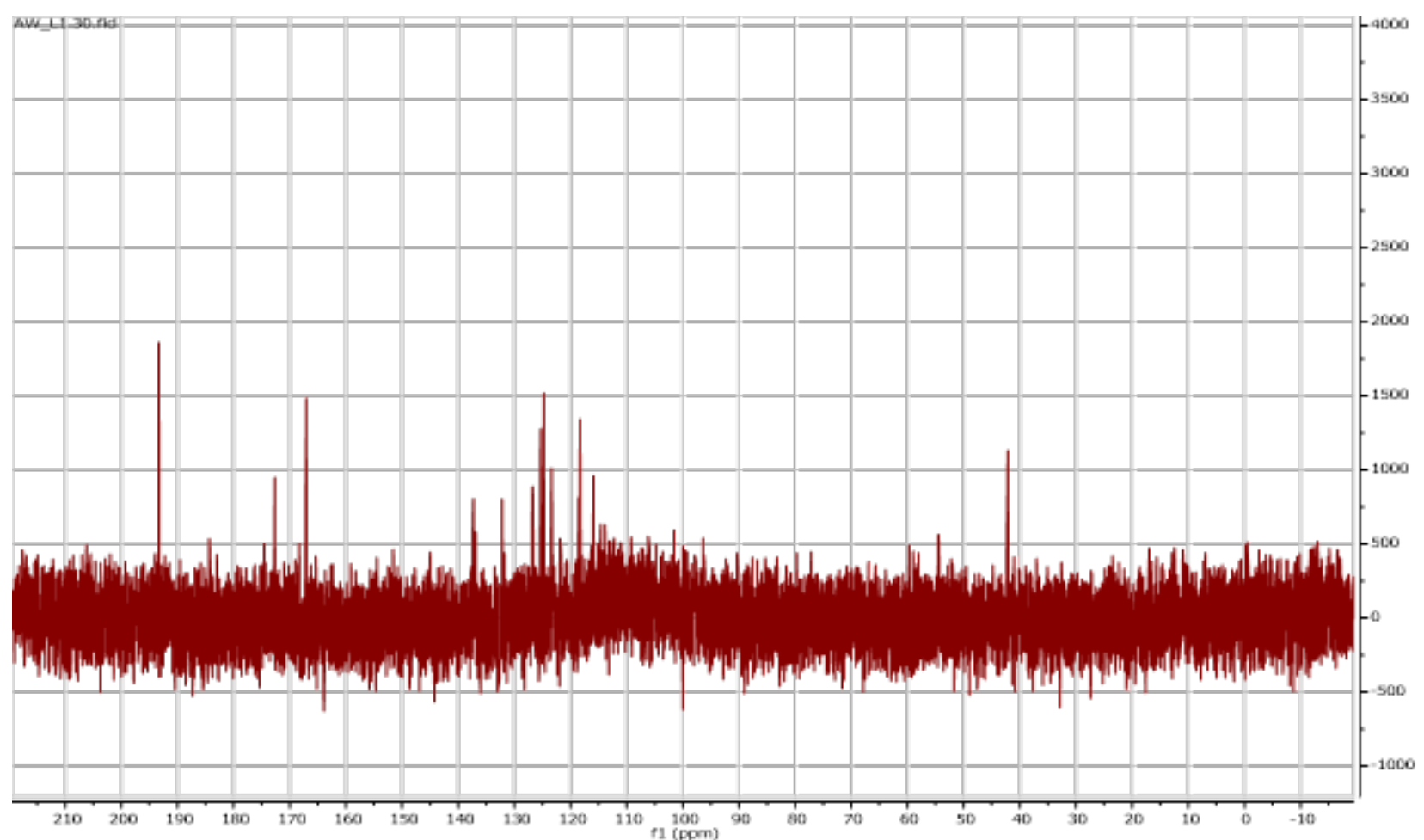

Figure S-9. Experimental ${ }^{13} \mathrm{C}$ NMR for the $\mathrm{H}_{2} \mathrm{~L}_{1} .{ }^{13} \mathrm{C}$ NMR spectra is recorded on Bruker AVIII 40, NMR $126 \mathrm{MHz}$, US. 


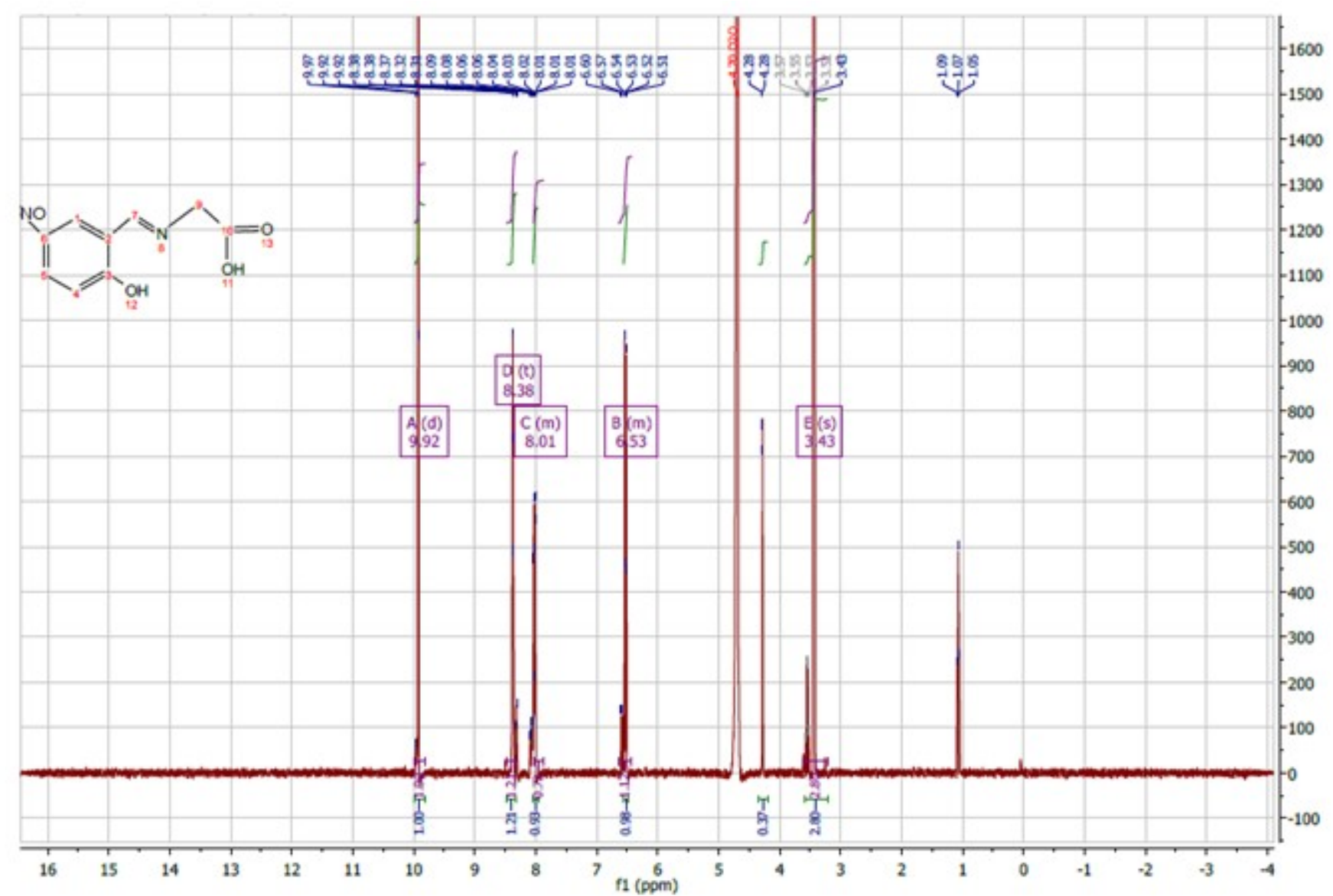

Figure S-10. Experimental ${ }^{1} \mathrm{H}$ NMR for the $\mathrm{H}_{2} \mathrm{~L}_{2} .{ }^{1} \mathrm{H}$ NMR spectra is recorded on Bruker AVIII 40, $500 \mathrm{MHz}, \mathrm{US}$ 


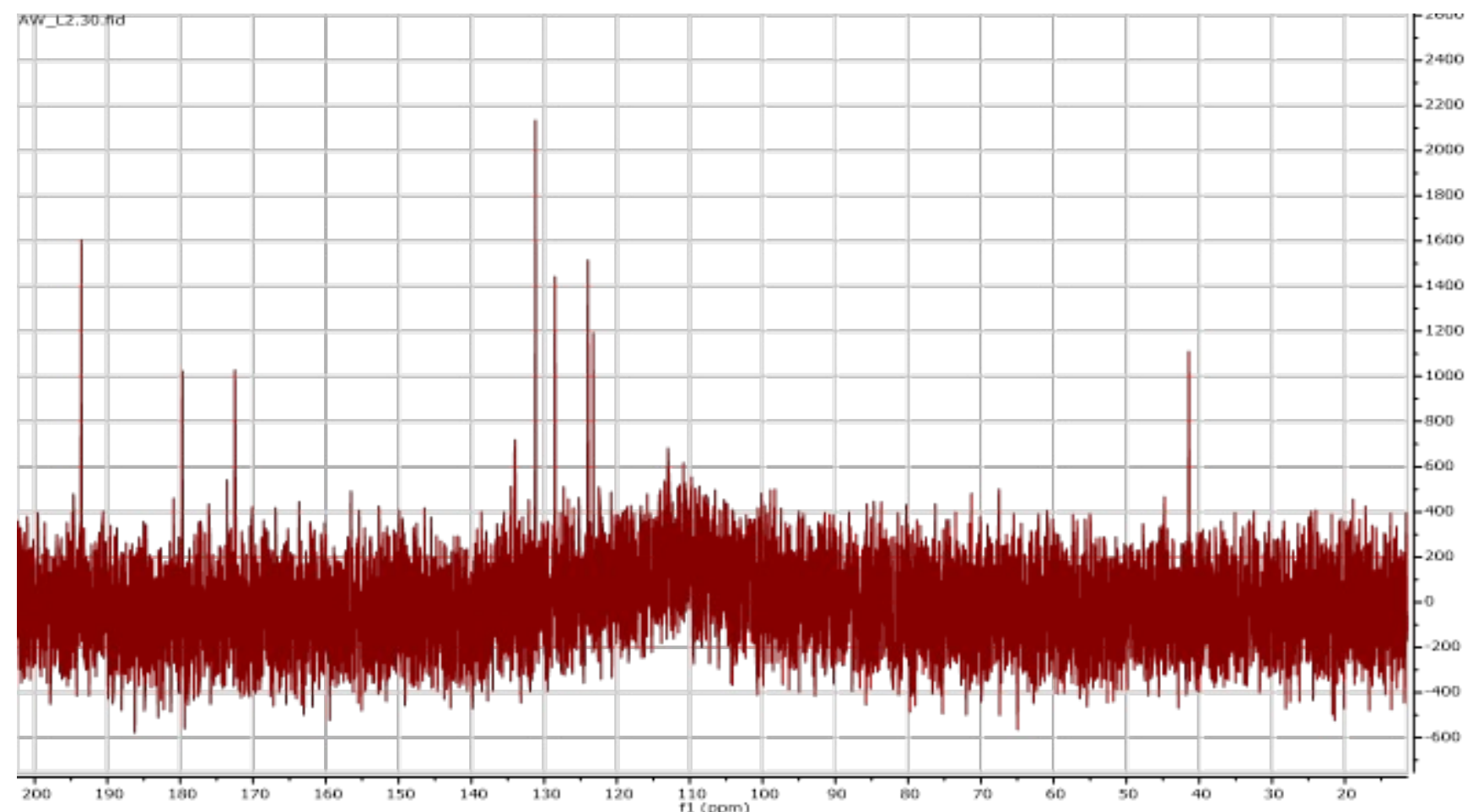

Figure S-11. Experimental ${ }^{13} \mathrm{C}$ NMR for the $\mathrm{H}_{2} \mathrm{~L}_{2} .{ }^{13} \mathrm{C}$ NMR spectra is recorded on Bruker AVIII 40, NMR $126 \mathrm{MHz}$, US. 


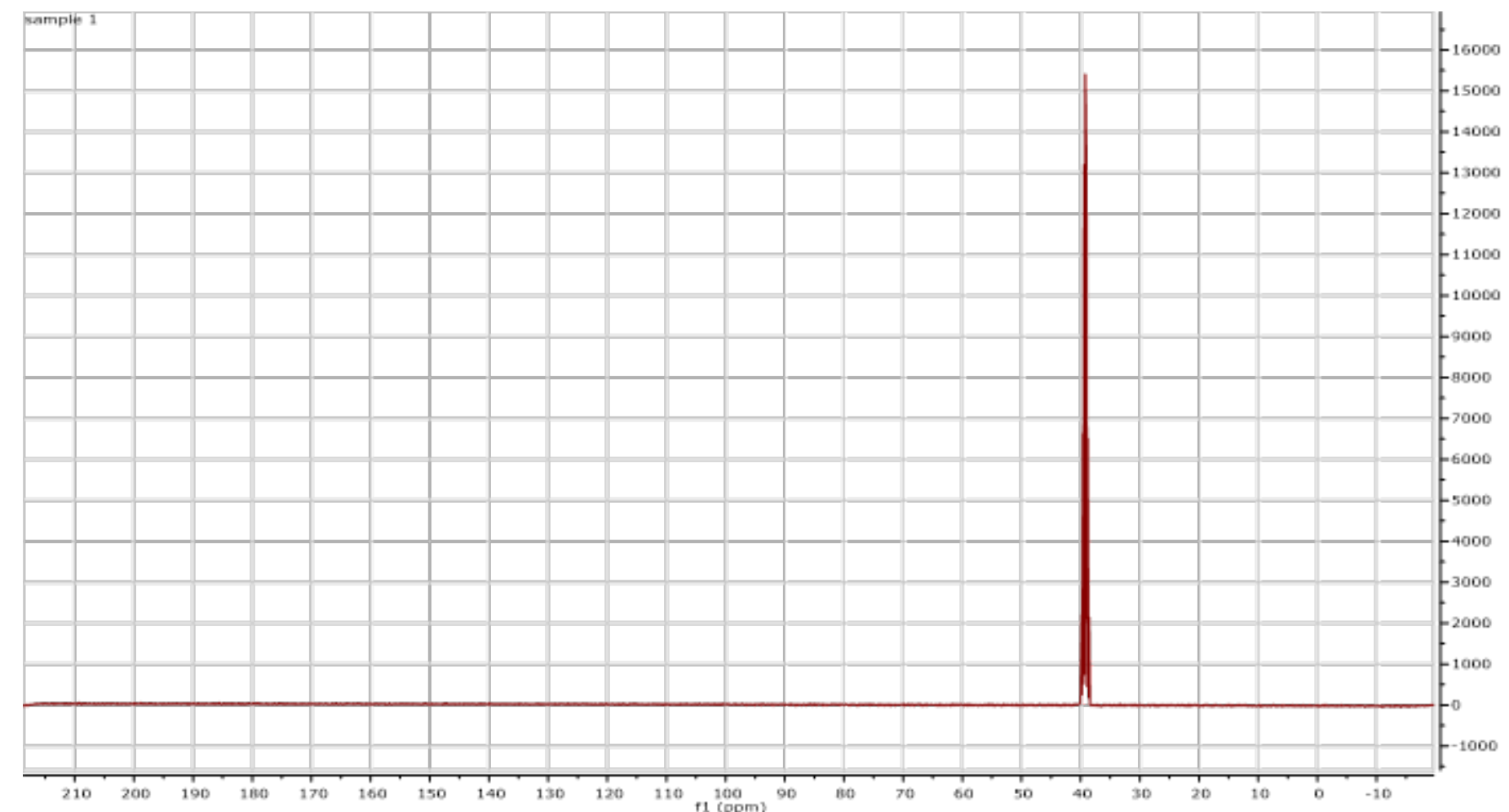

Figure S-12. Experimental ${ }^{1} \mathrm{H}$ NMR for the VOL $1 .{ }^{1} \mathrm{H}$ NMR spectra is recorded on Bruker AVIII $40,500 \mathrm{MHz}$, US. 


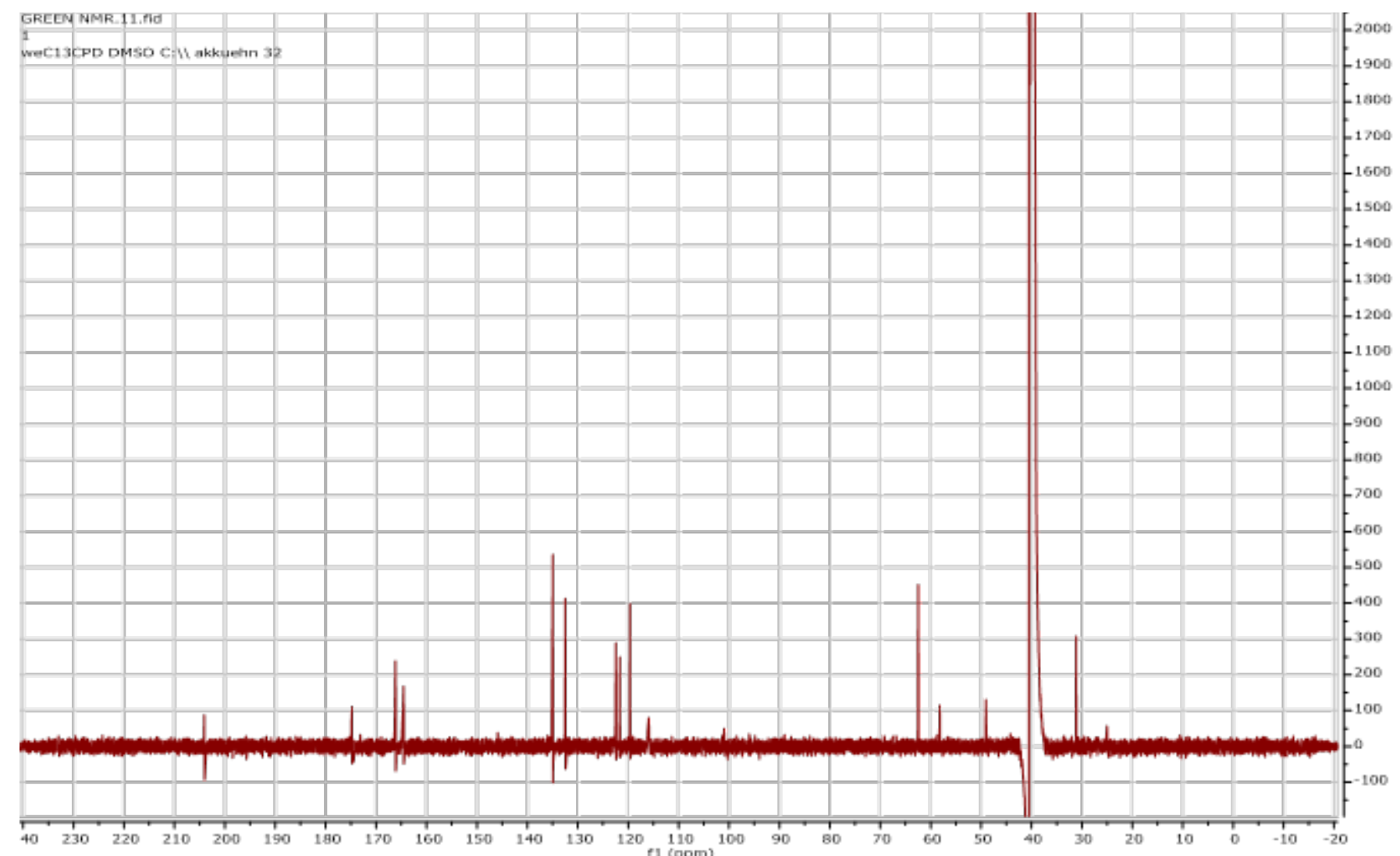

Figure S-13. Experimental ${ }^{13} \mathrm{C}$ NMR for the $\mathrm{VOL}_{1} .{ }^{13} \mathrm{C}$ NMR spectra is recorded on Bruker AVIII 40, NMR $126 \mathrm{MHz}$, US. 


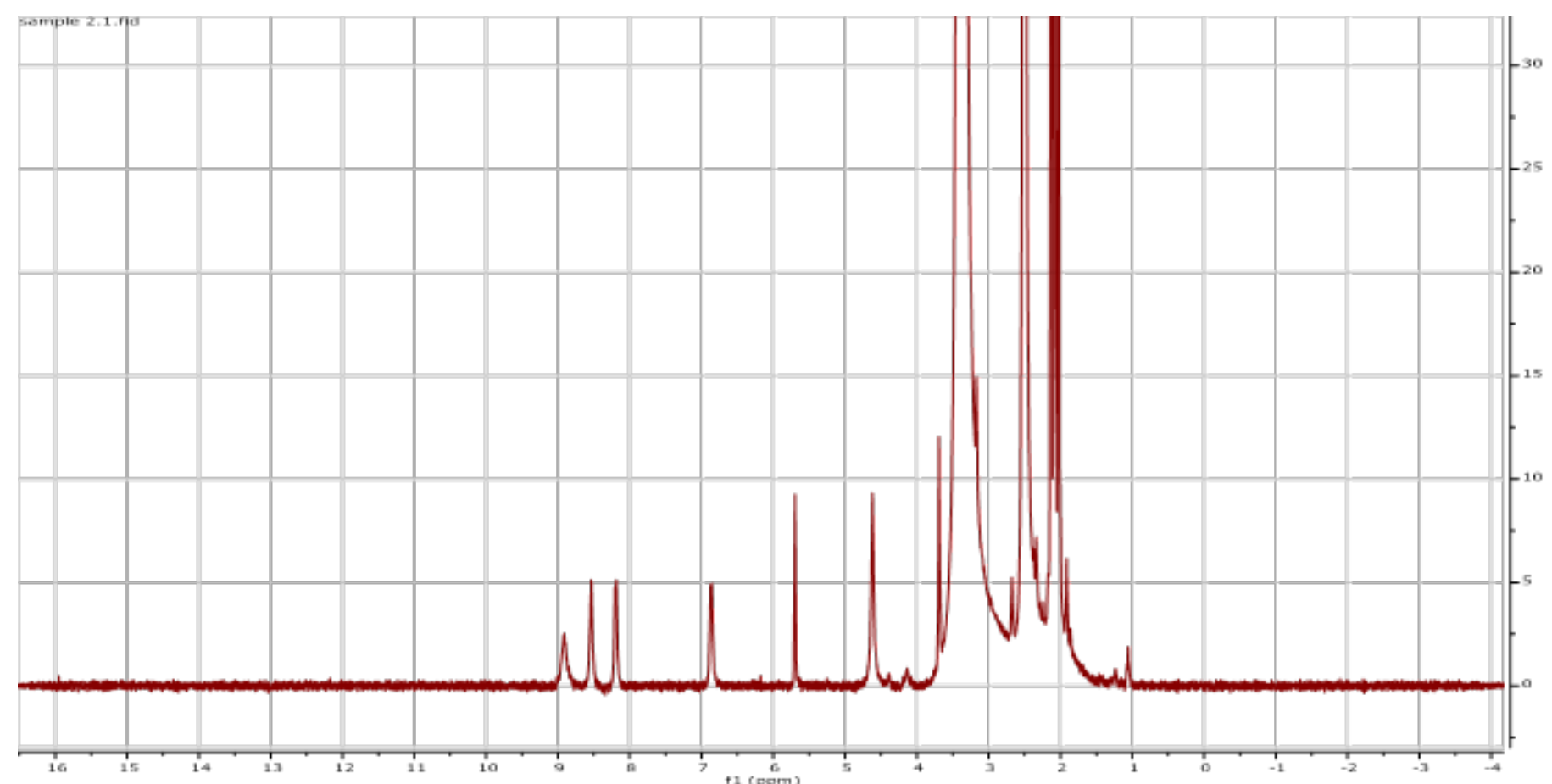

Figure S-14. Experimental ${ }^{1} \mathrm{H}$ NMR for the VOL2. ${ }^{1} \mathrm{H}$ NMR spectra is recorded on Bruker AVIII $40,500 \mathrm{MHz}, \mathrm{US}$. 


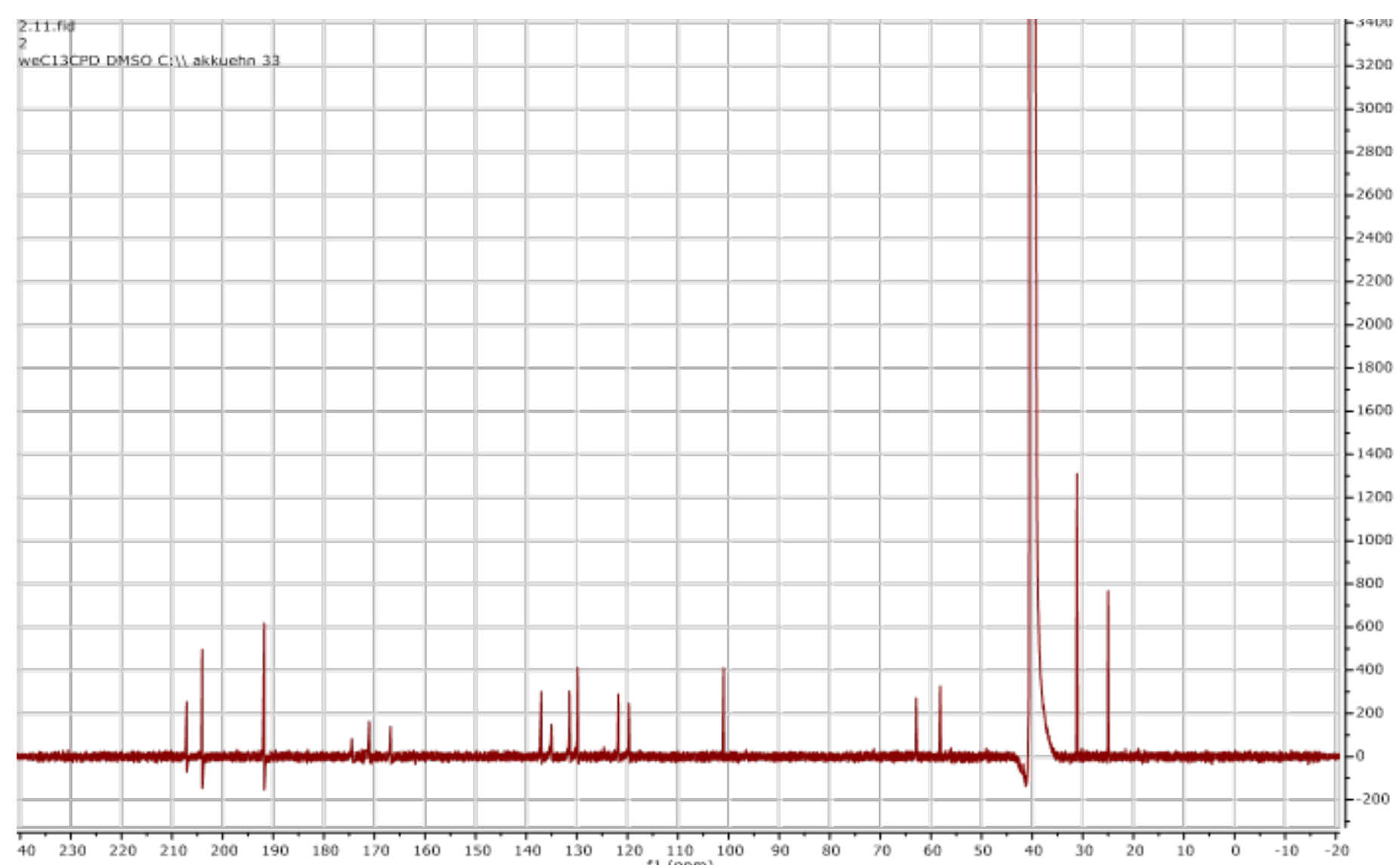

Figure S-15. Experimental ${ }^{13} \mathrm{C}$ NMR for the VOL2. ${ }^{13} \mathrm{C}$ NMR spectra is recorded on Bruker AVIII 40, NMR $126 \mathrm{MHz}$, US. 


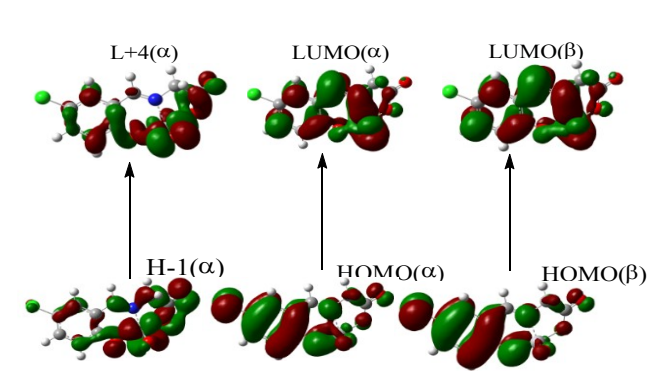

$430.0(\mathrm{~nm})$
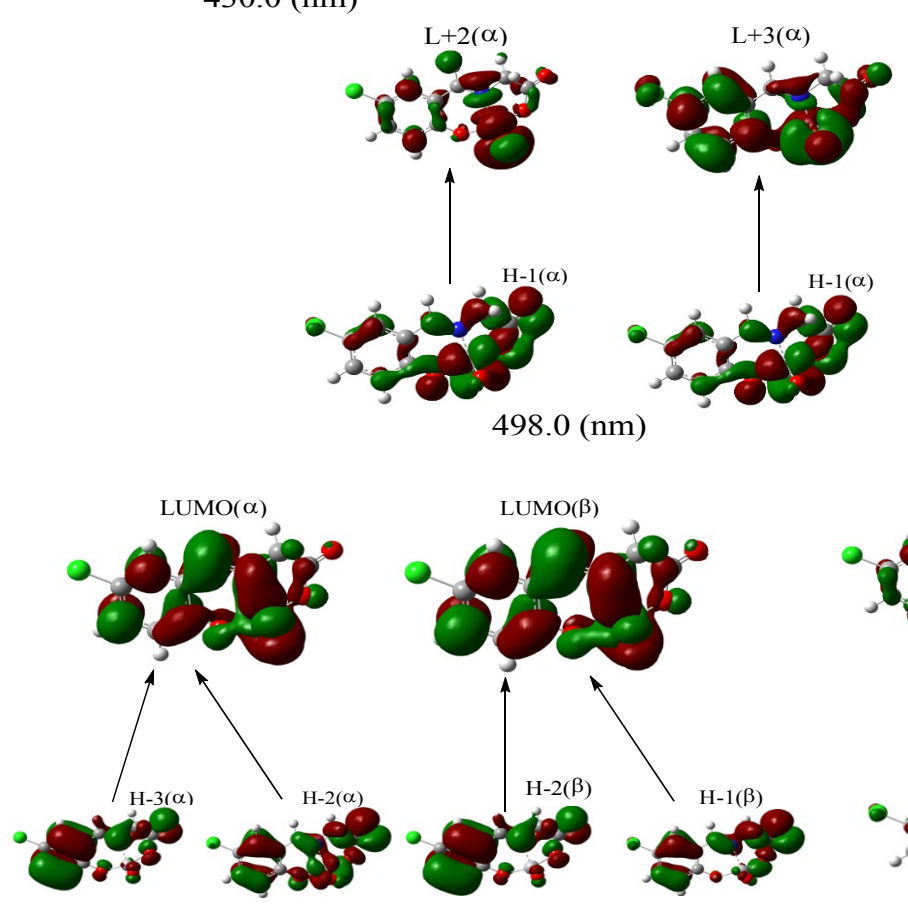

$404.5(\mathrm{~nm})$

Figure S-16. Schematic representation of the main orbital contributions to the TD-DFT/6-31+G(d,p) calculated excitations for the VOL ${ }_{1}$ complex. 


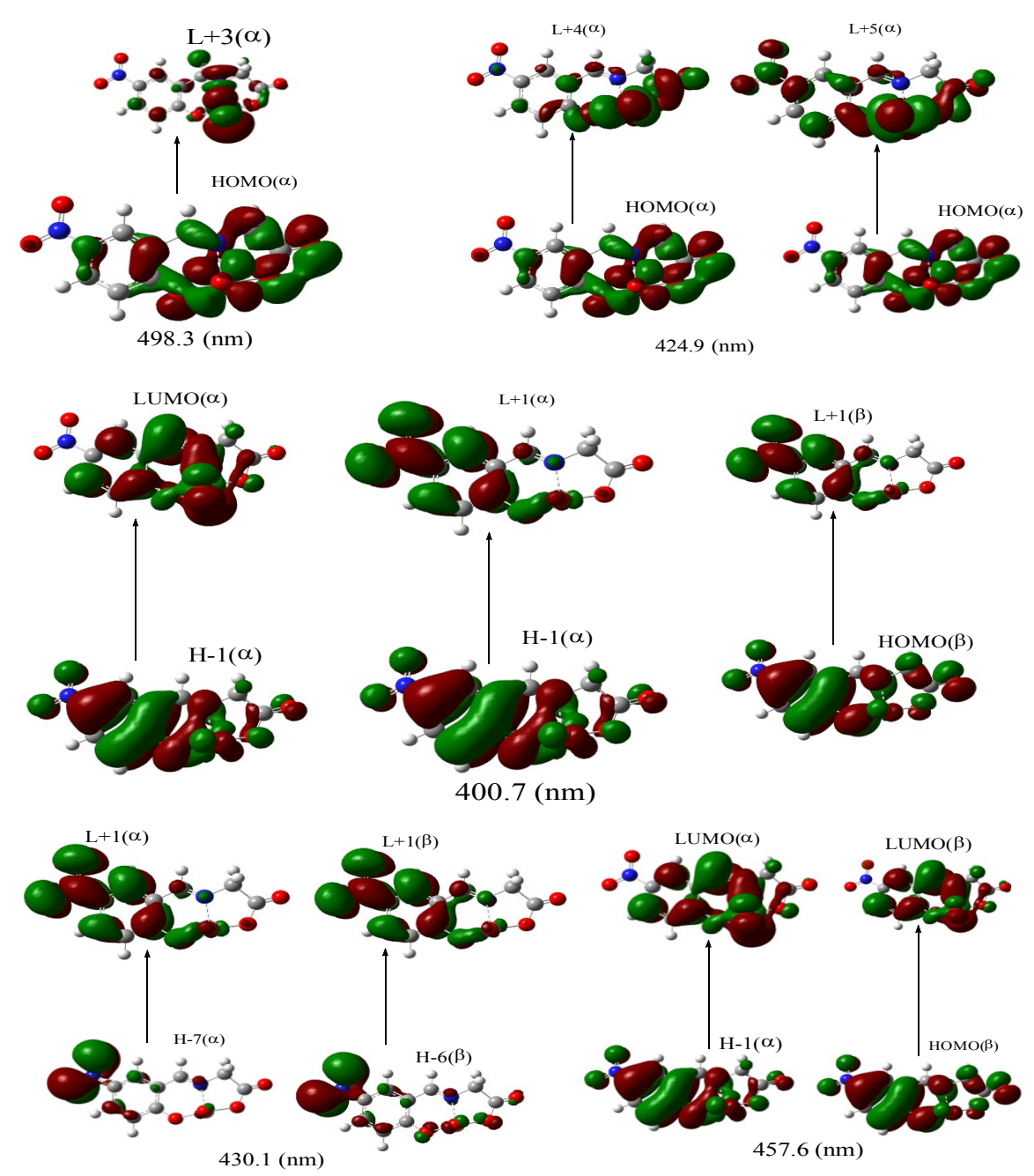

Figure S-17. Schematic representation of the main orbital contributions to the TD-DFT/6-31+G(d,p) calculated excitations for the VOL 2 complex. 


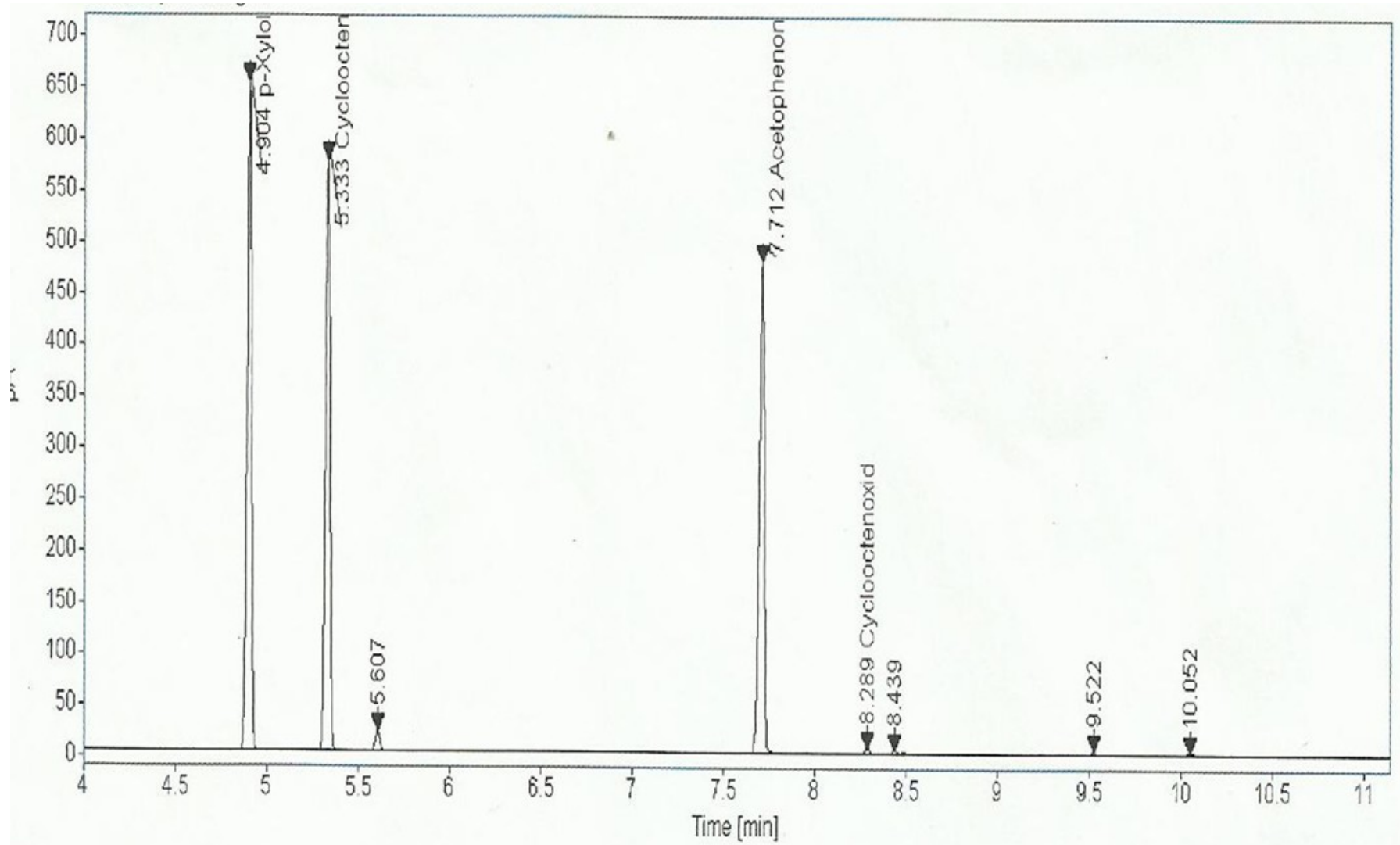

Figure S-18. Epoxidation of cyclooctene at $20^{\circ} \mathrm{C}$ after $2 \mathrm{~h}-$ complex $\left(\mathrm{VOL}_{1}\right)$. Measured using an Agilent GC Model $7890 \mathrm{~B}$ and GC column used is Agilent $\mathrm{HP}-5$ with dimensions $0.25 \mu \mathrm{m}$. 


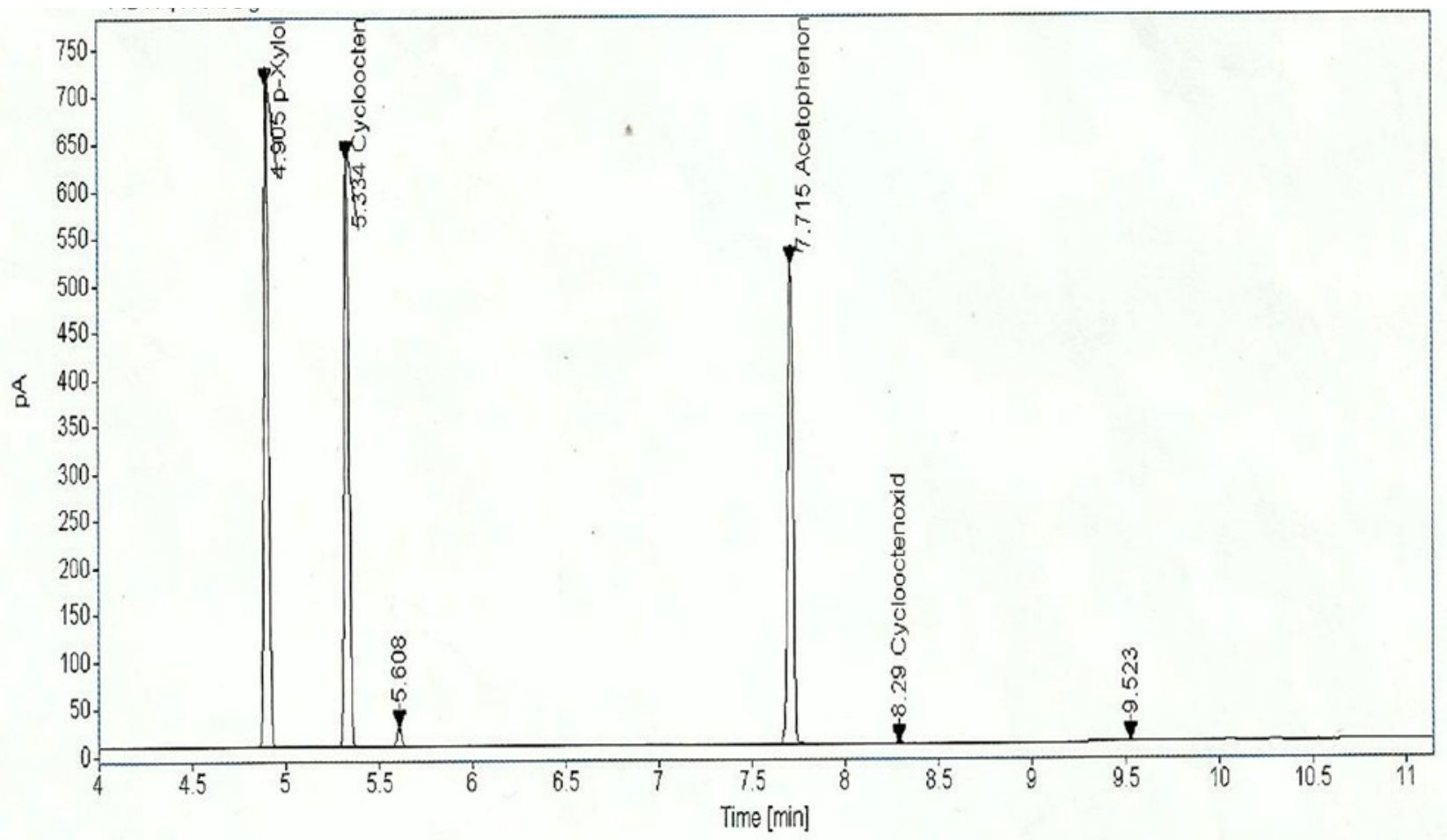

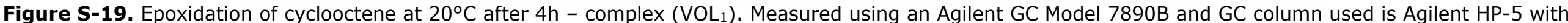
dimensions $0.25 \mu \mathrm{m}$. 


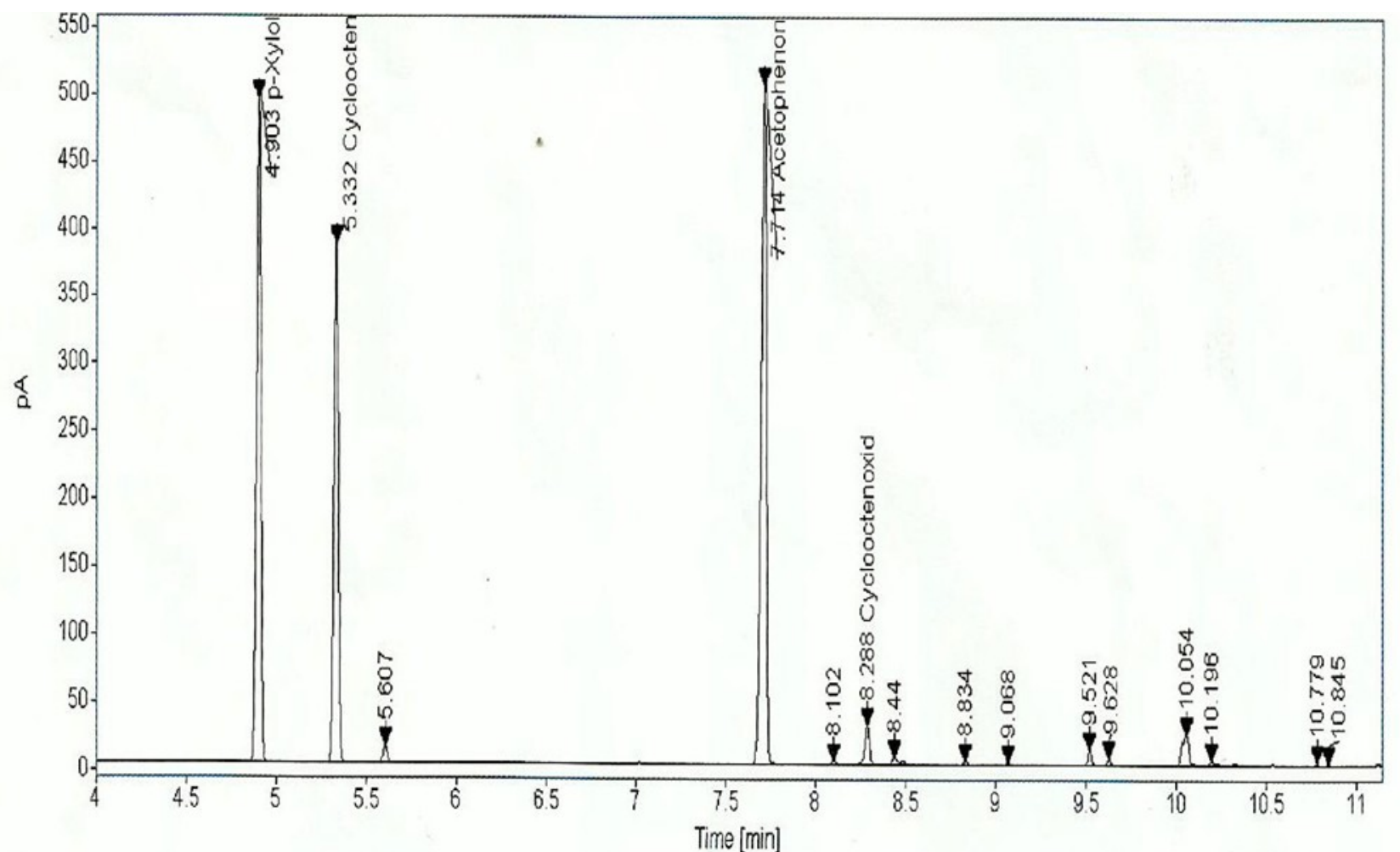

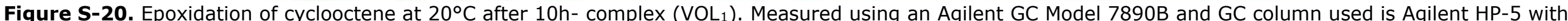
dimensions $0.25 \mu \mathrm{m}$. 


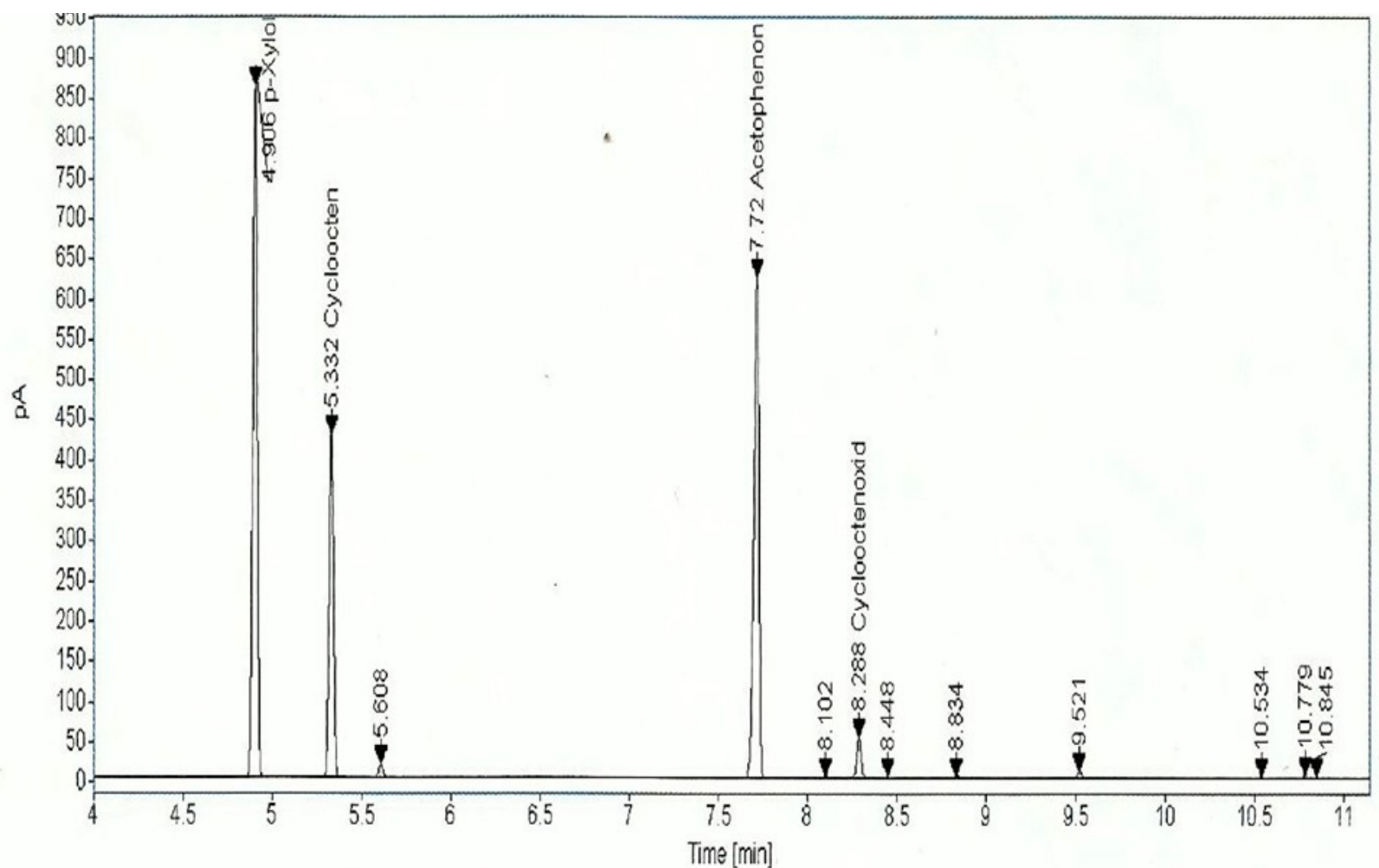

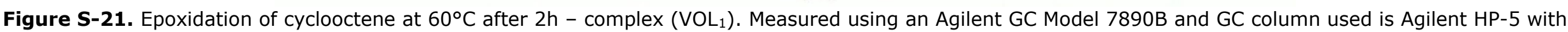
dimensions $0.25 \mu \mathrm{m}$. 


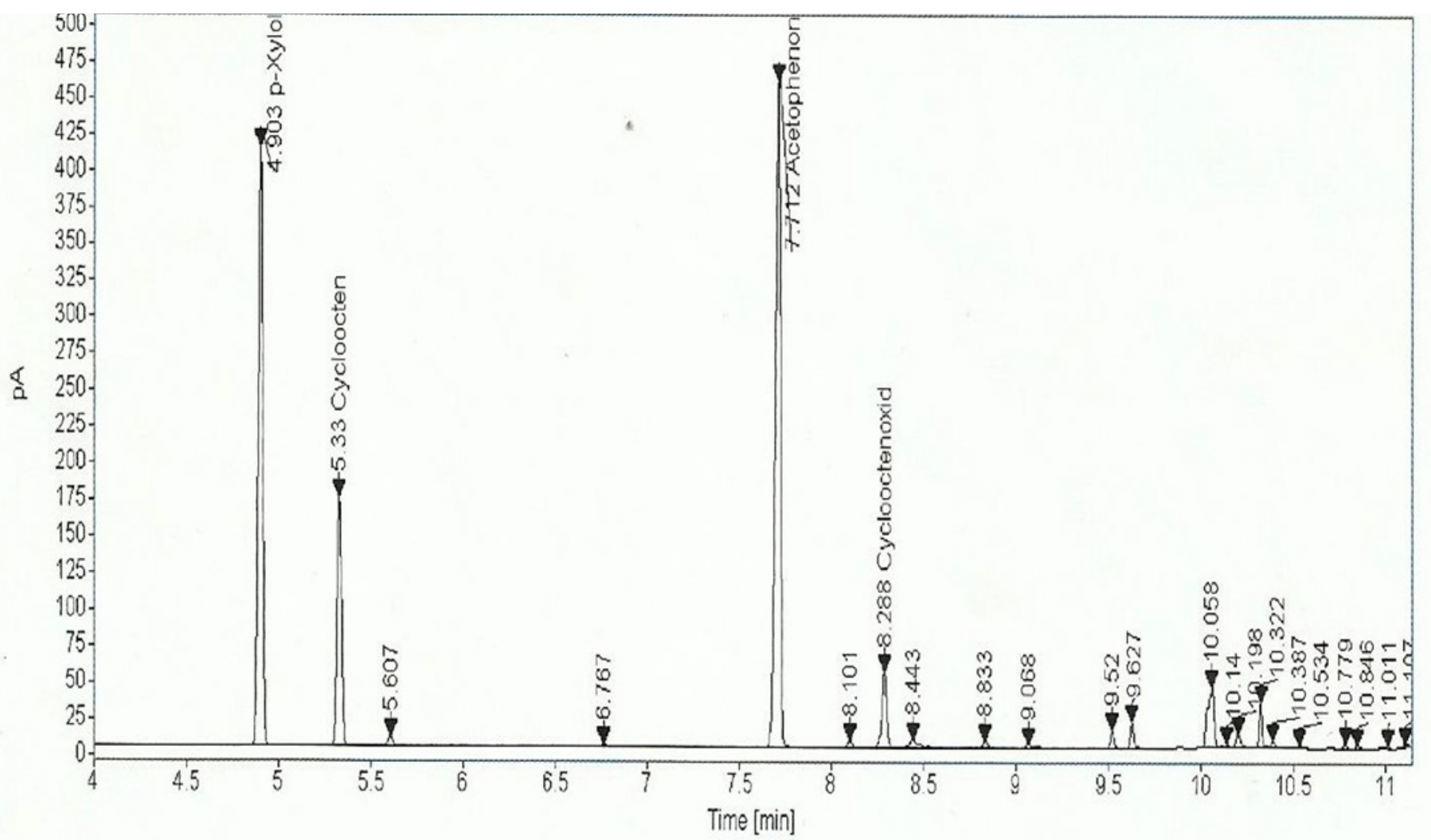

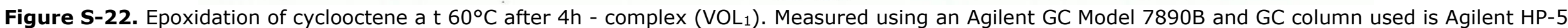
with dimensions $0.25 \mu \mathrm{m}$. 


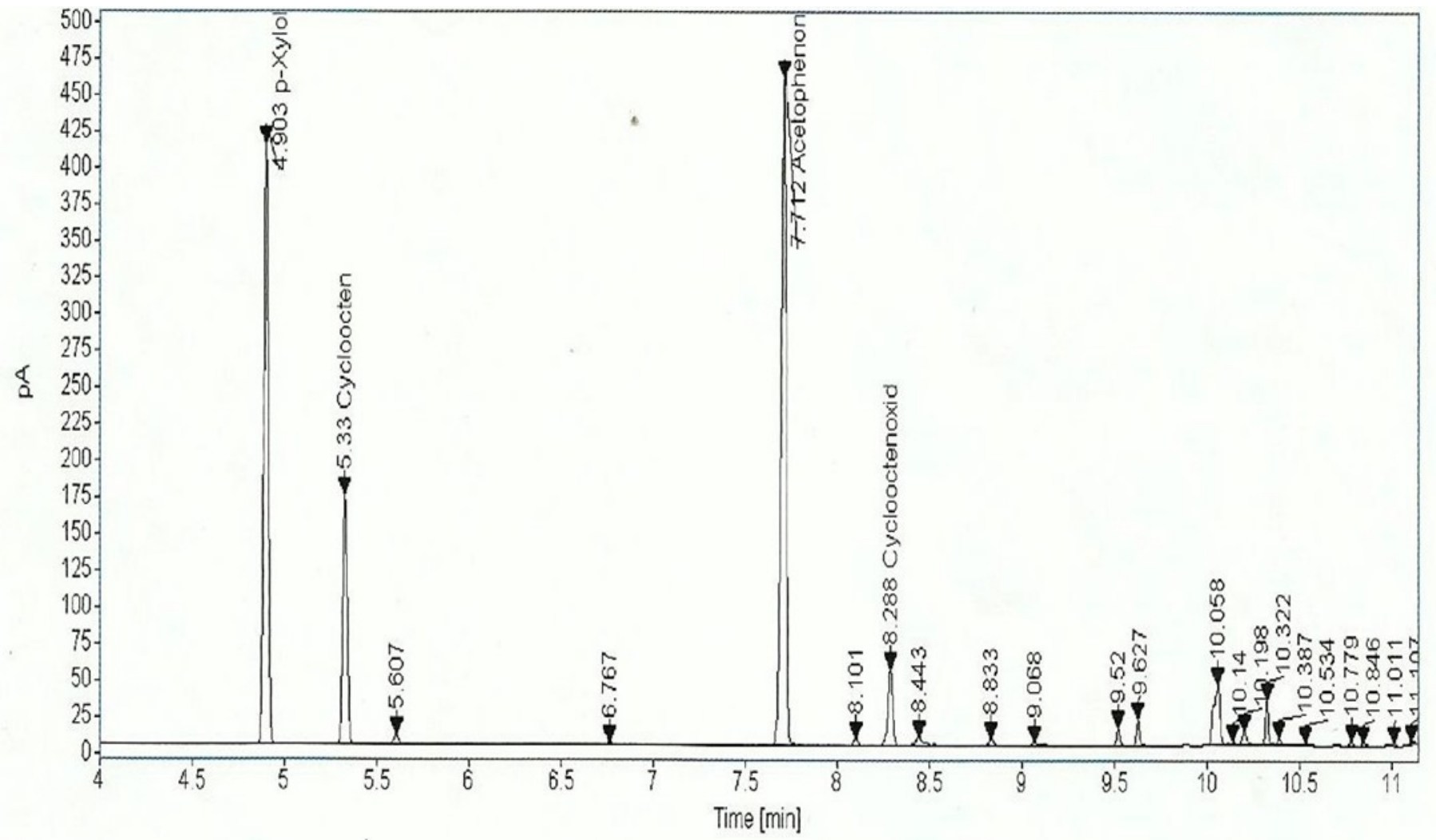

Figure S-23. Epoxidation of cyclooctene at $60^{\circ} \mathrm{C}$ after $10 \mathrm{~h}$ - complex $\left(\mathrm{VOL}_{1}\right)$. Measured using an Agilent GC Model $7890 \mathrm{~B}$ and GC column used is Agilent $\mathrm{HP}-5$ with dimensions $0.25 \mu \mathrm{m}$. 


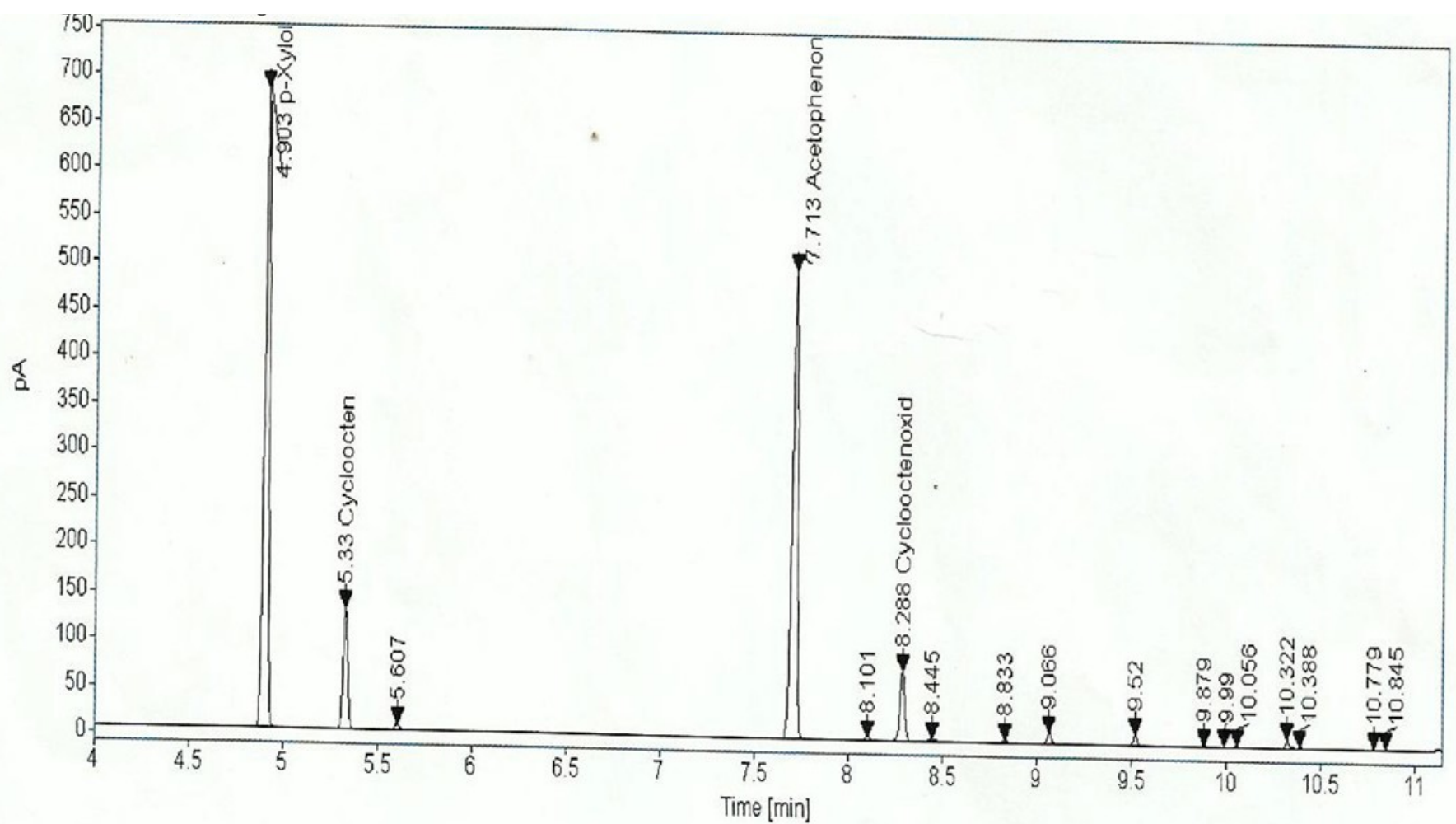

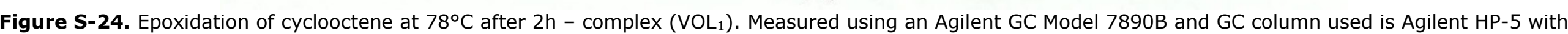
dimensions $0.25 \mu \mathrm{m}$. 


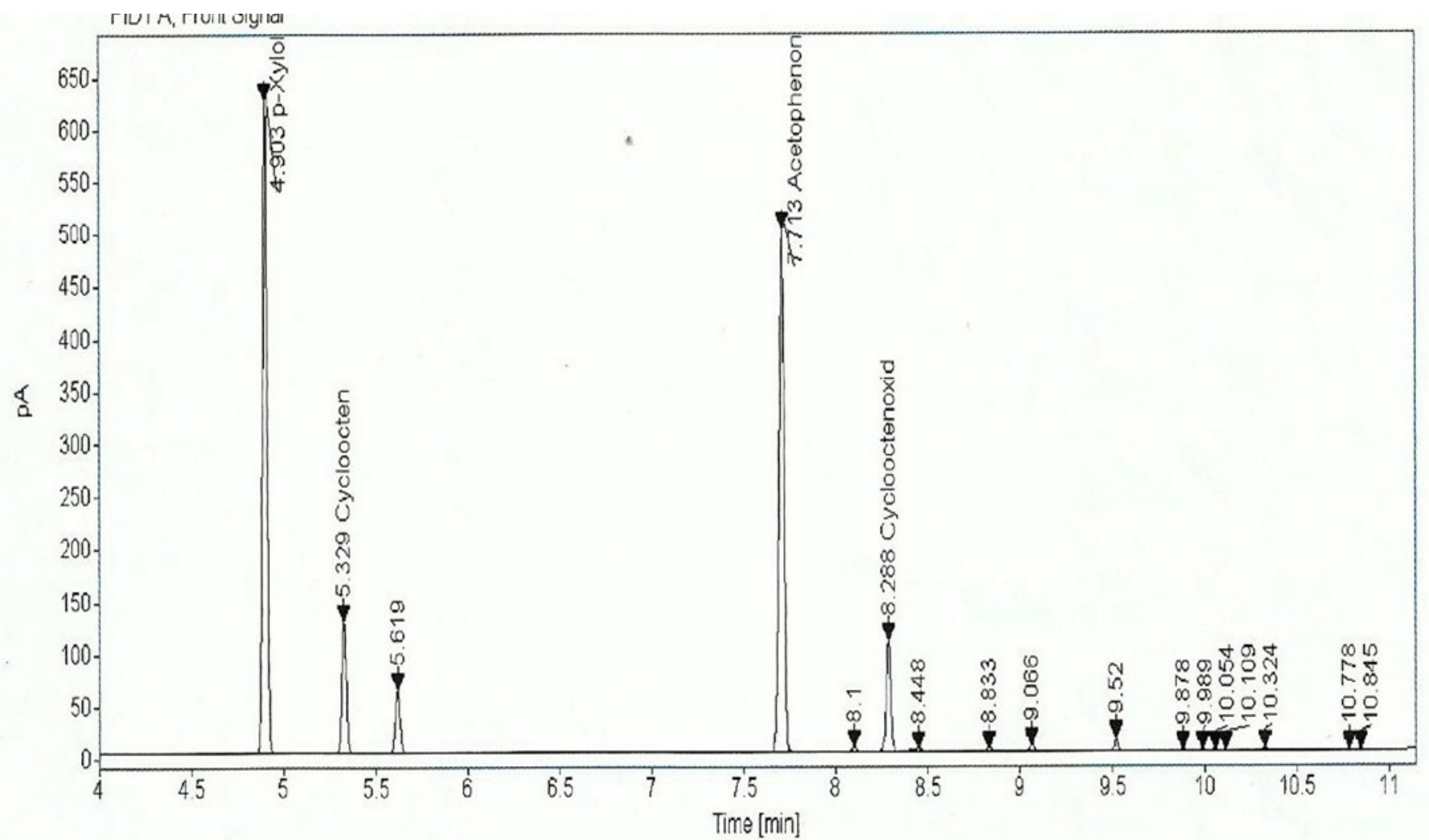

Figure S-25. Epoxidation of cyclooctene at $78^{\circ} \mathrm{C}$ after $4 \mathrm{~h}$ - complex $\left(\mathrm{VOL}_{1}\right)$. Measured using an Agilent GC Model $7890 \mathrm{~B}$ and $\mathrm{GC}$ column used is Agilent $\mathrm{HP}-5$ with dimensions $0.25 \mu \mathrm{m}$. 


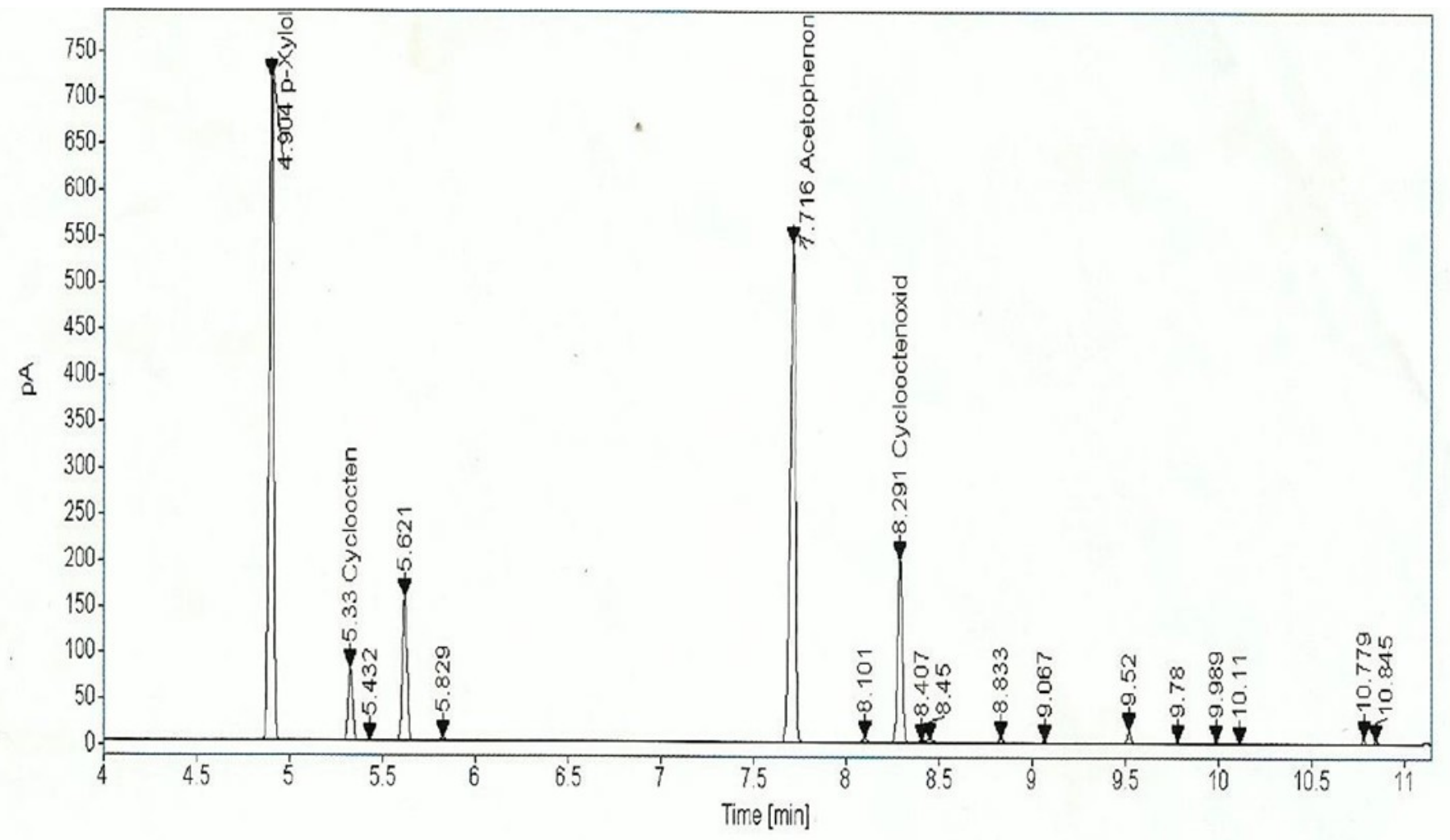

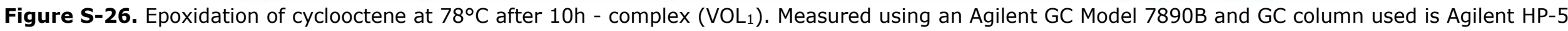
with dimensions $0.25 \mu \mathrm{m}$. 